Prepared in cooperation with the U.S. Fish and Wildlife Service

\title{
A Metabolism-Based Whole Lake Eutrophication Model to Estimate the Magnitude and Time Scales of the Effects of Restoration in Upper Klamath Lake, South-Central Oregon
}

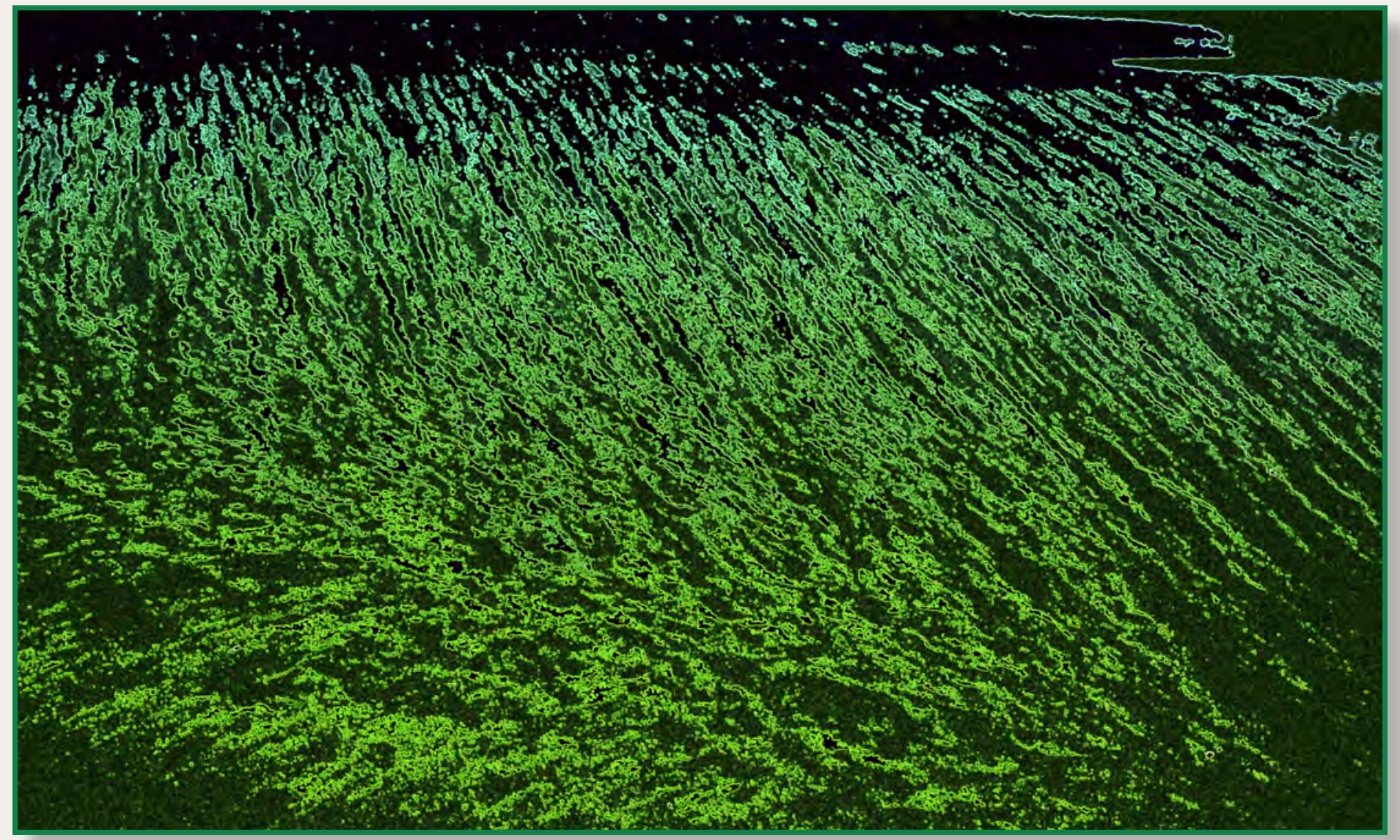

Scientific Investigations Report 2018-5042 
Cover: Photograph showing Aphanizomenon flos-aquae cluster in Upper Klamath Lake, south-central Oregon. Photograph by Susan Wherry, U.S. Geological Survey, July 15, 2015. 


\section{A Metabolism-Based Whole Lake Eutrophication Model to Estimate the Magnitude and Time Scales of the Effects of Restoration in Upper Klamath Lake, South-Central Oregon}

By Susan A. Wherry and Tamara M. Wood

Prepared in cooperation with the U.S. Fish and Wildlife Service

Scientific Investigations Report 2018-5042 


\title{
U.S. Department of the Interior \\ RYAN K. ZINKE, Secretary
}

\section{U.S. Geological Survey \\ William H. Werkheiser, Deputy Director \\ exercising the authority of the Director}

\author{
U.S. Geological Survey, Reston, Virginia: 2018
}

For more information on the USGS — the Federal source for science about the Earth, its natural and living resources, natural hazards, and the environment-visit https://www.usgs.gov or call 1-888-ASK-USGS.

For an overview of USGS information products, including maps, imagery, and publications, visit https://store.usgs.gov.

The findings and conclusions in this report are those of the authors and do not necessarily represent the views of the U.S. Fish and Wildlife Service.

Any use of trade, firm, or product names is for descriptive purposes only and does not imply endorsement by the U.S. Government.

Although this information product, for the most part, is in the public domain, it also may contain copyrighted materials as noted in the text. Permission to reproduce copyrighted items must be secured from the copyright owner.

Suggested citation:

Wherry, S.A., and Wood, T.M., 2018, A metabolism-based whole lake eutrophication model to estimate the magnitude and time scales of the effects of restoration in Upper Klamath Lake, south-central Oregon: U.S. Geological Survey Scientific Investigations Report 2018-5042, 43 p., https:/doi.org/10.3133/sir20185042.

ISSN 2328-0328 (online) 


\section{Contents}

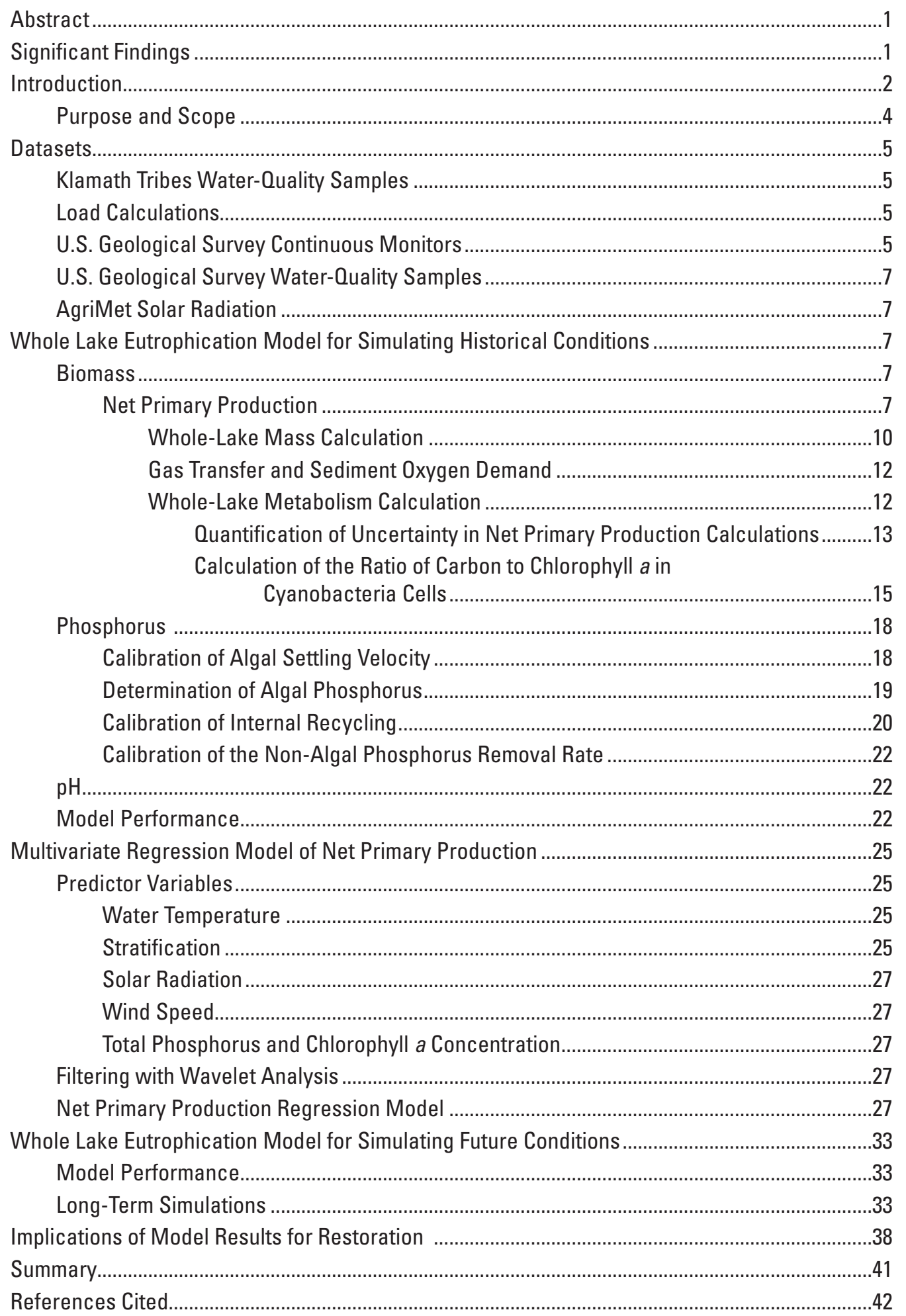




\section{Figures}

1. Map showing location of meteorological stations and continuous and discrete water-quality monitoring sites, Upper Klamath Lake, south-central Oregon 3

2. Flowchart showing whole lake eutrophication model dependencies using calculated net primary production .8

3. Scatterplots showing average dissolved oxygen in the upper 2 meters of the water column, as a function of the corresponding hourly measurement collected at 1 meter in depth, at U.S. Geological Survey core sites of Mid-North (MDN), Upper Klamath Lake at Williamson River outlet (WMR), Mid-Trench (MDT), and Rattlesnake Point (RPT), Upper Klamath Lake, south-central Oregon

4. Graph showing cumulative fraction of total lake surface area as a function of depth at full pool and the full-pool depths for the four U.S. Geological Survey core water-quality monitoring sites, Upper Klamath Lake, south-central Oregon

5. Graph showing carbon-to-chlorophyll a ratio of water samples collected in Upper Klamath Lake, south-central Oregon, June-September 2011

6. Graph showing carbon-to-chlorophyll a ratio of water samples collected in Upper Klamath Lake, south-central Oregon, August 18-19, 2011

7. Boxplot showing relative percentage of difference in carbon-to-chlorophyll a ratio of water samples collected in Upper Klamath Lake, south-central Oregon, June-September 2011

8. Graphs showing results of recalibrating the algal settling velocity parameter by using net primary production.

9. Graphs showing comparison of measured chlorophyll $a$ and particulate phosphorus (P), calculated as the difference between measured total and soluble reactive phosphorus (TP-SRP), and various approaches of model fitting — Linear model, and parabolic model.

10. Graphs showing recycled mass of phosphorus, as determined from equations 23 and 24 , as a function of lakewide average $\mathrm{pH}$ and water temperature, Upper Klamath Lake, south-central Oregon, 1991-2010

11. Graph showing comparison of calculated and predicted mass of phosphorus recycled from the sediments based on the calibrated, multivariate regression recycling model that used $\mathrm{pH}$ and water temperature as explanatory variables

12. Graphs showing lakewide averaged water-column total phosphorus, sediment mass of phosphorus, and lakewide averaged water-column chlorophyll a, 2004-10 ...24

13. Graphs showing comparison of net primary production, calculated from continuous dissolved oxygen and temperature, to lakewide average water temperature and the "mirrored" water temperature time series used as a predictor variable, 2005-15.

14. Graphs showing wavelet filtered high- and low-frequency components and original time series, June-0ctober 2005.

15. Graphs showing time series of net primary production, as calculated from continuous dissolved oxygen and temperature; lakewide average chlorophyll a values collected by the Klamath Tribes and U.S. Geological Survey; and net primary production as simulated with a multivariate regression model with meteorological data, water temperature, phosphorus, and chlorophyll $a$ as explanatory variables, in Upper Klamath Lake, south-central Oregon, 2005-10, 2012, 2014-15. 


\section{Figures-Continued}

16. Flowchart showing whole lake eutrophication model dependencies using simulated net primary production.

17. Graphs showing time series of lakewide average total phosphorus for three nutrient load reduction scenarios...

18. Graphs showing time series of mass of total phosphorus in the sediments for three nutrient load reduction scenarios.

19. Graphs showing simulated lakewide averaged total phosphorus in water column, phosphorus mass in sediment, and lakewide-averaged chlorophyll $a$ in water column for no reduction in external loads and three scenarios for load reduction, 30-35 years after instantaneous load reduction.

20. Graph showing time series of mass of total phosphorus in the sediments for 40-percent nutrient load reduction scenarios, for rate constants over three orders of magnitude and relative to an arbitrary starting concentration, indicating the time required in each case to establish a new equilibrium..

\section{Tables}

1. U.S. Geological Survey continuous and discrete monitoring sites used for lake metabolism calculations and uncertainty analysis, Upper Klamath Lake, south-central Oregon.

2. Descriptions of model terms used in this report .............................................................

3. Descriptions, values, and sources of parameters used in the whole lake eutrophication model. . .10

4. Estimated daily net primary production, seasonal average uncertainty interval with 95-percent level of confidence...

5. Hourly bias and uncertainties between U.S. Geological Survey core water-quality monitoring sites and depth-similar sites.

6. Combined average hourly measurement uncertainty for dissolved oxygen and temperature measured at each U.S. Geological Survey core water-quality monitoring site and region, 95-percent confidence interval

7. Total particulate carbon, phycocyanin, and chlorophyll a sample data, and calculations for chlorophyll $a$ and carbon-to-chlorophyll $a$ ratio at discrete sample depths, Upper Klamath Lake, south-central Oregon, June-September 2011

8. Performance statistics of the calibrated whole lake eutrophication model, 2005-10....23

9. Regression coefficients for the high- and low-frequency net primary productivity flux components based on calibration years 2005, 2007, 2009, 2012, and 2015.

10. Performance statistics for net primary productivity regression models for calibration $(2005,2007,2009,2012,2015)$ and validation $(2006,2008,2010,2014)$ years

11. Results of simulations of nutrient load reduction scenarios with the Upper Klamath Lake whole lake eutrophication model 


\section{Conversion Factors}

U.S. customary units to International System of Units

\begin{tabular}{|c|c|c|}
\hline Multiply & By & To obtain \\
\hline \multicolumn{3}{|c|}{ Length } \\
\hline foot $(\mathrm{ft})$ & 0.3048 & meter $(\mathrm{m})$ \\
\hline \multicolumn{3}{|c|}{ Area } \\
\hline acre & 4,047 & square meter $\left(\mathrm{m}^{2}\right)$ \\
\hline acre & 0.4047 & hectare (ha) \\
\hline
\end{tabular}

International System of Units to U.S. customary units

\begin{tabular}{lcl}
\hline \multicolumn{1}{c}{ Multiply } & By & \multicolumn{1}{c}{ To obtain } \\
\hline centimeter $(\mathrm{cm})$ & Length & \\
meter $(\mathrm{m})$ & 0.3937 & $\begin{array}{l}\text { inch (in.) } \\
\text { foot }(\mathrm{ft})\end{array}$ \\
\hline & 3.281 & \\
\hline square meter $\left(\mathrm{m}^{2}\right)$ & Area & square foot $\left(\mathrm{ft}^{2}\right)$ \\
square kilometer $\left(\mathrm{km}^{2}\right)$ & 10.76 & square mile $\left(\mathrm{mi}^{2}\right)$ \\
\hline & 0.3861 & \\
\hline milliliter $(\mathrm{mL})$ & Volume & ounce, fluid $(\mathrm{fl} . \mathrm{oz})$ \\
liter $(\mathrm{L})$ & 0.03382 & ounce, fluid $(\mathrm{fl} . \mathrm{oz})$ \\
\hline & 33.82 & foot per day $(\mathrm{ft} / \mathrm{d})$ \\
\hline meter per day $(\mathrm{m} / \mathrm{d})$ & Flow rate & foot squared per day $\left(\mathrm{ft}^{2} / \mathrm{d}\right)$ \\
meter squared per day $\left(\mathrm{m}^{2} / \mathrm{d}\right)$ & 3.281 & \\
\hline & 10.76 & ounce, avoirdupois $(\mathrm{oz})$ \\
\hline milligram $(\mathrm{mg})$ & Mass & ounce, avoirdupois $(\mathrm{oz})$ \\
gram $(\mathrm{g})$ & $3.5274 \times 10^{-5}$ & pound avoirdupois $(\mathrm{lb})$ \\
kilogram $(\mathrm{kg})$ & 0.03527 & ton \\
metric ton & 2.205 & pound per cubic foot $\left(\mathrm{lb} / \mathrm{ft}^{3}\right)$ \\
\hline
\end{tabular}

Temperature in degrees Celsius $\left({ }^{\circ} \mathrm{C}\right)$ may be converted to degrees Fahrenheit as $\left({ }^{\circ} \mathrm{F}\right)$ as

$$
{ }^{\circ} \mathrm{F}=\left(1.8 \times{ }^{\circ} \mathrm{C}\right)+32 .
$$




\section{Datums}

Vertical coordinate information is referenced to the Bureau of Reclamation datum, which is 1.78 feet above National Geodetic Vertical Datum of 1929 (NGVD 29).

Horizontal coordinate information is referenced to the North American Datum of 1927 (NAD27).

Elevation, as used in this report, refers to distance above the vertical datum.

\section{Supplemental Information}

Concentrations of chemical constituents in water are given in either milligrams per liter ( $\mathrm{mg} / \mathrm{L}$ ) or micrograms per liter $(\mu \mathrm{g} / \mathrm{L})$.

\section{Abbreviations}

$\begin{array}{ll}\text { AgriMet } & \text { Cooperative Agricultural Weather Network } \\ \text { AFA } & \text { Aphanizomenon flos-aquae } \\ \text { CR } & \text { community respiration } \\ \text { DO } & \text { dissolved oxygen } \\ \text { GPP } & \text { gross primary production } \\ \text { GUM } & \text { Guidance on Uncertainty in Measurement } \\ \text { KT } & \text { Klamath Tribes } \\ \text { NGWS } & \text { normalized global wavelet spectrum } \\ \text { NPP } & \text { net primary production } \\ \text { ppb } & \text { parts per billion } \\ \text { Reclamation } & \text { Bureau of Reclamation } \\ \text { SOD } & \text { sediment-oxygen demand } \\ \text { TMDL } & \text { Total Maximum Daily Load } \\ \text { TP } & \text { total phosphorus } \\ \text { TPC } & \text { total particulate carbon } \\ \text { UKL } & \text { Upper Klamath Lake } \\ \text { SWLE } & \text { scenario WLE } \\ \text { USGS } & \text { U.S. Geological Survey } \\ \text { WLE } & \text { whole lake eutrophication }\end{array}$





\title{
A Metabolism-Based Whole Lake Eutrophication Model to Estimate the Magnitude and Time Scales of the Effects of Restoration in Upper Klamath Lake, South-Central Oregon
}

\author{
By Susan A. Wherry and Tamara M. Wood
}

\section{Abstract}

A whole lake eutrophication (WLE) model approach for phosphorus and cyanobacterial biomass in Upper Klamath Lake, south-central Oregon, is presented here. The model is a successor to a previous model developed to inform a Total Maximum Daily Load (TMDL) for phosphorus in the lake, but is based on net primary production (NPP), which can be calculated from dissolved oxygen, rather than scaling up a small-scale description of cyanobacterial growth and respiration rates. This phase 3 WLE model is a refinement of the proof-of-concept developed in phase 2 , which was the first attempt to use NPP to simulate cyanobacteria in the TMDL model. The calibration of the calculated NPP WLE model was successful, with performance metrics indicating a good fit to calibration data, and the calculated NPP WLE model was able to simulate mid-season bloom decreases, a feature that previous models could not reproduce.

In order to use the model to simulate future scenarios based on phosphorus load reduction, a multivariate regression model was created to simulate NPP as a function of the model state variables (phosphorus and chlorophyll $a$ ) and measured meteorological and temperature model inputs. The NPP time series was split into a low- and high-frequency component using wavelet analysis, and regression models were fit to the components separately, with moderate success.

The regression models for NPP were incorporated in the WLE model, referred to as the "scenario" WLE (SWLE), and the fit statistics for phosphorus during the calibration period were mostly unchanged. The fit statistics for chlorophyll $a$, however, were degraded. These statistics are still an improvement over prior models, and indicate that the SWLE is appropriate for long-term predictions even though it misses some of the seasonal variations in chlorophyll $a$.

The complete whole lake SWLE model, with multivariate regression to predict NPP, was used to make long-term simulations of the response to 10-, 20-, and 40-percent reductions in tributary nutrient loads. The long-term mean water column concentration of total phosphorus was reduced by 9,18 , and 36 percent, respectively, in response to these load reductions. The long-term water column chlorophyll $a$ concentration was reduced by 4,13 , and 44 percent, respectively. The adjustment to a new equilibrium between the water column and sediments occurred over about 30 years.

\section{Significant Findings}

This report contains the following significant findings:

- The previous Upper Klamath Lake Total Maximum Daily Load (UKL TMDL) model was modified to use lakewide average net primary production to simulate the algal blooms as compared to "scaling up" growth and respiration terms that are more appropriate for small, homogeneous water parcels.

- Two models have been created - one model that can be run with calculated lakewide average net primary production and used to understand lake processes, and a second model that can be run with simulated lakewide average net primary production and used to predict long-term effects of management actions.

- The calculation of net primary production from dissolved oxygen (DO) monitors in Upper Klamath Lake, south-central Oregon, resulted in a faster growth rate for the cyanobacterial bloom than was used in prior modeling efforts; consequently, a faster calibrated settling rate also was required to satisfy mass balance requirements.

- A combination of $\mathrm{pH}$ - and temperature-dependent recycling mechanisms was better able than a single mechanism to describe the recycling of phosphorus from the sediments as calculated from mass balance.

- The calibrated rate constants for settling, recycling, and removal of non-algal phosphorus from the water column were all higher than constants used in prior modeling efforts, indicating faster exchange of phosphorus between the water column and the sediments in this system than was previously understood. 
- Phosphorus load reductions of 20 percent or less were shown to have proportional effects on long-term mean water column phosphorus concentrations; however, the effect on biomass was smaller (3-12 percent) because growth was not always limited by phosphorus.

- A phosphorus load reduction of 40 percent was required to achieve reductions in biomass that were proportional to the load reductions.

- Load reductions are more likely to result in similar, moderate biomass reductions in all years, rather than very large reductions in some years and very small reductions in others.

- The implications of this study for restoration time scales and the magnitude of the effects of restoration are qualitatively similar to the results of previous studies using a whole lake model of Upper Klamath Lake, although the approach taken was different. These implications include the following: (1) The time scale for the response to instantaneous nutrient load reductions is on the order of a few decades, as the coupled sediment and water column transition to a new equilibrium state; and (2) in response to load reductions, sediment storage decreases (but sediment storage does not tend toward 0 and does not have to be depleted before a substantial decrease in water column concentration can occur).

- Data collection that would reduce uncertainty in the UKL net primary production (NPP) calculation should focus on reaeration and respiration rates, and reduction of model uncertainty should focus on data collection to determine settling velocities and sediment total phosphorus (TP) recycle rates.

\section{Introduction}

Massive cyanobacterial blooms dominated by the cyanobacterium Aphanizomenon flos-aquae (AFA) have been occurring in Upper Klamath Lake (UKL) in south-central Oregon (fig. 1) since at least the middle of the 20th century (Phinney and Peek, 1961), the result of progressive eutrophication that can be dated to the early 1900s (Bradbury and others, 2004; Eilers and others, 2004). The associated poor water quality (including episodically low concentrations of $\mathrm{DO}$, high $\mathrm{pH}$, and high ammonia concentrations) has been methodically documented since the 1990s, with sample collection on an approximately biweekly interval (Jassby and Kann, 2010; Kann, 2016), and more recently (since 2002), with continuously recording water-quality datasondes (Wood and others, 2006; Hoilman and others, 2008; Lindenberg and others, 2009). These poor water-quality conditions are detrimental to the survival of endangered, endemic sucker species (Perkins and others, 2000; Banish and others, 2009), and the export of nutrients and organic carbon from the lake creates problems in downstream reaches of the Klamath River (Sullivan and others, 2011). To respond to these water-quality problems, in 2002, Oregon Department of Environmental Quality established a TMDL (Oregon Department of Environmental Quality, 2002) that set allowable limits on the amount of phosphorus entering the lake from external sources as a means to reduce the frequency, magnitude, and extent of cyanobacterial blooms and thereby improve water quality.

The establishment of the TMDL was informed by a zero-dimensional lake eutrophication model that approximated lake average concentrations of TP for the combined Upper Klamath and Agency Lakes (Walker, 2001). In 2011, the U.S. Geological Survey (USGS) began a multi-phased technical review and update of the UKL TMDL model to (1) evaluate the strengths and limitations of the model, (2) make improvements using information and data derived from studies completed since the initial development of the model, and (3) document model results in a way that emphasized its use as a tool for understanding the cycling of phosphorus in the coupled water column-sediment system. This report is third in a series of reports that document the phases of technical review and proposed updates of the original UKL TMDL model. These reports are best understood together as a body of work that, in sequence, presents a stepwise progression of improvement in model performance and associated understanding of the system, with the goal of informing restoration activities aimed at reducing tributary phosphorus loading to the lake.

In phase 1, several improvements - including updates to the initial sediment reservoir (Simon and others, 2009; Simon and Ingle, 2011) and changes to the calculation of limitation factors and assumptions of the algal submodel (Wood and others, 2013) - were implemented and proposed for the UKL TMDL model, which was then rescripted in $\mathrm{R}$ ( $\mathrm{R}$ Core Team, 2016). Modifications to the R-script model were used to analyze the long-term behavior of model simulations, and relate this behavior to implications for restoration (Wood and others, 2013). In phase 2, a longer dataset was used for calibration, and suggestions for several major modifications were made (Wherry and others, 2015). Among these was the suggestion that lake metabolism calculations derived from continuous monitors in the lake be substituted for the formulation that described algal growth as a maximum potential growth modified by limiting light, nutrient, and temperature factors. It was argued that the process of scaling up the original local-scale mechanistic description of growth to a single, large, averaged volume that represents the lake introduced excessive error, especially in a system like Upper Klamath Lake with high spatial variability. An alternative that eliminated the scaling-up problem was to calculate net lakewide primary production (gross primary production minus community respiration) from the oxygen budget using continuous sensors in multiple locations around the lake. 


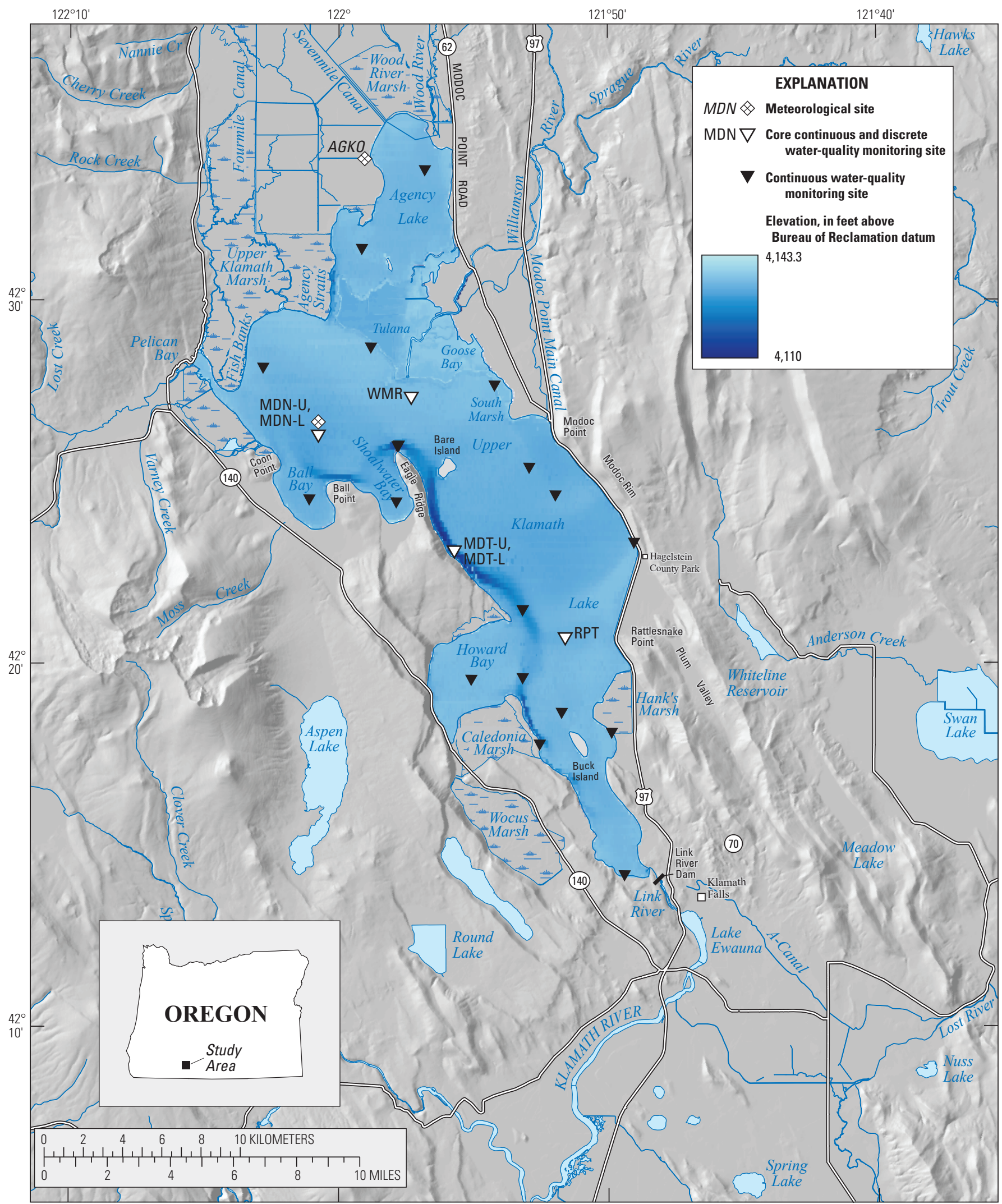

Base modified from USGS and other digital sources, various scales.

Coordinate system is UTM, Zone 10N; North American Datum of 1927.

Figure 1. Location of meteorological stations and continuous and discrete water-quality monitoring sites, Upper Klamath Lake, south-central Oregon. See table 1 for descriptions of site name abbreviations. 
In this third phase, we assume that community respiration is dominated by autotrophs; therefore, we refer to the calculation of gross primary production minus community respiration as net primary production, as compared to net ecosystem production, while acknowledging that heterotrophs contribute somewhat to community respiration. To emphasize that an assumption about community respiration is being made, these values hereinafter are referred to as "calculated" net primary production. Calculation of the oxygen budget for the entire lake from a few monitor locations also incorporates error, but it has the potential to be more accurate than the previous approach.

A proof-of-concept of the lake metabolism approach using 3 years of DO data collected from 2006 to 2008 was developed in phase 2, and the results were promising (Wherry and others, 2015). A large source of error in the original model and subsequent iterations was the lack of any mechanism to simulate decreases in mid-season blooms (Wood and others, 2013), and the lake metabolism approach overcame that problem to a large extent (Wherry and others, 2015). A problem that remained was that lake metabolism calculated from DO sensors does not have predictive power for restoration scenarios, as the concentration of DO was not part of the model solution. Incorporating DO in the model as a state variable would defeat the purpose, as it would require the same process-based description of cyanobacterial growth and respiration that was in the original model. Instead, an attempt was made to create a sub-model of whole lake metabolism that predicted net primary production as a function of explanatory variables that are either independently observable and not expected to change with nutrient management (wind speed, water temperature, stratification, and solar radiation), or state variables that are calculated internally by the model itself (phosphorus and chlorophyll $a$, the surrogate for biomass). These sub-model predictions hereinafter are referred to as "simulated" NPP. The approach of creating a sub-model was moderately successful, and additional enhancements were identified that could improve model performance including accommodating deeper mixing and focusing on empirical predictions of NPP using a single model for the entire season (Wherry and others, 2015).

In this third phase, the USGS was tasked with incorporating one of the improvements that was identified in the second report (Wherry and others, 2015) - the incorporation of lake metabolism in the model as a substitute for terms describing cyanobacteria growth explicitly at small scales and then scaling those up to the entire volume of the lake (hereinafter referred to as the "scaling up" approach). The new approach is referred to as the "lake metabolism" approach. To emphasize the distinction between this version of the eutrophication model and previous iterations, as well as to emphasize the utility of the model beyond establishing TMDL targets, hereinafter we refer to this new type of model as the "whole lake eutrophication (WLE) model". The final products are two WLE models, one dependent on calculated historical NPP and one dependent on simulated NPP. The calculated NPP WLE is more accurate in simulating historical chlorophyll $a$ concentrations and seasonal dynamics, but is limited to the time period for which NPP can be calculated from measurements. The simulated NPP WLE is less accurate when simulating chlorophyll $a$ seasonal dynamics, but can provide insights on long-term trends and average conditions resulting from management actions.

Although the biomass in UKL is dominated by cyanobacteria, the original TMDL model and its appropriate parameters and variables were described by the term "algal" instead of "cyanobacterial." This report continues that convention for certain terms - algal settling velocity, algal phosphorus, and non-algal phosphorus.

\section{Purpose and Scope}

This report refines the demonstration of a WLE model that uses NPP in place of estimates of biomass that are scaled up from terms describing cyanobacteria growth and respiration at small scales. NPP, which is the net effect of gross primary production and community respiration, can be calculated using measurements of DO, water temperature, and wind speed from continuous monitors in the lake. In Wherry and others (2015), this calculation was limited to 3 years, 2006-08, and in this report the calculation is expanded to 9 years (2005-10, 2012, and 2014-15), for which all the necessary data are available. Additionally, in Wherry and others (2015), an attempt was made to separate calculated NPP into its gross primary production (GPP) and community respiration (CR) components by assuming that average nighttime CR rates could be applied over the entire day. Although this is a widely used assumption, the resulting daily average respiration rates could vary significantly over an entire season. To reduce this source of uncertainty and because separating NPP into components of GPP and CR was not necessary for the TMDL model, we decided to focus on developing an accurate lakewide NPP calculation and a regression model for its prediction.

A regression model that estimates calculated NPP as a function of variables other than DO is developed with data from the same years. The purpose of the regression model is to simulate NPP based on observable variables that will be independent of nutrient reduction scenarios and state variables calculated internally by the model. This allows the WLE model to simulate the response of the lake to possible nutrient load reduction scenarios.

Several changes have been made to the algorithm and parameter calibration describing recycling of phosphorus in the sediments, including:

- A combination of temperature- and $\mathrm{pH}$-dependent recycling algorithms;

- A modification of the form of the $\mathrm{pH}$-dependent recycling; 
- A new calibration of the rate parameters controlling recycling and deposition, using the NPP calculations as a substitute for an explicit growth term in the chlorophyll $a$ mass balance;

- An upward revision of the phosphorus cell quota; and

- A new estimate of the carbon-to-chlorophyll $a$ ratio in cyanobacterial cells, which is required from the lake metabolism approach. This value is estimated with a short-term particulate carbon dataset collected by the USGS in 2011.

In this report, loading and calibration data for the 6 years (2005-10) in which NPP was calculated and UKL loading data are available are combined to create a 6-year historical dataset. The WLE model is first calibrated and run with the historical calculation of NPP from continuous monitors to assess the performance of the lake metabolism approach in simulating the calibration dataset. Based on the success of the lake metabolism approach, a multivariate regression that predicts NPP from independent predictor variables, excluding DO, is developed to give the model predictive power. The WLE model is then run in "scenario" mode with the simulated NPP predicted by the multivariate regression. Finally, long-term simulations of 60 years with the WLE model in "scenario" mode and using simulated NPP are presented for three nutrient reduction scenarios from 10 to 40 percent. Implications for restoration are discussed.

\section{Datasets}

Descriptions of the several datasets used in development of the WLE model are compiled here under one heading, with identification of the steps in the process where each particular dataset was used.

\section{Klamath Tribes Water-Quality Samples}

A biweekly dataset of water quality in UKL for the longer calibration period was developed using measured biweekly/monthly (depending on season) TP, chlorophyll $a$, and $\mathrm{pH}$ data collected by the Klamath Tribes (KT) at nine sites. The data were averaged across space and time to represent the lakewide average value at a 14-d interval, following the procedure outlined in Kann and Walker (1999). This dataset hereinafter is referred to as the "KT biweekly dataset."

\footnotetext{
${ }^{1}$ The 12-month period from October 1 , for any given year, through September 30, of the following year. The water year is designated by the calendar year in which it ends.
}

The KT biweekly dataset used in this study spans 1991-2010, corresponding to the years covered by the load calculations and the data used in Wherry and others (2015). The entire length of this record was used to determine the phosphorus content of biomass and internal recycling parameters. A shorter length of record comprising water years ${ }^{1}$ 2005-10 was used to calibrate the algal settling velocity, and as the validation data for the WLE model, because this shorter record overlapped with the continuous monitor sonde data used to calculate NPP.

\section{Load Calculations}

The WLE model requires inflows and outflows from the lake, and the inflow load of TP. The daily hydrologic inflows and outflows and daily loads of phosphorus spanned 1991-2010, and were developed by Walker and others (2012). The daily inflow load of TP was calculated using linearly interpolated phosphorus concentrations from biweekly measurements.

\section{U.S. Geological Survey Continuous Monitors}

Calculations of NPP were made using hourly measurements of DO and water temperature recorded at water-quality monitoring datasondes located at four sites on the lake: (1) Upper Klamath Lake at Williamson River outlet (WMR); (2) Rattlesnake Point (RPT); (3) Mid-North, upper and lower sondes (MDN-U and MDN-L); and (4) Mid-Trench, upper and lower sondes (MDT-U and MDT-L) (fig. 1; table 1). Two of these sites had datasondes recording $1 \mathrm{~m}$ from the lake surface and $1 \mathrm{~m}$ from the bottom; the other two sites had a datasonde recording $1 \mathrm{~m}$ from the lake bottom if the water column depth was greater than $2 \mathrm{~m}$, or at one-half water column depth if the depth was less than $2 \mathrm{~m}$. These sites hereinafter are referred to as the USGS "core" sites. Records at the USGS core sites were available from about mid-May through the end of September, 2005-15.

Wind speed and air temperature data used in the NPP calculations and in the NPP regression model were recorded at a platform in the northern part of the lake at site MDN (fig. 1). These meteorological data were not collected in 2013, and were collected only from July onward in 2011, precluding the calculation of NPP in those years. Therefore, NPP was calculated for 2005-10, 2012, and 2014-2015, and the regression model was calibrated and validated using the same period. The calibration was done over years 2005, 2007, 2009, 2012 , and 2015, and validation was done for years 2006, 2008, 2010, and 2014.

Estimates of the uncertainty in the NPP calculation due to spatial variability were made using additional datasonde records that overlapped records from the USGS core sites in $1-5$ years (table 1). Details of the uncertainty calculations are provided in section, "Quantification of Uncertainty in Net Primary Production Calculations." 
Table 1. U.S. Geological Survey continuous and discrete monitoring sites used for lake metabolism calculations and uncertainty analysis, Upper Klamath Lake, south-central Oregon.

[Abbreviatons: bws, below water surface; MET, meteorological; WQ, water quality; N/A, not applicable]

\begin{tabular}{|c|c|c|c|c|c|c|c|c|}
\hline Site name & $\begin{array}{c}\text { Site name } \\
\text { abbreviation }\end{array}$ & Type & USGS site No. & Latitude & Longitude & $\begin{array}{c}\text { Full-pool } \\
\text { measured } \\
\text { depth } \\
\text { (meters } \\
\text { bws) }\end{array}$ & Years & $\begin{array}{l}\text { Stage-similar } \\
\text { core site }\end{array}$ \\
\hline \multicolumn{9}{|c|}{ Core sites for metabolism analysis } \\
\hline $\begin{array}{l}\text { Upper Klamath Lake at } \\
\text { Williamson River outlet }\end{array}$ & WMR & WQ & 422719121571400 & $42^{\circ} 27^{\prime} 19^{\prime \prime}$ & $121^{\circ} 57^{\prime} 14^{\prime \prime}$ & 2.5 & $2005-10$ & N/A \\
\hline Rattlesnake Point & RPT & WQ & 422042121513100 & $42^{\circ} 20^{\prime} 41.6^{\prime \prime}$ & $121^{\circ} 51^{\prime} 31.4^{\prime \prime}$ & 3.4 & $2005-10$ & N/A \\
\hline Mid-North, lower sonde & MDN-L & WQ & 422622122004000 & $42^{\circ} 26^{\prime} 21.5^{\prime \prime}$ & $122^{\circ} 00^{\prime} 40^{\prime \prime}$ & 4.2 & $2005-10$ & N/A \\
\hline Mid-North, upper sonde & MDN-U & WQ & 422622122004003 & $42^{\circ} 26^{\prime} 21.5^{\prime \prime}$ & $122^{\circ} 00^{\prime} 40^{\prime \prime}$ & 4.2 & $2005-10$ & N/A \\
\hline Mid-Trench, lower sonde & MDT-L & WQ & 422305121553800 & $42^{\circ} 23^{\prime} 5.1^{\prime \prime}$ & $121^{\circ} 55^{\prime} 38.2^{\prime \prime}$ & 15 & $2005-10$ & N/A \\
\hline Mid-Trench, upper sonde & MDT-U & WQ & 422305121553803 & $42^{\circ} 23^{\prime} 5.1^{\prime \prime}$ & $121^{\circ} 55^{\prime} 38.2^{\prime \prime}$ & 15 & $2005-10$ & N/A \\
\hline South Hanks Marsh & SHM & WQ & 421805121494800 & $42^{\circ} 18^{\prime} 5.1^{\prime \prime}$ & $121^{\circ} 49^{\prime} 47.8^{\prime \prime}$ & 2.2 & $2007-08$ & WMR \\
\hline Goose Bay East & GBE & WQ & 422749121540700 & $42^{\circ} 27^{\prime} 38.8^{\prime \prime}$ & $121^{\circ} 54^{\prime} 7.5^{\prime \prime}$ & 2.4 & $2006-10$ & WMR \\
\hline Agency Lake South & AGS & WQ & 423124121583400 & $42^{\circ} 31^{\prime} 24.9^{\prime \prime}$ & $121^{\circ} 59^{\prime} 3.4^{\prime \prime}$ & 2.5 & $2005-10$ & WMR \\
\hline Howard Bay & HDB & WQ & 421933121550000 & $42^{\circ} 19^{\prime} 33^{\prime \prime}$ & $121^{\circ} 55^{\prime} 00^{\prime \prime}$ & 2.5 & $2005-08$ & WMR \\
\hline Skillet Handle & SHL & WQ & 421746121522800 & $42^{\circ} 17^{\prime} 46^{\prime \prime}$ & $121^{\circ} 52^{\prime} 28^{\prime \prime}$ & 2.5 & 2006 & WMR \\
\hline South Shore & SSR & WQ & 421410121492000 & $42^{\circ} 14^{\prime} 9.9^{\prime \prime}$ & $121^{\circ} 49^{\prime} 19.7^{\prime \prime}$ & 2.5 & $2006-10$ & WMR \\
\hline Hagelstein Park & HPK & WQ & 422319121585700 & $42^{\circ} 23^{\prime} 19^{\prime \prime}$ & $121^{\circ} 48^{\prime} 57.2^{\prime \prime}$ & 2.6 & 2006 & WMR \\
\hline North Buck Island & NBI & WQ & 421838121513900 & $42^{\circ} 18^{\prime} 38^{\prime \prime}$ & $121^{\circ} 51^{\prime} 39^{\prime \prime}$ & 2.8 & $2005-10$ & WMR \\
\hline Fish Banks & FBS & WQ & 422808122024400 & $42^{\circ} 28^{\prime} 8.8^{\prime \prime}$ & $122^{\circ} 2^{\prime} 43.5^{\prime \prime}$ & 2.8 & $2005-10$ & WMR \\
\hline Agency Lake North & AGN & WQ & 423335121564300 & $42^{\circ} 33^{\prime} 35^{\prime \prime}$ & $121^{\circ} 56^{\prime} 43^{\prime \prime}$ & 3.0 & $2005-10$ & RPT \\
\hline Shoalwater Bay & SHB & WQ & 422444121580400 & $42^{\circ} 24^{\prime} 26.1^{\prime \prime}$ & $121^{\circ} 57^{\prime} 47.1^{\prime \prime}$ & 3.3 & 2005 & RPT \\
\hline $\begin{array}{l}\text { South End of Trench, upper } \\
\text { sonde }\end{array}$ & SET-U & WQ & 422128121530603 & $42^{\circ} 21^{\prime} 28^{\prime \prime}$ & $121^{\circ} 53^{\prime} 6^{\prime \prime}$ & 7.0 & $2006-08$ & MDN-U \\
\hline Eagle Point, lower sonde & EPT-L & WQ & 422559121574400 & $42^{\circ} 25^{\prime} 59.2^{\prime \prime}$ & $121^{\circ} 57^{\prime} 44.1^{\prime \prime}$ & 12.5 & $2005-10$ & MDT-L \\
\hline Eagle Point, upper sonde & EPT-U & WQ & 422559121574403 & $42^{\circ} 25^{\prime} 59.2^{\prime \prime}$ & $121^{\circ} 57^{\prime} 44.1^{\prime \prime}$ & 12.5 & $2005-08$ & MDT-U \\
\hline
\end{tabular}




\section{U.S. Geological Survey Water-Quality Samples}

Depth-integrated water samples for chlorophyll $a$ analysis were collected on an approximately weekly interval at the four USGS core sites during 2005-2006 and 2008-2015. Values at the USGS core sites were averaged and are compared graphically with the calculations of NPP and chlorophyll $a$ from the KT biweekly data, to show how the bloom cycle based on NPP calculations from DO compare to biomass estimates from two other datasets. The depth-integrated chlorophyll $a$ values also were used to estimate the carbonto-chlorophyll $a$ ratio in cyanobacteria cells, as described in section, "Calculation of the Ratio of Carbon to Chlorophyll $a$ in Cyanobacteria Cells."

\section{AgriMet Solar Radiation}

The solar radiation data used in developing the regression model for NPP was collected at the Bureau of Reclamation (Reclamation) Cooperative Agricultural Weather Network (AgriMet) meteorological station AGKO located at Agency Lake (fig. 1). Daily global solar radiation data were downloaded from the AgriMet database (Bureau of Reclamation, 2016).

\section{Whole Lake Eutrophication Model for Simulating Historical Conditions}

The set of dependent model equations (Walker, 2001; Wherry and others, 2015) comprises three mass balance equations for whole-lake mass of total phosphorus $(P)$, whole-lake biomass as measured by the surrogate chlorophyll $a(B)$, and the sediment mass of total phosphorus $(S)$, with model terms and parameters described in tables 2 and 3:

$$
\begin{gathered}
\frac{d B}{d t}=B_{N P P}-u_{a l g} B z^{-1}-Q_{o u t} B V^{-1}, \\
\frac{d P}{d t}=L_{P}+R-D-Q_{o u t} P V^{-1}, \text { and } \\
\frac{d S}{d t}=D-R-U_{B} S Z_{S}^{-1} .
\end{gathered}
$$

The biomass and phosphorus equations are linked through the deposition term and the phosphorus content of cyanobacteria cells (fig. 2). The water column and sediment phosphorus equations are linked through the recycling and the deposition terms (fig. 2). The inputs for equation terms for inflow load of TP to the lake, $L_{P}$, outflow discharge, $Q_{\text {out }}$, average lake depth, $z$, and lake volume, $V$, were determined from the daily mass balance of Walker and others (2012); and the burial velocity, $U_{B}$, and the depth of active sediments, $Z_{S}$, were the same as those used by Walker (2001) (table 3). The remaining model terms, including:

- Rate of change in biomass through net primary production, $B_{N P P}$;

- Rate of settling of biomass through net primary production, $u_{\text {alg }} B z^{-1}$;

- Rate of recycling of phosphorus from the sediments, $R$; and

- Rate of transfer of phosphorus from the water column to the sediments through deposition, $D$,

were determined through various methods of calculation and calibration described in the following sections. The model time step is $1 \mathrm{~d}$; however, a biweekly model could be implemented by accumulating the NPP and appropriate input variables over 2-week intervals.

Two additional constraints are imposed on the concentration of chlorophyll $a$ - a minimum concentration that was set to 5 parts per billion (ppb) (the 10th percentile of November-March values from the KT biweekly data), and a maximum concentration that constrains algal phosphorus to not exceed the amount of TP available.

\section{Biomass}

\section{Net Primary Production}

The change in the whole-lake mass of DO over each day as a result of net primary production was calculated from hourly measurements of DO and temperature collected seasonally (roughly mid-May through September) at four USGS continuous monitoring sites with the longest period of record (2005-15) (MDN, MDT, RPT, and WMR in fig. 1). Wind speed was collected at 10- or 15-min intervals at a buoy located at monitoring site MDN (fig. 1) and was subsampled to $1-\mathrm{h}$ intervals. The time series were pre-processed by linearly interpolating gaps of $6 \mathrm{~h}$ or less. Longer gaps were filled at each hour with a weighted average of the values collected at the same hour of the day prior to and after the gap. Most gaps were short, lasting only hours, but a few gaps spanned several days. Gaps in wind speed data occurring in 2011 and 2013 were long enough to prevent the calculation of NPP in those years. 


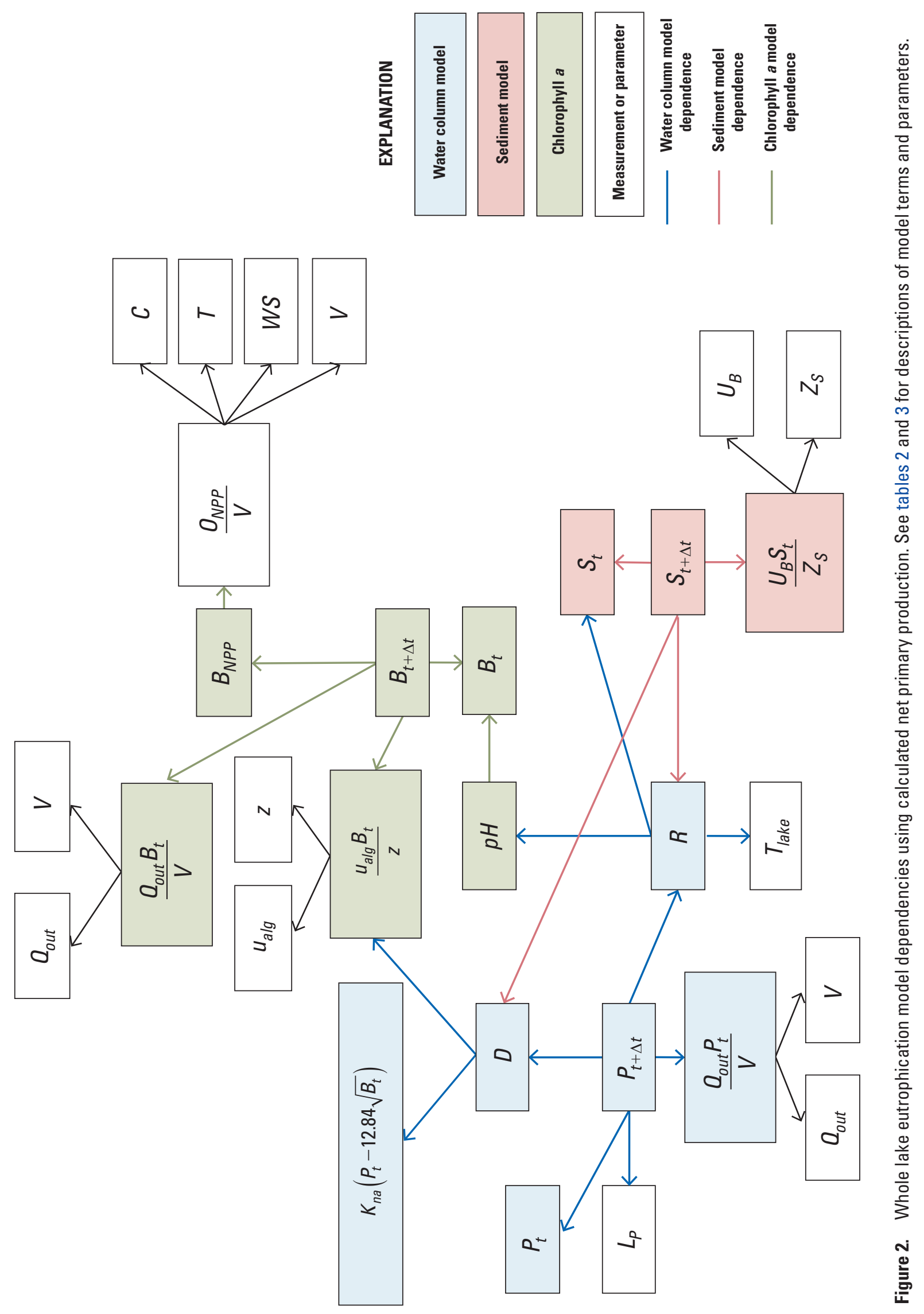


Table 2. Descriptions of model terms used in this report.

\begin{tabular}{|c|c|c|}
\hline Symbol & Units & Description \\
\hline$A$ & square meters & Lake area \\
\hline$B$ & parts per billion & Chlorophyll $a$ concentration \\
\hline$B_{N P P}$ & parts per billion per day & Chlorophyll $a$ concentration converted from NPP \\
\hline$C$ & milligram per liter & Dissolved oxygen concentration \\
\hline$C_{\text {sat }}$ & milligram per liter & Saturation dissolved oxygen concentration \\
\hline$D$ & kilogram per day & Rate of deposition of phosphorus from water column to sediments \\
\hline$G$ & gram per hour & Rate of change in mass of dissolved oxygen due to reaeration \\
\hline$S O D$ & gram per hour & Whole-lake mass of sediment oxygen demand \\
\hline$\Phi_{S O D}$ & grams of oxygen per square meter per day & Sediment oxygen demand \\
\hline$K_{L, 20}$ & meter per hour & Film transfer coefficient at 20 degrees Celsius \\
\hline$K_{n a}$ & per day & Nonalgal phosphorus removal rate \\
\hline$L_{P}$ & kilogram per day & Inflow load of total phosphorus \\
\hline$N P P$ & grams of oxygen per square meter per day & Net primary production \\
\hline$O$ & gram & Whole-lake mass of dissolved oxygen \\
\hline$O_{N P P}$ & gram & Whole-lake change in mass of dissolved oxygen due to NPP \\
\hline$P$ & kilogram & Whole-lake mass of total phosphorus \\
\hline$P_{\text {alg }}$ & kilogram & Whole-lake mass of algal phosphorus \\
\hline$P_{n a}$ & kilogram & Whole-lake mass of nonalgal phosphorus \\
\hline$p H$ & $\mathrm{pH}$ standard units & Lakewide average $\mathrm{pH}$ \\
\hline$p N P P$ & grams of oxygen per square meter per day & Predicted NPP \\
\hline$Q_{\text {out }}$ & cubic meters per day & Lake outflow rate \\
\hline$R$ & kilogram per day & Rate of recycling of phosphorus from the sediments \\
\hline$S$ & kilogram & Sediment mass of total phosphorus \\
\hline$S I$ & Langleys per day & Average solar radiation \\
\hline STRAT & degrees Celsius & Indicator of stratification \\
\hline$T_{\text {lake }}$ & degrees Celsius & Average lake temperature based on Klamath Tribes sites \\
\hline$T$ & degrees Celsius & Water temperature at U.S. Geological Survey sites \\
\hline$T_{\text {USGS }}$ & degrees Celsius & Average lake temperature based on U.S. Geological Survey core sites \\
\hline$t$ & day & Time \\
\hline$V$ & cubic meters & Mean volume of the lake over the timestep \\
\hline$z$ & meter & Average lake depth over the time step \\
\hline$z_{\text {full }}$ & meter & Site specific full pool depth \\
\hline$\Delta t$ & day & Time step \\
\hline$W S$ & meter per second & Wind speed translated to 10 meters above the water surface \\
\hline$\Delta T_{U S G S}$ & degrees Celsius per day & Change in daily water temperature \\
\hline
\end{tabular}


Table 3. Descriptions, values, and sources of parameters used in the whole lake eutrophication model.

[Symbol: -, no units]

\begin{tabular}{|c|c|c|c|c|}
\hline Parameter description & $\begin{array}{l}\text { Parameter } \\
\text { symbol }\end{array}$ & Value & Units & Sources of parameters \\
\hline Algal phosphorus as function of chlorophyll $a(B)$ & $P_{\text {alg }}$ & $12.84 \times \sqrt{\mathrm{B}}$ & parts per billion & This study \\
\hline Algal carbon to chlorophyll $a$ ratio & $\delta_{\text {Chla:C }}$ & $1 / 49$ & $\begin{array}{l}\text { gram chlorophyll } a \text { per gram } \\
\text { carbon }\end{array}$ & This study \\
\hline Initial sediment total phosphorus concentration & $s_{0}$ & 335 & $\begin{array}{l}\text { milligram phosphorus per } \\
\text { kilogram }\end{array}$ & Wood and others, 2013 \\
\hline Sediment phosphorus burial velocity & $U_{B}$ & 1.4 & millimeter per year & $\begin{array}{l}\text { Eilers and others, 2001; } \\
\text { Walker, } 2001\end{array}$ \\
\hline Active sediment depth & $Z_{S}$ & 10 & centimeter & $\begin{array}{l}\text { Eilers and others, 2001; } \\
\text { Walker, } 2001\end{array}$ \\
\hline Threshold for $\mathrm{pH}$-dependent recycling & $p H_{\text {thresh }}$ & 7.8 & - & This study \\
\hline Maximum $\mathrm{pH}$ from measurements & $p H_{\max }$ & 10.2 & - & This study \\
\hline Temperature-dependent recycling rate & $K_{R, T}$ & $3.07 \pm 0.34$ & per year & This study \\
\hline $\begin{array}{l}\text { Threshold for temperature-dependent recycling, } \\
\text { based on a temperature threshold of } \\
5 \text { degrees Celsius }\end{array}$ & $\theta_{\text {thresh }}$ & $1.065^{(5-20)}$ & - & This study \\
\hline
\end{tabular}

\section{Whole-Lake Mass Calculation}

The lakewide mass of DO was determined from the hourly DO data at four continuous monitoring sites (table 1). All four sites had sondes measuring concentrations at $1 \mathrm{~m}$ depth. Two sites, MDN and MDT, had sondes measuring concentrations at $1 \mathrm{~m}$ above the bottom of the lake. The lake was divided into an upper section that included all volume less than $2 \mathrm{~m}$ in depth, and a lower section that included all volume greater than $2 \mathrm{~m}$ depth. The partition at $2 \mathrm{~m}$ in depth was determined by reviewing weekly profiles and by comparing $1-\mathrm{m}$ values collected by the continuously recording sondes to the upper section averages as determined from weekly profiles (fig. 3).

The measurements at the upper sondes were averaged at each hour to determine the average DO concentration and temperature in the upper $2 \mathrm{~m}$ of the lake. The four sites were weighted in the average based on a consideration of the stage-surface area curve for the lake which was based on bathymetry data collected during May and June 1996 (Neuman, 2017). The shallowest areas of the lake that constitute most of the surface area are not well-represented by the four USGS core sites, which are located in areas with full pool depths of 2.5, 3.4, 4.2, and $15 \mathrm{~m}$ (Hoilman and others,
2008; table 1). This is particularly true since 2008, when restoration at the Williamson River Delta was completed and 5,500 acres surrounding the mouth of the Williamson River were inundated by breaching levees, leading to more surface area represented by the shallowest depths. The stage-surface area curve in figure 4 represents the post-2008 conditions, and also includes Agency Lake (fig. 1) where there currently are no continuous monitoring sites. Given the lack of monitoring in areas of the lake less than $2 \mathrm{~m}$ deep, and a lack of information about the stage-surface area curve at depths greater than $2.5 \mathrm{~m}$ (fig. 4), a simple weighting scheme was used to average the four USGS core sites. The upper sonde at MDT was given a weight of 0.04 to represent the region of the lake deeper than $5 \mathrm{~m}$, and the remaining sites were given equal weights of 0.32 . The DO concentration $C_{u p}$ and temperature $T_{u p}$ in the upper section of the lake at each hour $i$ were calculated as:

$$
\begin{gathered}
C_{u p, i}=0.32 \times C_{W M R, i}+0.32 \times C_{R P T, i} \\
+0.32 \times C_{M D N U, i}+0.04 \times C_{M D T U, i}, \text { and } \\
T_{u p, i}=0.32 \times T_{W M R, i}+0.32 \times T_{R P T, i} \\
+0.32 \times T_{M D N U, i}+0.04 \times T_{M D T U, i} .
\end{gathered}
$$



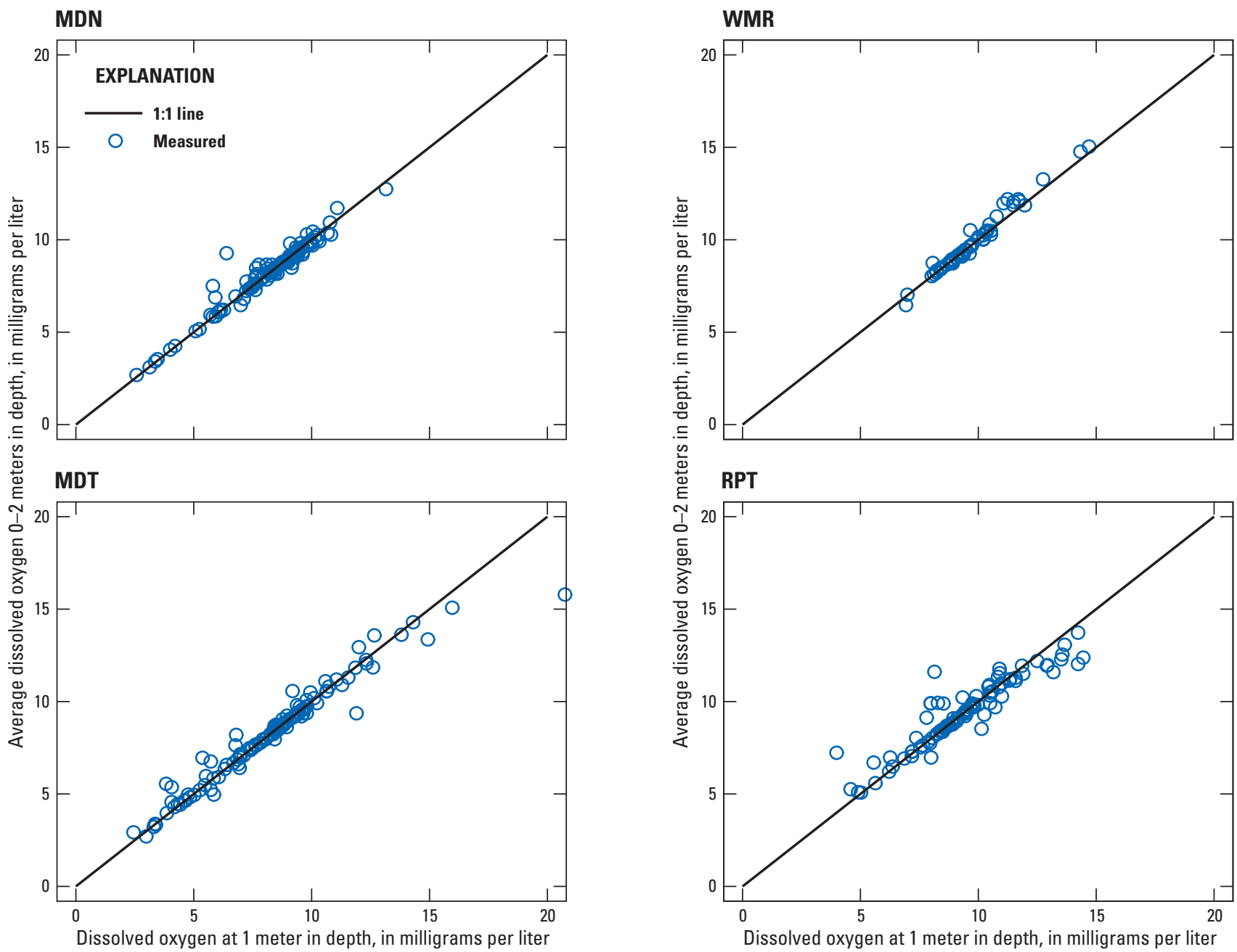

Figure 3. Average dissolved oxygen in the upper 2 meters of the water column, as a function of the corresponding hourly measurement collected at 1 meter in depth, at U.S. Geological Survey core sites of Mid-North (MDN), Upper Klamath Lake at Williamson River outlet (WMR), Mid-Trench (MDT), and Rattlesnake Point (RPT), Upper Klamath Lake, south-central Oregon.

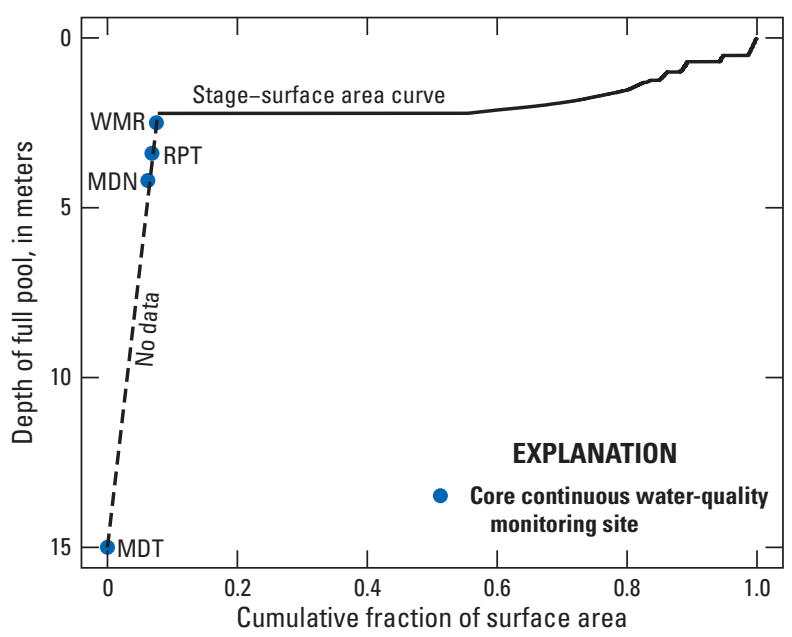

Figure 4. Cumulative fraction of total lake surface area as a function of depth at full pool (1,262.9 meters or 4,143.3 feet) and the full-pool depths for the four U.S. Geological Survey core water-quality monitoring sites, Upper Klamath Lake, south-central Oregon. 
The lower sites also were averaged at each hour to determine the average DO concentration at depths greater than $2 \mathrm{~m}$. The two lower sondes at sites MDN and MDT were given equal weighting:

$$
\begin{gathered}
C_{\text {low }, i}=0.5 \times C_{M D N L, i}+0.5 \times C_{M D T L, i}, \text { and } \\
T_{l o w, i}=0.5 \times T_{M D N L, i}+0.5 \times T_{M D T L, i} .
\end{gathered}
$$

Bathymetry data were used to quantify the proportion of volume in each section of the lake, which was 67 percent in the upper $2 \mathrm{~m}$ and the remaining 33 percent below $2 \mathrm{~m}$. The total mass of DO in the lake at each hour, therefore, was determined by:

$$
O_{i}=\left(0.67 \times C_{u p, i}+0.33 \times C_{l o w, i}\right) \times V .
$$

\section{Gas Transfer and Sediment Oxygen Demand}

The rate of change in mass of DO owing to gas transfer at the water surface was determined using wind speed to calculate a film transfer coefficient and applying that transfer rate to the difference between saturation DO (calculated from the average temperature measured at the upper sondes) and average DO at the upper sondes; averages were weighted by site as in equation 4. Saturation DO was calculated using the Benson and Krause equations (U.S. Geological Survey, 2011). The film transfer coefficient, in meters per hour, was calculated from hourly wind speed data using the following equation (Gelda and Effler, 2002a):

$$
K_{L, 20}=\left\{\begin{array}{c}
0.2 W S / 24, W S \leq 3.5 \mathrm{~m} / \mathrm{s} \\
0.057 W S^{2} / 24, W S>3.5 \mathrm{~m} / \mathrm{s}
\end{array} .\right.
$$

Equation 9 was developed for a smaller, deeper lake (Onondaga Lake, which also has high winds). Staehr and others (2010) reported that a highly productive lake in which NPP is the small difference of large values of gross primary production and respiration, the sensitivity of metabolism calculations to the estimate of the film transfer coefficient was low (-2.3-2.1 percent in the calculation of respiration, given a 50-percent change in film transfer coefficient). Lacking direct measurements of the gas transfer at the water surface, therefore, equation 9 was considered adequate for Upper Klamath Lake. Wind speed was measured at a height of $2 \mathrm{~m}$ above water surface, but equation 9 was developed using 10-m measurement height, wind speed estimates; therefore, the values were translated to $10-\mathrm{m}$ values, $W S$, using a logarithmic approximation (Martin and McCutcheon, 1999). The film transfer rates were temperature-corrected using the Van ' $t$ Hoff equation, with input parameter, $\theta$, equal to 1.024 (Gelda and Effler, 2002a), and applied to the DO deficit to calculate the rate of change in mass of DO each hour as a result of gas transfer at the air-water interface:

$$
G_{i}=K_{L, 20} \times 1.024^{\left(T_{u p}-20\right)} \times\left(C_{s a t}-C_{u p}\right) \times A,
$$

where

$$
A \quad \text { is the surface area of the lake. }
$$

The rate of change in mass of DO owing to sediment-oxygen demand (SOD) was temperature corrected using the average water temperature measured at the two lower water column sondes and the Van 't Hoff equation, with $\theta$ equal to 1.065 (Wood, 2001):

$$
S O D_{i}=\left(\frac{\Phi_{S O D, 20}}{24}\right) \times 1.065^{\left(T_{\text {oow }}-20\right)} \times A,
$$

where

$$
\begin{gathered}
\Phi_{S O D, 20} \text { is equal to } 1.6 \text { grams oxygen }\left(\mathrm{O}_{2}\right) \text { per square } \\
\text { meter per day }\left[\left(1.6 \mathrm{~g} \mathrm{O}_{2} / \mathrm{m}^{2}\right) / \mathrm{d}\right] \text { (Wood, } \\
\text { 2001). }
\end{gathered}
$$

\section{Whole-Lake Metabolism Calculation}

Each day, the whole-lake change in the mass of DO as a result of net primary production was calculated by accumulating, midnight to midnight, the change in whole-lake mass of DO, the influx from gas transfer at the air-water interface, and the loss from sediment oxygen demand (Gelda and Effler, 2002b; $\Delta t=1 \mathrm{~h}$ ):

$$
O_{N P P}=\sum_{h=1}^{24} O_{N P P, i}=\sum_{h=1}^{24}\left\{\left(O_{i}-O_{i-1}\right)-G_{i} \Delta t+S O D_{i} \Delta t\right\} .
$$

$O_{N P P}$ is the whole-lake change in DO each day that can be attributed to net primary production, the difference between photosynthetic production and respiratory consumption of $\mathrm{O}_{2}$. Daily lakewide NPP was calculated by dividing by the total surface area of the lake to arrive at units of $\left[\left(\mathrm{g} \mathrm{O}_{2} / \mathrm{m}^{2}\right) / \mathrm{d}\right]$.

The whole lake-change in the biomass surrogate chlorophyll $a$ can be related to NPP with two stoichiometric factors (Wherry and others, 2015):

$$
B_{N P P}=\delta_{C: O} \delta_{C h l a: C} O_{N P P} / V \Delta t,
$$

where

$$
\begin{gathered}
\delta_{C: O} \quad \text { is the stoichiometric ratio of carbon to oxygen } \\
\text { in photosynthesis reaction and its reverse, } \\
\text { respiration }\left(2.67 \text { grams oxygen }\left[\mathrm{O}_{2}\right]\right. \text { per } \\
\text { grams carbon } \left.\left[\mathrm{g} \mathrm{O}_{2} / \mathrm{g} \mathrm{C}\right]\right) \text {; and } \\
\text { is the stoichiometric ratio of chlorophyll } a \text { to } \\
\text { C in cyanobacteria cells. }
\end{gathered}
$$

The latter ratio was determined from water samples collected in the lake, as described in section, "Calculation of the Ratio of Carbon to Chlorophyll $a$ in Cyanobacteria Cells," and was equal to $49 \mathrm{~g} \mathrm{C}$ per g chlorophyll $a$. 
As developed in section, "Quantification of Uncertainty in Net Primary Production Calculations," the estimated uncertainty around the daily values due to measurement error and spatial variability is about $\left[\left(3 \mathrm{~g} \mathrm{O}_{2} / \mathrm{m}^{2}\right) / \mathrm{d}\right]$ (table 4$)$, which, when converted with equation (13) and divided by a reasonable average depth for the lake of $2.2 \mathrm{~m}$ (fig. 4), amounts to an uncertainty of about $10 \mathrm{mg} / \mathrm{L}$ or $10 \mathrm{ppb} / \mathrm{d}$ in the rate of change of chlorophyll $a, B_{N P P}$.

\section{Quantification of Uncertainty in Net Primary Production Calculations}

The calculation of whole-lake mass of DO based on hourly continuous monitor data collected at four sites represents biological activity occurring over a large area with considerable spatial variability and also excludes the effects of advection. We can quantify the uncertainty in the result of that calculation. For our evaluation, we will assume that the uncertainty in the NPP calculation is driven primarily by the spatial variability of $\mathrm{DO}$ and temperature within the lake, ignoring the uncertainty in the estimate of SOD and in the equations for the film transfer coefficient or reaeration. Manufacturer estimates of instrument error are included, although those values likely are dwarfed by spatial uncertainty.

To determine the uncertainty for an hourly calculation of NPP, we followed the techniques outlined in the Guidance on Uncertainty in Measurement (GUM; Bureau International des Poids et Mesures, 2008) for combining uncertainty from measurements (in this case, DO and water temperature), used to determine a measurand (in this case, NPP). The combined uncertainty of NPP, based on the law of square propagation, results in the following equation for combined uncertainty:

$$
\begin{aligned}
u_{c}^{2}\left(O_{N P P}\right) & =\left(\frac{\partial O_{N P P}}{\partial C_{u p}}\right)^{2} u^{2}\left(C_{u p}\right)+\left(\frac{\partial O_{N P P}}{\partial T_{u p}}\right)^{2} u^{2}\left(T_{u p}\right) \\
& +\left(\frac{\partial O_{N P P}}{\partial T_{l o w}}\right)^{2} u^{2}\left(T_{l o w}\right),
\end{aligned}
$$

where

$u_{c} \quad$ is the combined standard uncertainty; and $u \quad$ is the standard uncertainty for each measured variable, which combines instrument and spatial uncertainty.

The partial derivatives, which are sensitivity factors, are calculated as:

$$
\begin{gathered}
\frac{\partial O_{N P P}}{\partial C_{u p}}=K_{L, 20} \times A \times 1.024^{\left(T_{u p}-20\right)}, \\
\frac{\partial O_{N P P}}{\partial T_{u p}}=-K_{L, 20} \times\left(C_{s a t}-C_{u p}\right) \times A \times \ln (1.024) \times 1.024^{\left(T_{u p}-20\right)},
\end{gathered}
$$

Table 4. Estimated daily net primary production, seasonal average uncertainty interval with 95-percent level of confidence.

[Abbreviations: $\left[\left(\mathrm{g} \mathrm{O}_{2} / \mathrm{m}^{2}\right) / \mathrm{d}\right]$, grams oxygen $\left(\mathrm{O}_{2}\right)$ per square meter per day; NPP, net primary production; \pm , plus or minus]

\begin{tabular}{cc}
\hline Year & $\begin{array}{c}\text { NPP uncertainty } \\
{\left[\left(\mathbf{g} \mathbf{~}_{\mathbf{2}} / \mathbf{m}^{\mathbf{2}}\right) / \mathbf{d}\right]}\end{array}$ \\
\hline 2005 & 2.95 \\
2006 & 3.22 \\
2007 & 3.29 \\
2008 & 3.16 \\
2009 & 3.25 \\
2010 & 3.02 \\
2012 & 3.06 \\
2014 & 2.94 \\
2015 & 2.61 \\
Average & 3.05 \\
\hline
\end{tabular}

$$
\frac{\partial O_{N P P}}{\partial T_{\text {low }}}=\Phi_{S O D, 20} \times A \times \ln (1.065) \times 1.065^{\left(T_{\text {low }}-20\right)},
$$

where we have assumed equal uncertainty in DO concentrations between any two consecutive hours. The spatial uncertainty of measurements was determined by using the full set of continuous monitor data, including all 23 sites, spanning 2005-10. Each USGS core site was compared to all other sites of similar depth, without replacement, over the complete hourly record covered by each pair of sites, and finding two standard deviations in the difference of hourly values to quantify the 95 -percent confidence interval. Spatial uncertainty for each USGS core site was determined by combining all the uncertainties from each pairing with equal weights, and considering the correlation between site-specific uncertainty. For example, the uncertainty at a site core that is similar in depth to a number, $\mathrm{N}$, of other sites would be evaluated following GUM guidance for combined uncertainty of correlated input quantities as follows:

$$
\begin{aligned}
& u_{C}^{2}(\text { core })=\sum_{i=1}^{N}\left(\frac{1}{N}\right)^{2} \times u^{2}\left(\text { core }- \text { site }_{i}\right) \\
& +2 \sum_{i=1}^{N-1} \sum_{j=2}^{N}\left(\frac{1}{N}\right)^{2} \times u\left({\text { core } \left.- \text { site }_{i}\right) \times u\left(\text { core }^{-} \text {site }_{j}\right)}\right) \\
& \times r\left(\text { core }- \text { site }_{i}, \text { core }- \text { site }_{j}\right),
\end{aligned}
$$

where

$r \quad$ is the correlation coefficient between the time series when core is compared to site $_{i}$ and site $_{j}$.

and 
Spatial uncertainty was indicated for each of the USGS core sites for upper sonde DO, upper sonde water temperature, and lower sonde water temperature. Hourly uncertainties are reported in table 5. The lakewide uncertainty results were then determined by combining uncertainty from each of the four USGS core sites for each of the measured variables following GUM guidance for combined uncertainty of correlated input quantities and using the spatial weighting, $w$, of equations 4-8:

$$
\begin{aligned}
u_{c}^{2}(U K L) & =\sum_{i=1}^{N} w_{i}^{2} \times u^{2}\left(\text { core }_{i}\right)+2 \sum_{i=1}^{N-1} \sum_{j=2}^{N} w_{i} \times w_{j} \\
& \times u\left(\text { core }_{i}\right) \times u\left(\text { core }_{j}\right) \times r\left(\text { core }_{i}, \text { core }_{j}\right) .
\end{aligned}
$$

Assuming the same lakewide hourly uncertainty for each variable across a season, the lakewide combined uncertainty results were then used in equation 14 to calculate hourly lakewide NPP uncertainty. Hourly uncertainties for the

Table 5. Hourly bias and uncertainties between U.S. Geological Survey core water-quality monitoring sites and depth-similar sites.

[See table 1 for full names of core site name abbreviations. Abbreviations: ${ }^{\circ} \mathrm{C}$, degrees Celsius; DO, dissolved

\begin{tabular}{|c|c|c|c|c|c|}
\hline Site name & $\begin{array}{c}\text { Site name } \\
\text { abbreviation }\end{array}$ & $\begin{array}{c}\text { Core site } \\
\text { bias for DO } \\
\text { (mg/L) }\end{array}$ & $\begin{array}{c}\text { SD of } \\
\text { difference } \\
\text { in DO } \\
\text { (mg/L) }\end{array}$ & $\begin{array}{c}\text { Core site } \\
\text { bias for } \\
\text { temperature } \\
\left({ }^{\circ} \mathrm{C}\right)\end{array}$ & $\begin{array}{c}\text { SD of } \\
\text { difference in } \\
\text { temperature } \\
\left({ }^{\circ} \mathrm{C}\right)\end{array}$ \\
\hline \multicolumn{6}{|c|}{ WMR core site } \\
\hline Williamson Delta West & WDW & 1.25 & 2.70 & -0.31 & 0.92 \\
\hline South Hanks Marsh & SHM & 2.95 & 3.33 & -0.07 & 1.26 \\
\hline Goose Bay East & GBE & 0.83 & 2.24 & -0.43 & 1.15 \\
\hline Agency Lake South & AGS & 0.79 & 2.62 & -0.25 & 0.84 \\
\hline Howard Bay & HDB & 0.85 & 3.12 & -0.35 & 0.86 \\
\hline Skillet Handle & SHL & 0.49 & 2.76 & -0.88 & 1.10 \\
\hline South Shore & SSR & -0.23 & 3.07 & -1.14 & 1.00 \\
\hline Hagelstein Park & HPK & 0.62 & 1.94 & -0.29 & 1.18 \\
\hline North Buck Island & NBI & 0.23 & 1.89 & 0.14 & 0.87 \\
\hline Fish Banks & FBS & 0.56 & 2.17 & 0.01 & 0.99 \\
\hline \multicolumn{6}{|c|}{ RPT core site } \\
\hline Agency Lake North & AGN & 0.42 & 2.62 & -0.73 & 0.99 \\
\hline Shoalwater Bay & SHB & 0.71 & 2.09 & -0.76 & 0.65 \\
\hline Ball Bay & BLB & 1.59 & 2.06 & -0.46 & 0.64 \\
\hline Modoc Point & MPT & 0.14 & 1.48 & 0.19 & 0.57 \\
\hline Modoc Rim & MRM & -0.26 & 1.62 & 0.16 & 0.62 \\
\hline \multicolumn{6}{|c|}{ MDN-L core site } \\
\hline $\begin{array}{l}\text { South End of Trench, } \\
\text { lower sonde }\end{array}$ & SET-L & 0.97 & 2.13 & -0.04 & 0.62 \\
\hline \multicolumn{6}{|c|}{ MDN-U core site } \\
\hline Entrance to Howard Bay & EHB & 1.17 & 2.12 & 0.19 & 0.83 \\
\hline Entrance to Ball Bay & EBB & 3.10 & 2.59 & 0.54 & 0.83 \\
\hline $\begin{array}{l}\text { South End of Trench, } \\
\text { upper sonde }\end{array}$ & SET-U & 0.72 & 2.22 & -0.40 & 0.74 \\
\hline \multicolumn{6}{|c|}{ MDT-L core site } \\
\hline Eagle Point, lower sonde & EPT-L & 0.91 & 1.68 & 0.15 & 0.47 \\
\hline \multicolumn{6}{|c|}{ MDT-U core site } \\
\hline Eagle Point, upper sonde & EPT-U & 1.64 & 2.65 & 0.62 & 1.02 \\
\hline
\end{tabular}
oxygen; $\mathrm{SD}$, standard deviation; $\mathrm{mg} / \mathrm{L}$, milligram per liter] 
individual core sites and for the combined lakewide average are reported in table 6 . Because the ultimate product is the daily NPP calculated by accumulating the hourly NPP values over each day, we finally had to determine the uncertainty in daily NPP. To accomplish this, we used the GUM equation for combined uncertainty of correlated input quantities to account for the autocorrelation observed in an hourly time series. The autocorrelation function, $a c f$, was determined for hourly lakewide NPP uncertainty over the entire season, with a maximum lag of $24 \mathrm{~h}$, and it was assumed that this function could be applied to each day to determine daily NPP uncertainty:

$$
\begin{aligned}
u_{c}^{2}\left(O_{N P P_{d}}\right) & =\sum_{i=1}^{24} u^{2}\left(O_{N P P_{i}}\right)+2 \sum_{i=1}^{24-1} \sum_{j=2}^{24} u\left(O_{N P P_{i}}\right) \\
& \times u\left(O_{N P P_{j}}\right) \times a c f_{\text {lag }=j-i}
\end{aligned}
$$

\section{Calculation of the Ratio of Carbon to Chlorophyll $a$ in Cyanobacteria Cells}

During 2011, at approximately weekly intervals during June-September, the USGS collected water samples at two locations in the water column at site MDT for the analysis of total particulate carbon (TPC). During August 18-19, 2011, samples were collected eight times over a 24 -h period (every
$3 \mathrm{~h}$ ). At the same time, profiles of phycocyanin were obtained with a datasonde lowered through the water column, and a depth-integrated water sample was collected that was analyzed for chlorophyll $a$ concentration. These three datasets were combined to obtain $\delta_{\text {Chla:C }}($ table 7 ).

First, the profile of phycocyanin was integrated to obtain the total depth-averaged concentration of phycocyanin in cells per milliliter. This integrated phycocyanin profile was compared to the depth-integrated chlorophyll $a$ sample to obtain an average ratio of phycocyanin to chlorophyll $a$ over the water column. Second, the phycocyanin value from the profile at the depth of the TPC sample was converted to chlorophyll $a$ using the ratio from the first step. This provided a ratio of TPC to chlorophyll $a$ at the TPC sample depth.

There were 35 samples for which both steps in this process could be completed. The median value of $1 / \delta_{\text {Chla: }}$ from those samples was $49.45 \mathrm{~g}$ carbon per gram chlorophyll $a$ (49 $\mathrm{g}$ was used in this study) with a standard deviation of $42.35 \mathrm{~g}$. Thus, there was a large range of values, from 8.39 to $193.31 \mathrm{~g}$, around the median. There was some evidence of a change in the ratio through the season, such that values were highest during late June and lowest in mid-August (fig. 5). Samples collected over a 24-h period in August had the entire range of variability, however (fig. 6), so it was not possible to identify a definitive seasonal pattern. An analysis of variance test did not detect a statistically significant difference in the values between the upper and lower water column.

Table 6. Combined average hourly measurement uncertainty for dissolved oxygen and temperature measured at each U.S. Geological Survey core water-quality monitoring site and region, 95-percent confidence interval.

[See table 1 for full names of core site name abbreviations. Abbreviations: ${ }^{\circ} \mathrm{C}$, degrees Celsius; DO, dissolved oxygen; mg/L, milligram per liter;

\begin{tabular}{|c|c|c|c|c|c|}
\hline Site name & $\begin{array}{c}\text { Site name } \\
\text { abbreviation }\end{array}$ & $\begin{array}{c}\text { Combined DO } \\
\text { spatial } \\
\text { uncertainty } \\
\text { (mg/L) }\end{array}$ & $\begin{array}{l}\text { Combined } \\
\text { temperature } \\
\text { spatial } \\
\text { uncertainty } \\
\left({ }^{\circ} \mathrm{C}\right)\end{array}$ & $\begin{array}{c}\text { Combined DO } \\
\text { spatial+0.2 } \\
\text { instrument } \\
\text { uncertainty } \\
\text { (mg/L) }\end{array}$ & $\begin{array}{c}\text { Combined } \\
\text { temperature } \\
\text { spatial+0.1 } \\
\text { instrument } \\
\text { uncertainty } \\
\left({ }^{\circ} \mathrm{C}\right)\end{array}$ \\
\hline \multicolumn{6}{|c|}{ Core site } \\
\hline $\begin{array}{l}\text { Upper Klamath Lake at } \\
\text { Williamson River outlet }\end{array}$ & WMR & 3.29 & 1.42 & 3.30 & 1.42 \\
\hline Rattlesnake Point & RPT & 2.62 & 0.85 & 2.63 & 0.85 \\
\hline Mid-North, lower sonde & MDN-L & 4.25 & 1.24 & 4.26 & 1.24 \\
\hline Mid-North, upper sonde & MDN-U & 3.62 & 1.22 & 3.62 & 1.22 \\
\hline Mid-Trench, lower sonde & MDT-L & 3.35 & 0.93 & 3.36 & 0.94 \\
\hline Mid-Trench, upper sonde & MDT-U & 5.29 & 2.05 & 5.30 & 2.05 \\
\hline \multicolumn{6}{|c|}{ Upper Klamath Lake region } \\
\hline Upper lake (0-2 meters) & & N/A & N/A & 2.64 & 1.22 \\
\hline Lower lake (2-15 meters) & & $\mathrm{N} / \mathrm{A}$ & N/A & 3.35 & 1.09 \\
\hline
\end{tabular}
N/A, not applicable] 


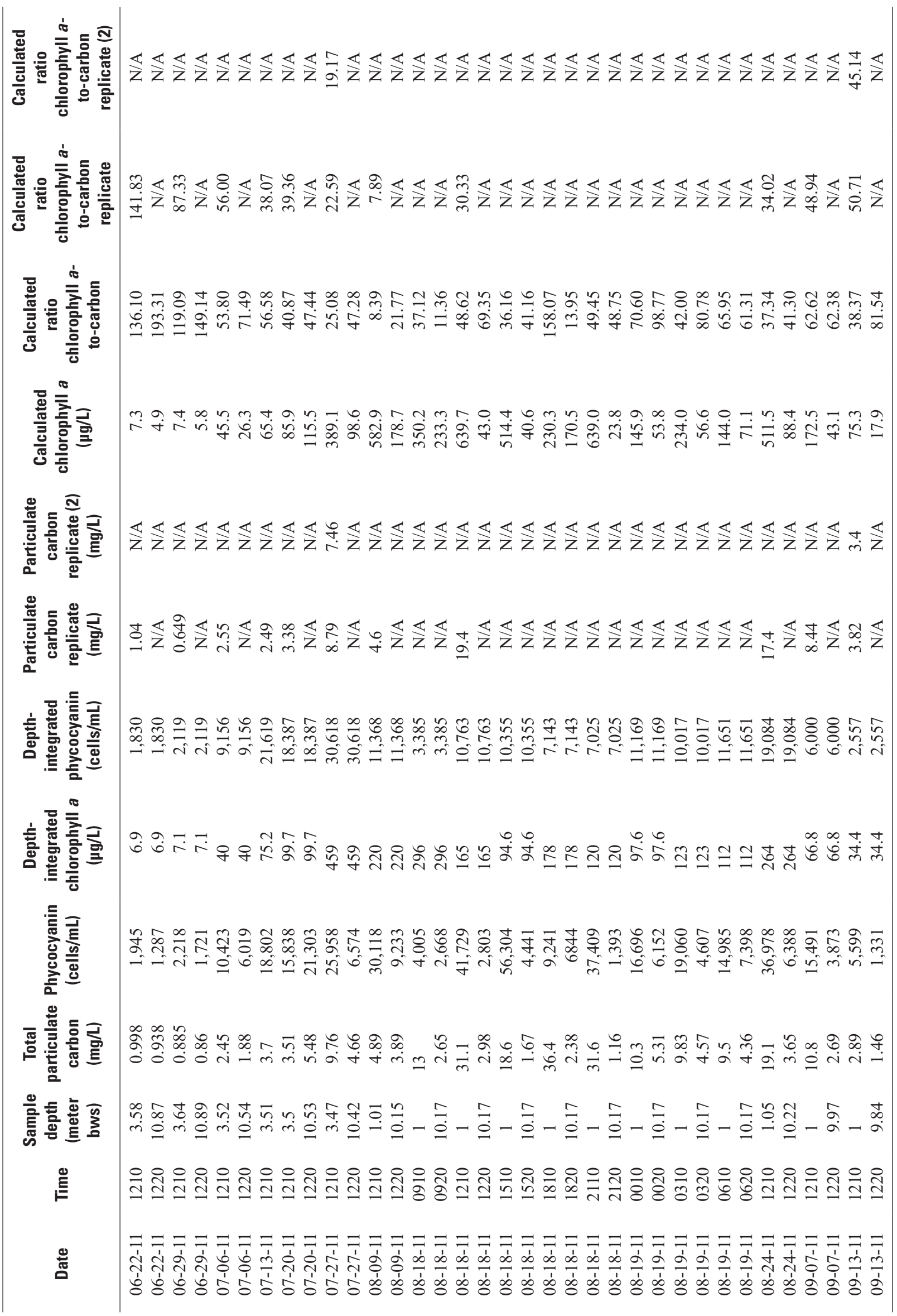


On a few dates, replicate samples were collected. The median relative percentage difference of the replicate-sample pairs was 16.2 percent (fig. 7), which indicates that the range in values was larger than could be accounted for by variability in both the analytical methods for TPC and the method for

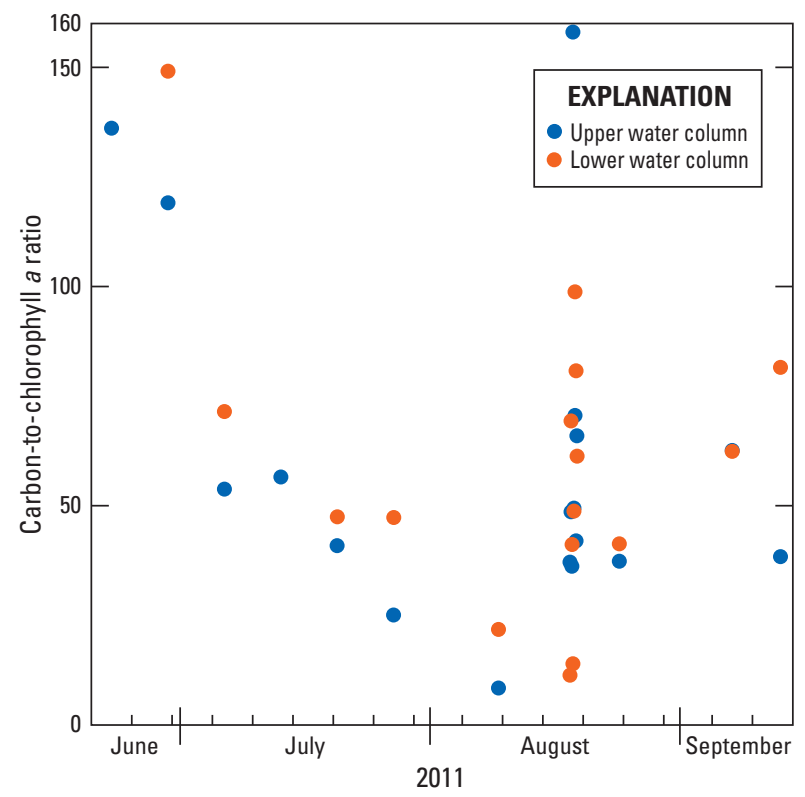

Figure 5. Carbon-to-chlorophyll a ratio of water samples collected in Upper Klamath Lake, southcentral Oregon, June-September 2011. calculating chlorophyll $a$ concentration at the sample depth from phycocyanin profiles. This suggests that the large variability in $\delta_{C h l a: C}$ has an environmental explanation, but further investigation is required to identify the factors that determine the cyanobacteria biomass composition.

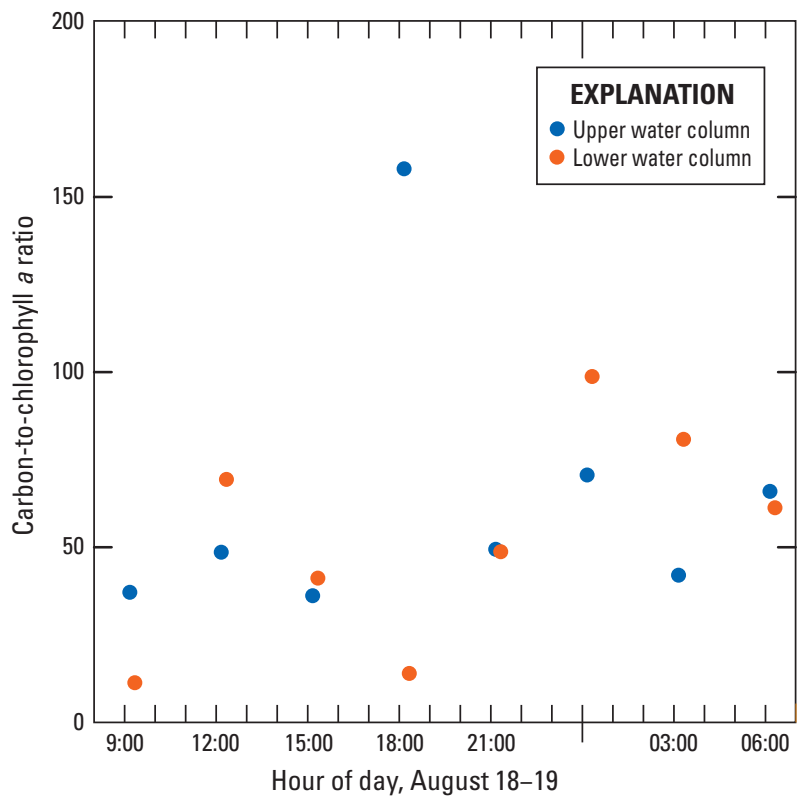

Figure 6. Carbon-to-chlorophyll a ratio of water samples collected in Upper Klamath Lake, southcentral Oregon, August 18-19, 2011.

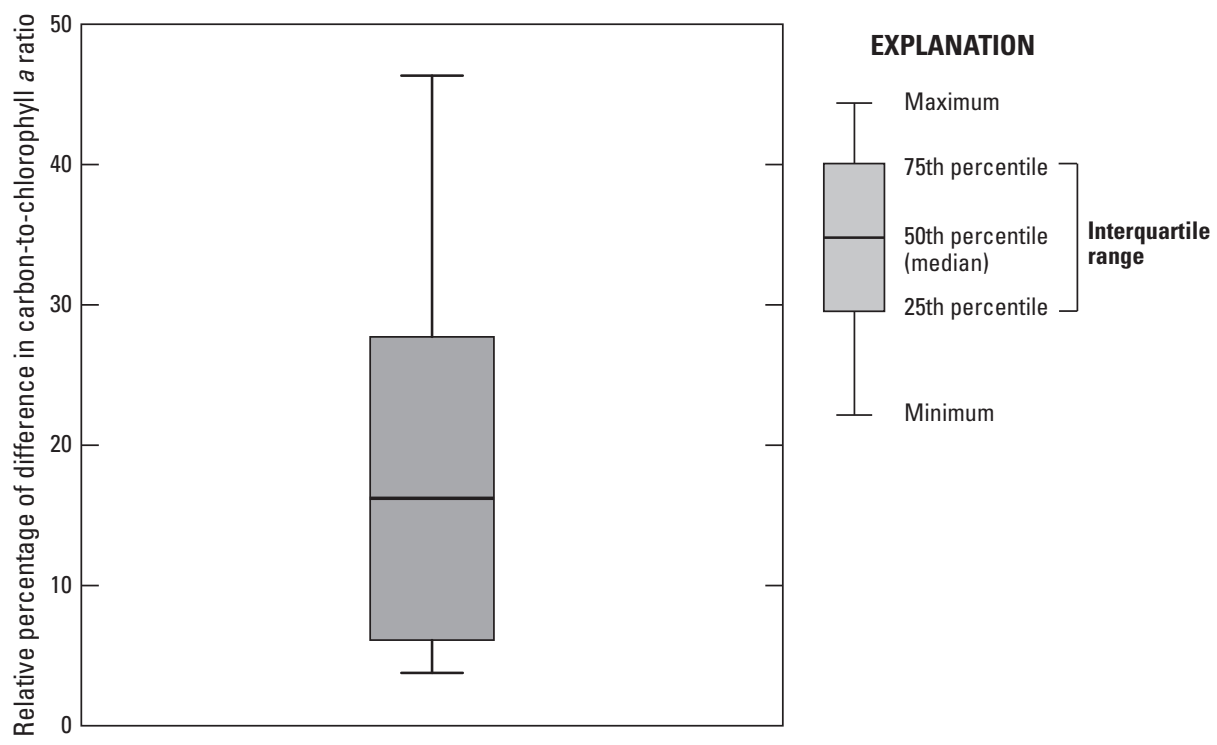

Figure 7. Relative percentage of difference in carbon-to-chlorophyll a ratio of water samples collected in Upper Klamath Lake, south-central Oregon, June-September 2011. 


\section{Phosphorus}

The phosphorus mass balance requires a deposition and recycling term that determines the fluxes between the water column and sediments. The calibration of rates that control deposition and recycling was completed in a sequence of steps described in this section, starting with the deposition term.

TP is composed of an organic fraction, primarily cyanobacterial biomass that is referred to as the "algal" fraction $P_{a l g}$, and an inorganic fraction that is referred to as the "non-algal" fraction $P_{n a}$. The non-algal fraction can be dissolved in the water column as bioavailable orthophosphate, but some of that fraction also can be sorbed to sediments and, therefore, there is a removal rate in the model associated with the non-algal fraction. We have used the same form for the deposition term in equations 2 and 3 that was used in previous iterations of the TMDL model (Walker, 2001):

$$
D=K_{n a} P_{n a}+\frac{u_{a l g}}{z} P_{a l g}=K_{n a}\left(P-P_{a l g}\right)+\frac{u_{a l g}}{z} P_{a l g}
$$

The calculation of deposition requires the determination of the algal settling velocity, $u_{\text {alg }}$, the non-algal phosphorus removal rate, $K_{\mathrm{na}}$, and the allocation of $P$ between algal and non-algal forms.

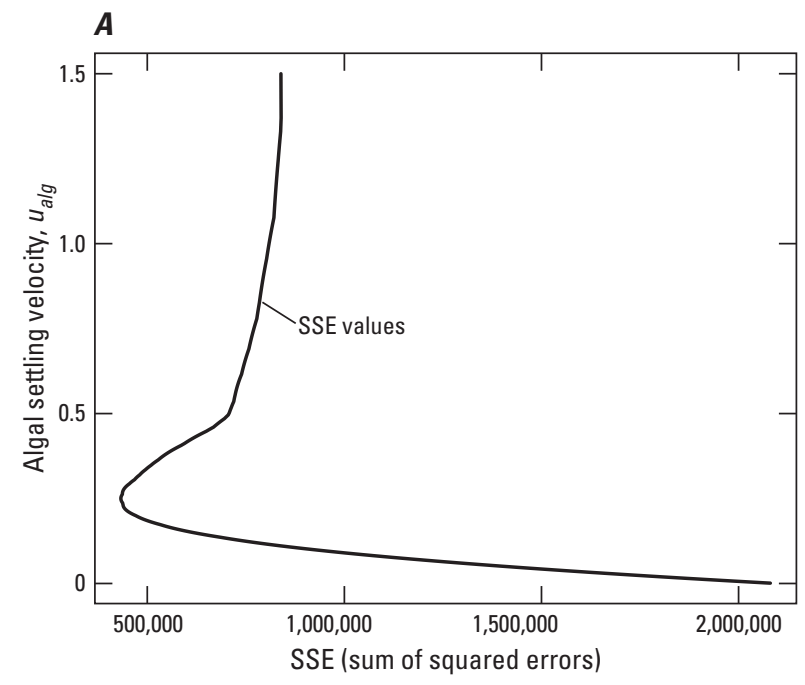

\section{Calibration of Algal Settling Velocity}

Algal settling velocity was determined by discretizing and rearranging equation 1 to solve for the biomass at a time step $j$ :

$$
B_{j}=B_{j-1}+B_{N P P_{j}} \Delta t-\left(\frac{u_{a l g}}{z_{j}}+\frac{Q_{o u t, j}}{V_{j}}\right) B_{j-1} \Delta t .
$$

The time step $\Delta \mathrm{t}$ is $14 \mathrm{~d}$. The right-hand side of the equation was calculated with the KT biweekly chlorophyll $a$, and average lake depth $(z)$, volume $(V)$, and outflow $\left(Q_{\text {out }}\right)$ from the Walker daily loading dataset, subsampled to a 14-d interval to match the chlorophyll $a$ data. The daily $B_{N P P}$ time series calculated using equation 13 was filtered to remove high frequencies $(<4 \mathrm{~d})$ and subsampled at a 14-d interval to match the chlorophyll $a$ data. Algal settling velocity values were assumed to range from 0.001 to $2.0 \mathrm{~m} / \mathrm{d}$ (Bowie and others, 1985), and the best value was determined by correlating chlorophyll $a$, as calculated by equation 22 and constrained to be greater than or equal to 0 , with measured chlorophyll $a$ concentrations from 2005 to 2010 . The sum of squared error was minimized with algal settling velocity $\left(u_{\text {alg }}\right)=$ $0.25 \mathrm{~m} / \mathrm{d}(\mathrm{N}=39$, fig. 8). The resulting correlation between

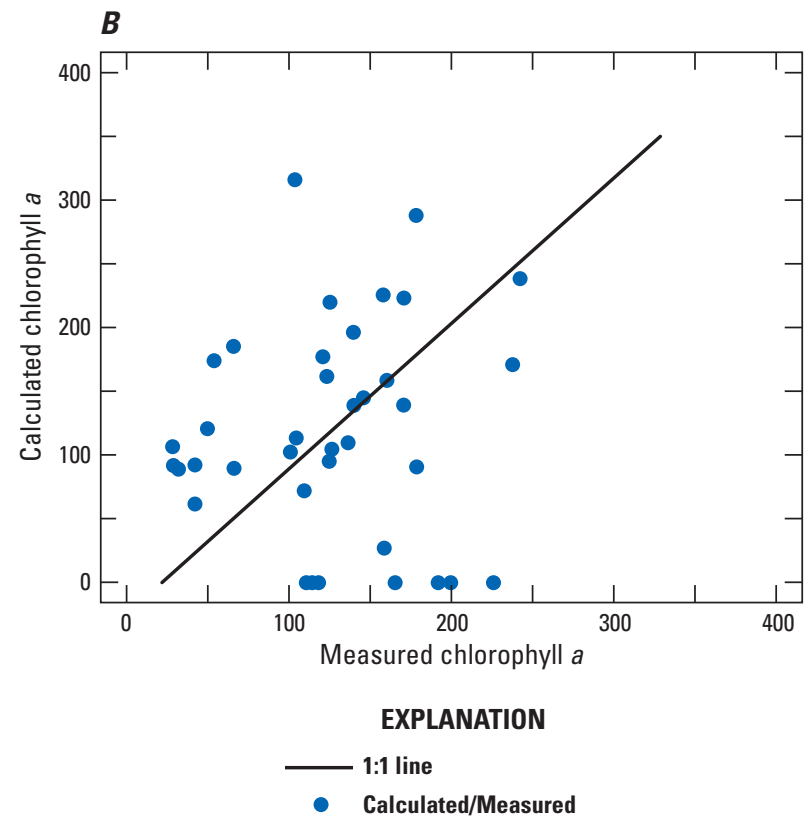

Figure 8. Results of recalibrating the algal settling velocity parameter by using net primary production. $A$, Calibration of algal settling velocity as a function of the sum of squared errors (SSE) produced when predicting biomass, 2005-10. SSE is minimized when algal settling velocity $\left(u_{a / g}\right)=0.25$ meter per day $(\mathrm{m} / \mathrm{d})$. $B$, Chlorophyll $a$ as calculated with equation 13 compared to measured chlorophyll $a$, with $u_{\text {alg }}$ set to $0.25 \mathrm{~m} / \mathrm{d}, 2005-10$. 
calculated and measured chlorophyll $a$ was low (correlation coefficient 0.11 , fig. 8). As discussed in phase 2 of this study, the treatment of net settling velocity as a single calibration parameter is an oversimplification because the net settling velocity varies in time with environmental conditions and the proportion of buoyant and non-buoyant colonies in the water column, which explains the difficulty with getting a highly constrained single value for the parameter.

\section{Determination of Algal Phosphorus}

The deposition term $D$ requires the allocation of $P$ between $P_{n a}$ and $P_{a l g}$. Earlier versions of the TMDL model for UKL used a constant ratio (referred to as the algal cell phosphorus quota) of $0.6 \mathrm{mg}$ phosphorus per mg chlorophyll $a$ to calculate the $P_{a l g}$ component. In this study, we compared algal phosphorus calculated from that constant ratio to particulate phosphorus calculated as the difference between measured total and soluble reactive phosphorus in the KT biweekly data during 1991-2010. This comparison resulted in an underestimation of particulate phosphorus, as estimated by the algal cell phosphorus quota (fig. 9). Some of this difference is attributable to the fact that other forms, which are not represented in the ratio calculation, contribute to the particulate phosphorus pool-inorganic phosphorus sorbed to sediments, organic detritus, and zooplankton. We assume, however, that in this highly eutrophic lake and particularly at the highest chlorophyll $a$ concentrations, most of the particulate phosphorus is incorporated in algal biomass.

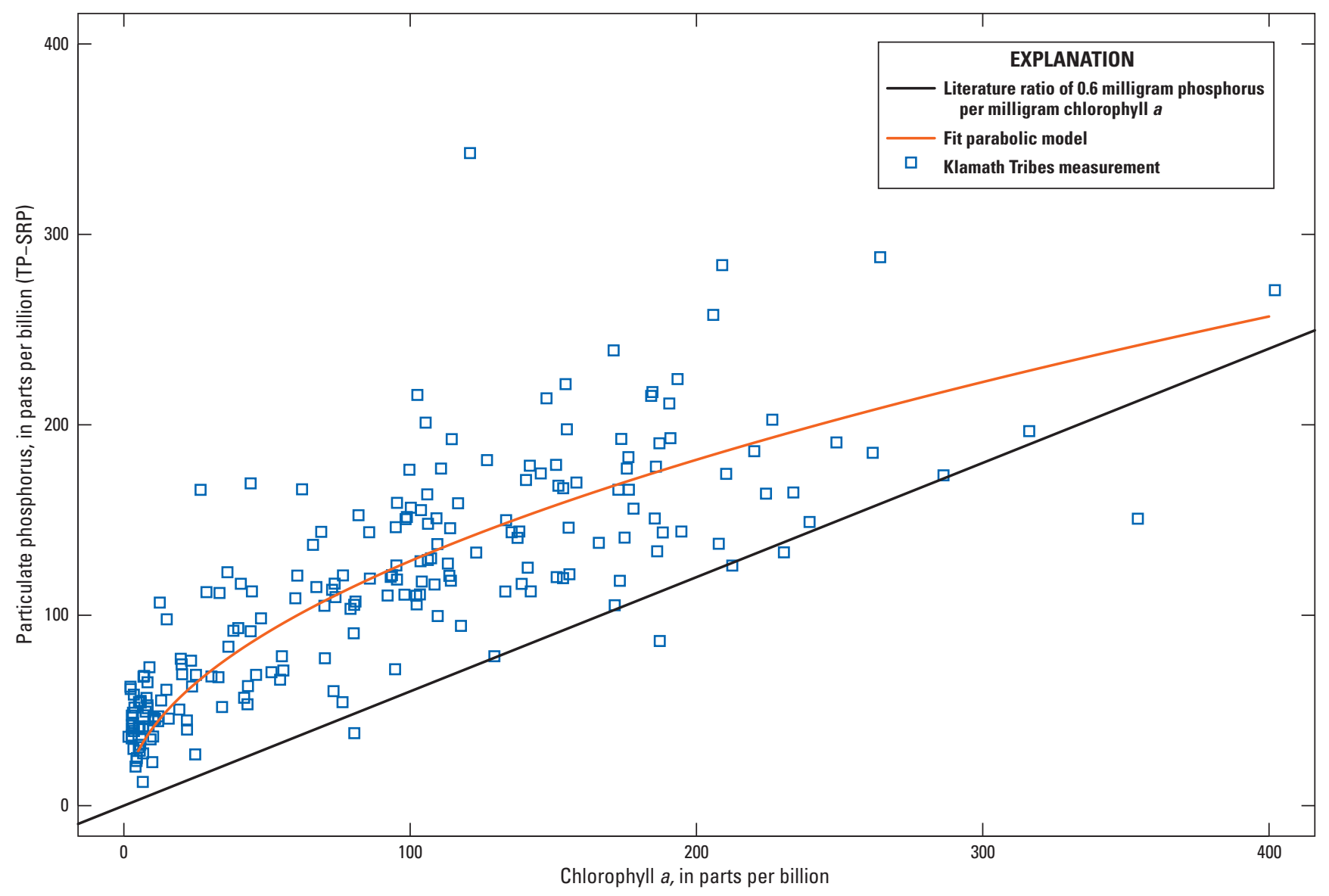

Figure 9. Comparison of measured chlorophyll $a$ and particulate phosphorus (P), calculated as the difference between measured total and soluble reactive phosphorus (TP-SRP), and various approaches of model fitting - Linear model (coefficient of determination $\left.\left[R^{2}\right]=0.84\right)$, and parabolic model $\left(R^{2}=0.93\right)$. Measurements were collected during $1991-2010$ by the Klamath Tribes and averaged across nine sites. 
A parabolic relation of the form,

$$
\frac{P_{a l g}}{V}=12.84 \times \sqrt{B},
$$

fit the concentration data well (coefficient of determination $\left[\mathrm{R}^{2}\right]=0.93$ ) and allowed for particulate phosphorus in excess of calculated algal phosphorus at a given chlorophyll $a$ concentration. This equation was used to relate algal phosphorus to cyanobacteria biomass in the WLE model (fig. 9).

\section{Calibration of Internal Recycling}

For this study, we revisited the recycling term $R$ that appears as a source in the mass balance for water column phosphorus and a sink for sediment phosphorus. The original model (Walker, 2001) used a pH-dependent recycling term that simulated $\mathrm{pH}$-dependent release of phosphate ions from sediments under aerobic conditions, primarily as a result of competition from hydroxide ions for sorption sites (Jacoby and others, 1982). Previous revisions of the TMDL model (Wood and others, 2013; Wherry and others, 2015) examined the use of a temperature-dependent recycling term, which was an acknowledgment that bacterial degradation and metabolic processing by benthic invertebrates in the sediments are likely to be temperature-mediated. In the WLE model, these dependencies were combined, which allowed $\mathrm{pH}$ - and temperature-dependent processes to be described with a single recycling term.

To evaluate the $\mathrm{pH}$ - and temperature-dependent terms, we needed an estimate of $R$, the mass of TP recycled from the sediments per day. The estimate of $R$ was determined by rearranging equation 2 and substituting the variables with available measurements and calibrated parameters describing settling:

$$
R=\frac{d P}{d t}+Q_{o u t} P V^{-1}+K_{n a}\left(P-P_{a l g}\right)+u_{a l g} P_{a l g} z^{-1}-L_{P}
$$

The Walker daily loading dataset (which provided inflow and outflow TP loads, and mass balance estimates of change in TP storage) was subsampled to match the dates of the KT biweekly dataset measurements of TP and chlorophyll $a$. These measurements were combined with the estimates of $P_{a l g}$ (eq. 23) and $u_{a l g}$ (as described in sections, "Determination of Algal Phosphorus" and "Calibration of Algal Settling Velocity"), and the previously calibrated $K_{n a}$ value of 0.016 per day (Wherry and others, 2015), and substituted in the right-hand side of equation 24 to estimate $R$, the mass of TP recycled from sediments, on all the sample dates in the KT biweekly dataset, 1991-2010. This approach makes the assumption that the spatially averaged and temporally interpolated values of TP and chlorophyll $a$ from the KT biweekly dataset are representative of the true lakewide average concentrations on the biweekly interval days.

The estimates of $R$ obtained from equation 24 were then combined with explanatory variables calculated from $\mathrm{pH}$ and lake temperature to create a dataset that could be used to fit a multivariate linear regression equation of recycling. In this equation, $R$ is the dependent variable and the recycle rate modifiers calculated from $\mathrm{pH}$ and lake temperature are the independent variables:

$$
R=\left[\begin{array}{l}
\max \left(0, \frac{p H-p H_{\text {thresh }}}{p H_{\text {max }}-p H_{\text {thresh }}}\right)^{2} \times K_{R, p H} \\
+\max \left(0, \theta^{\left(T_{\text {tate }}-20\right)}-\theta_{\text {thresh }}\right) \times K_{R, T}
\end{array}\right] \times S_{\text {avg }},
$$

where

$$
\begin{array}{cl}
R \quad & \begin{array}{c}
\text { is the mass of total phosphorus (TP) recycled } \\
\text { from sediments each day; }
\end{array} \\
S_{\text {avg }} & \text { is the mass of TP in the sediment based } \\
& \text { on the bulk density of sediment and the } \\
& \text { active sediment depth }(0.12 \text { gram per } \\
& \text { cubic centimeter and } 10 \text { centimeters, } \\
& \text { respectively; Wood and others, 2013), and } \\
& \text { the most current estimate of the sediment } \\
& \text { TP concentration, } s_{0}-335 \text { milligrams } \\
& \text { phosphorus per kilogram sediment (Wood } \\
& \text { and others, 2013); and } \\
K_{R, p H} \text { and } & \text { are the maximum recycle rates represented as } \\
K_{R, T} & \text { unknown coefficients. }
\end{array}
$$

The form of the $\mathrm{pH}$-dependent term is different from that used in the TMDL model, which was based on a cumulative normal distribution function (Wherry and others, 2015). The sigmoid shape of the cumulative normal distribution function did not describe the dependence of $R$ on $\mathrm{pH}$ as well as the polynomial form adopted for the WLE model; a threshold $\mathrm{pH}$ of 7.8 was used based on visual inspection of the data (fig. 10). The form of temperature dependence also differs from previous versions of the TMDL model. For the WLE model, a Van 't Hoff formulation was adopted, with $\theta=1.065$, which was consistent with the temperature dependence for SOD and resulted in a better fit of the data (fig. 10). A threshold temperature for recycling of $5{ }^{\circ} \mathrm{C}\left(\theta_{\text {thresh }}=0.3888\right)$ was used based on the minimum daily lakewide average temperature from the input dataset. The changes in form of $\mathrm{pH}$ and temperature-dependent recycling terms resulted in better fits with the calculated recycling data (fig. 10). 


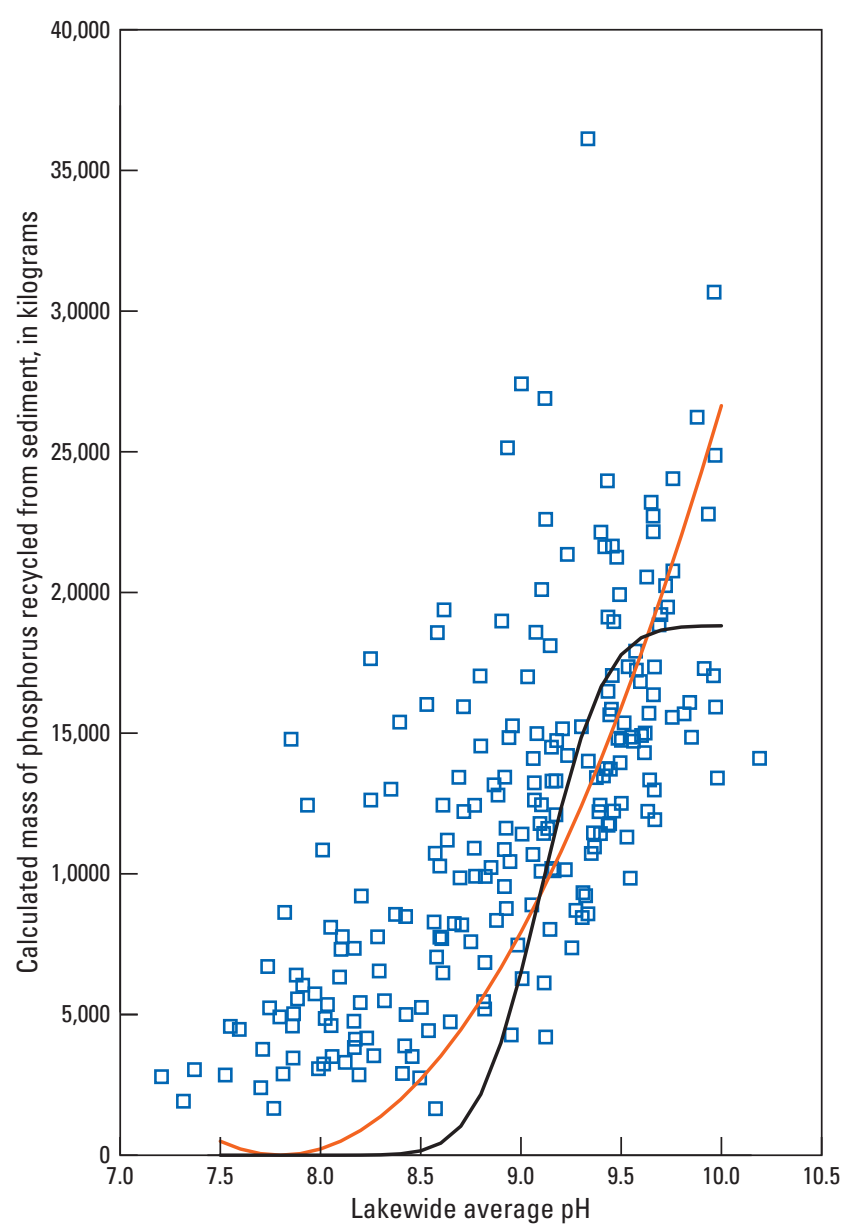

EXPLANATION

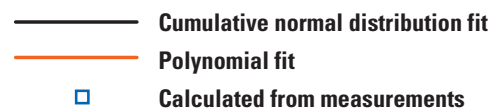

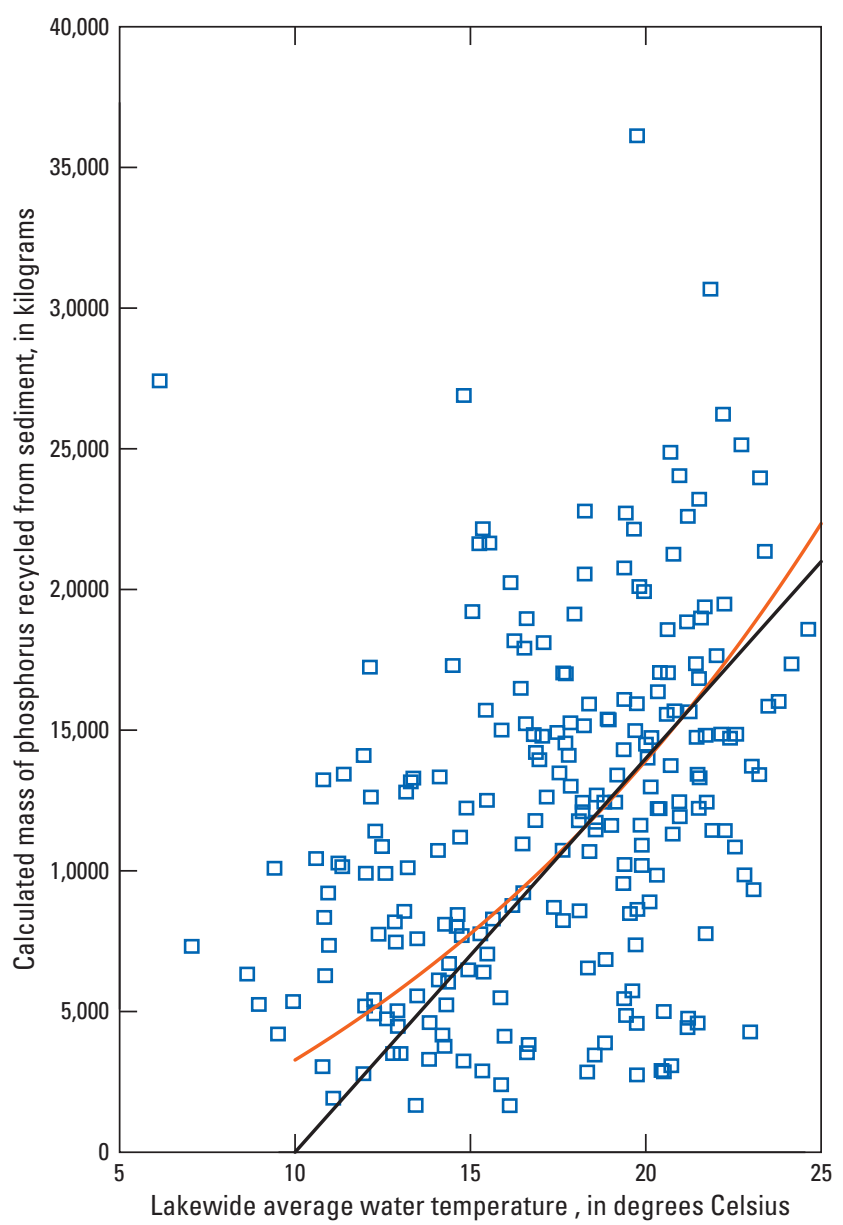

EXPLANATION

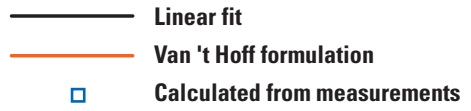

Figure 10. Recycled mass of phosphorus, as determined from equations 23 and 24, as a function of lakewide average $\mathrm{pH}$ and water temperature, Upper Klamath Lake, south-central Oregon, 1991-2010. 


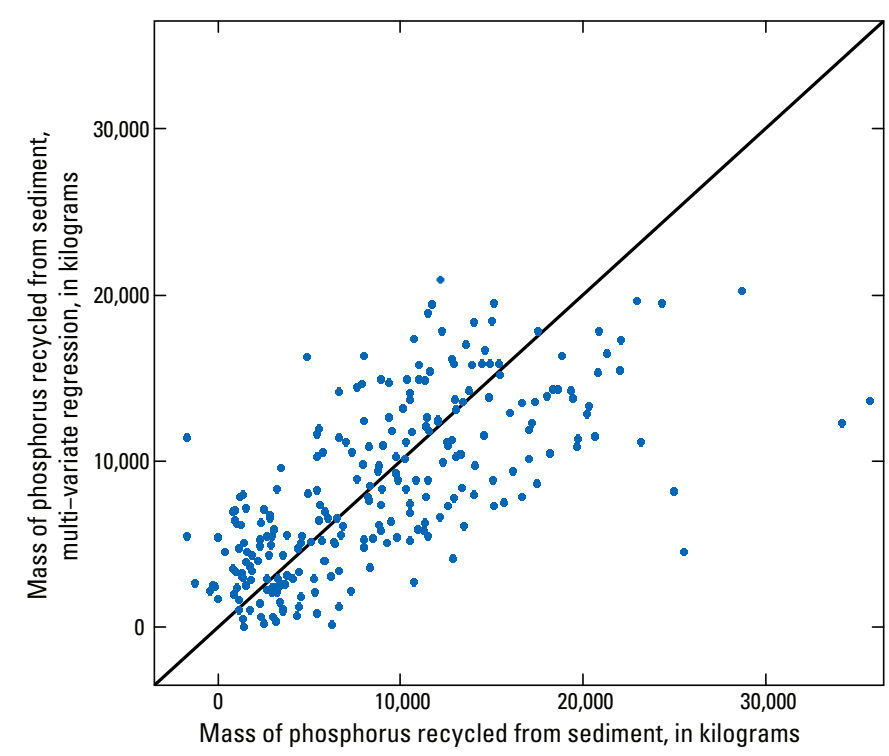

EXPLANATION

- 1:1 line

- Calculated/Simulated

\section{Calibration of the Non-Algal Phosphorus Removal Rate}

The non-algal phosphorus removal rate, $K_{n a}$, was not well-constrained in previous versions of the TMDL model (Wherry and others, 2015). The WLE model takes a different approach to the calibration of this parameter. Values of $K_{R, p H}$ and $K_{R, T}$ were obtained from the linear regression of equation 25 with $K_{n a}$ set to the previously calibrated value of 0.016 per year and to a high value of 0.2 per year. These two sets of recycle rate constants were used with a large range of potential $K_{n a}$ values to simulate the 6 years of calibration data with the WLE model. The final chosen $K_{n a}$ value of 0.12 per year minimized the root mean square error (RMSE) and maximized the Nash-Sutcliffe (NS) metric of TP concentration, when the simulation was compared to the calibration data. This value of $K_{n a}$ also nearly minimized the RMSE of chlorophyll $a$ concentration, but whereas RMSE of chlorophyll $a$ was minimized for all values of $K_{n a}$ exceeding 0.12 , the RMSE of TP increased at higher values, so the value of 0.12 was well-constrained.

Once the calibration value of $K_{n a}$ was determined, the linear regression of equation 25 was repeated with the new value. The best simulation of recycled TP mass was produced by the model that used a combination $\mathrm{pH} /$ water temperaturebased approach with final values of $K_{R, p H}=5.51 /$ years $( \pm 0.47)$ and $K_{R, T}=3.07 /$ years $( \pm 0.34)\left(\mathrm{R}^{2}=0.81, \mathrm{~N}=248\right.$; fig. 11 and table 3 ). These rates are $2-4$ times greater than
Figure 11. Comparison of calculated and predicted (regression) mass of phosphorus recycled from the sediments based on the calibrated, multivariate regression recycling model that used $\mathrm{pH}$ and water temperature as explanatory variables.

those previously determined for the original model using the iterative calibration process, and are in the same range as the values determined for the models run with calculated metabolism during 2006-08 (Wherry and others, 2015).

\section{pH}

The calculation of the recycling term of the phosphorus mass balance (eq. 2), in the form given in equation 25 within the WLE model, requires the calculation of $\mathrm{pH}$ from the model state variables. This is accomplished using a regression of $\mathrm{pH}$ and chlorophyll $a$ :

$$
p H=7.161+0.4211 \times \ln (B),
$$

which is taken from the TMDL model (Wherry and others, 2015).

\section{Model Performance}

Previous versions of the TMDL model calibrated the recycling rate by running the model forward in time through a historical period for a range of values and minimizing an objective function based on residual error. A consistent confounding issue with this method was that the recycling was calibrated to the transient part of the solution to the equations, which meant that even under scenarios of no reduction in 
external loads, simulations that were meant to describe current conditions evolved over the initial decades before arriving at a steady-state condition that was different from current conditions. In essence, simulations of nutrient-reduction scenarios combined the effects of nutrient reduction with the effects of a transient solution independent of nutrient reduction, and it was difficult to separate the two effects and identify the effects of nutrient reduction alone. This problem was largely solved in the WLE model and indicates that the set of parameter values in table 3 are representative of a system in a state of dynamic equilibrium between phosphorus content of the sediments and the water column. When the model was run through 5 cycles of the calibration years, there was expected variability from year to year but very little variability in the entire 6-year cycle between the first and subsequent cycles.

The WLE model simulated TP concentration over the calibration years $2005-10$, with an $\mathrm{R}^{2}$ of 0.65 and a NS statistic of 0.55 (table 8; fig. 12), representing an improvement over the performance of the TMDL model. The most recent revisions of that model presented $\mathrm{R}^{2}$ values from 0.15 to 0.52 , and NS statistics from -0.03 to 0.20 (table 5 in Wherry and others, 2015). The WLE model is biased low (bias of $-23.8 \mu \mathrm{g} \mathrm{P} / \mathrm{L}$ ), whereas the TMDL model was consistently biased high, by between 2.2 and $61.7 \mu \mathrm{g}$ P/L. The WLE model simulated chlorophyll $a$ over the calibration years 2005-10 with an $\mathrm{R}^{2}$ of 0.58 and an NS statistic of 0.53 , as compared to an $\mathrm{R}^{2}$ from 0.18 to 0.27 and an NS statistic from -0.16 to 0.17 in the most recent revisions of the TMDL model. The WLE model is biased low (bias of $-16.5 \mu \mathrm{g}$ chlorophyll $a / \mathrm{L}$ ), whereas the bias in the TMDL model was from -3.1 to $22.0 \mu \mathrm{g}$ chlorophyll $a / \mathrm{L}$. Thus, the fit statistics generally are better for the WLE model. The bias in the TMDL model was positive primarily because of the influence of the transient solution to the equations that occurred early in the calibration dataset; in later years, the bias primarily was negative, and consistent with the WLE model (fig. 2 in Wherry and others, 2015).

The WLE model simulations consistently underestimated peak values of chlorophyll $a$ and TP, but captured the seasonal cycle well and, in most years, simulated mid-season decreases in chlorophyll $a$ that were evident in the water sample data (fig. 12). This shows an important improvement of the NPP approach over the scaling up approach, as the scaling up approach was not able to simulate such decreases in the bloom, as noted by Wherry and others (2015).

Table 8. Performance statistics of the calibrated whole lake eutrophication model, 2005-10.

[Number of samples=77. Abbreviations: NPP, net primary production; NS, Nash-Sutcliffe; R, correlation coffficient; $\mathrm{R}^{2}$, coefficient of determination; RMSE, root mean square error; $\mathrm{TP}$, total phosphorus; ppb, parts per billion; N/A, not applicable]

\begin{tabular}{|c|c|c|c|c|c|c|}
\hline NPP & $\begin{array}{l}\text { Upper limit } \\
\text { for control } \\
\text { by TP } \\
\text { (ppb) }\end{array}$ & $\mathbf{R}$ & $\mathbf{R}^{2}$ & Bias & RMSE & NS \\
\hline \multicolumn{7}{|c|}{ Total phosphorus } \\
\hline $\begin{array}{l}\text { Calculated from } \\
\text { dissolved oxygen }\end{array}$ & N/A & 0.81 & 0.65 & -23.8 & 61.4 & 0.55 \\
\hline \multirow{4}{*}{$\begin{array}{l}\text { Calculated from multi- } \\
\text { variate regression }\end{array}$} & 80 & 0.80 & 0.64 & -23.5 & 62.1 & 0.54 \\
\hline & 100 & 0.80 & 0.64 & -23.5 & 62.1 & 0.54 \\
\hline & 120 & 0.80 & 0.64 & -23.5 & 62.2 & 0.54 \\
\hline & 150 & 0.79 & 0.63 & -23.5 & 62.7 & 0.54 \\
\hline \multicolumn{7}{|c|}{ Chlorophyll $a$} \\
\hline $\begin{array}{l}\text { Calculated from } \\
\text { dissolved oxygen }\end{array}$ & N/A & 0.76 & 0.58 & -16.5 & 54.7 & 0.53 \\
\hline \multirow{4}{*}{$\begin{array}{l}\text { Calculated from multi- } \\
\text { variate regression }\end{array}$} & 80 & 0.71 & 0.50 & -18.6 & 59.3 & 0.45 \\
\hline & 100 & 0.71 & 0.50 & -18.4 & 59.2 & 0.45 \\
\hline & 120 & 0.71 & 0.51 & -18.0 & 59.0 & 0.45 \\
\hline & 150 & 0.70 & 0.49 & -16.0 & 58.9 & 0.45 \\
\hline
\end{tabular}



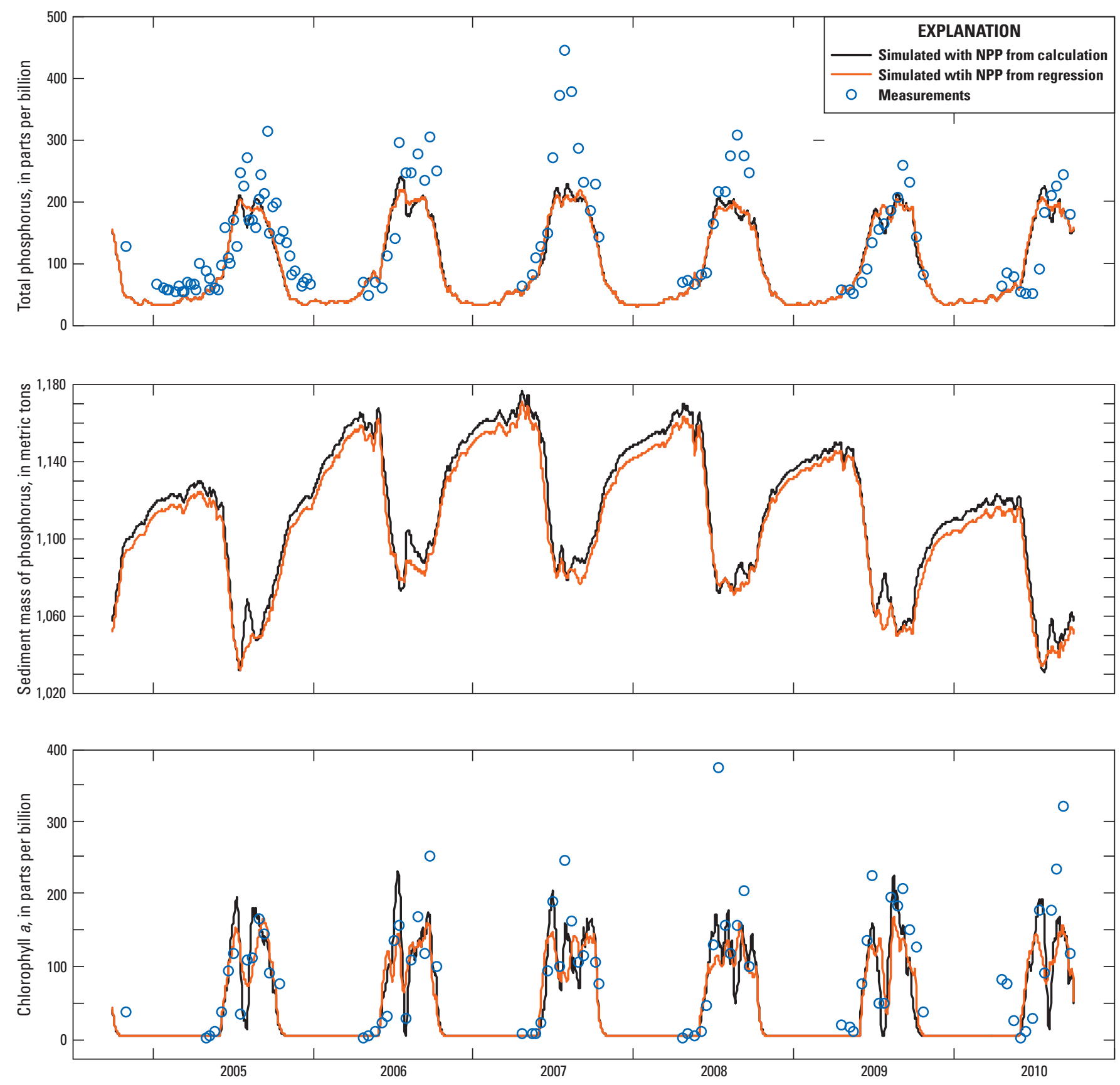

Figure 12. Lakewide averaged water-column total phosphorus, sediment mass of phosphorus, and lakewide averaged water-column chlorophyll a, 2004-10. Measured values are from the Klamath Tribes biweekly dataset. Simulated values use net primary production (NPP) as calculated from continuous dissolved oxygen and temperature measurements, and NPP as determined by multivariate regression with measured temperature, wind, phosphorus, and chlorophyll a as explanatory variables. 


\section{Multivariate Regression Model of Net Primary Production}

With a daily lakewide NPP time series as calculated from continuous monitors, the WLE model could be used to simulate chlorophyll $a$ and TP concentrations during the period of observations and to provide insight into the values of rate constants controlling important processes, particularly the settling and recycling rates that couple the water column and sediment phosphorus. In order to use the model to simulate nutrient load reduction scenarios associated with restoration activities, however, it is necessary to be able to predict NPP based on measured variables that are independent of nutrient load reductions (meteorological or water temperature), and to state variables that are simulated by the model as it steps forward in time (phosphorus and chlorophyll $a$ concentrations). Dissolved oxygen is not a state variable of the model and, because it depends on photosynthesis and respiration, would change with nutrient load reductions, so we investigated the development of a multivariate regression model to predict daily lakewide NPP based on other explanatory variables.

The process of model development began with calculating the daily lakewide NPP time series and identifying appropriate predictor variables, which included water temperature, indicators of stratification, solar radiation, wind speed, TP, and chlorophyll $a$ concentrations. Based on differences in response time scales, variables were deconstructed into high- and low-frequency components by wavelet analysis. The deconstructed time series were then used to calibrate high- and low-frequency multivariate regression models of NPP, which could be combined to predict NPP over an entire season.

\section{Predictor Variables}

The set of explanatory variables considered for the predictive model of daily lakewide NPP were selected based on knowledge of the system and past modeling results (Wherry and others, 2015). The variables considered were various measures of water temperature, stratification, solar radiation, wind speed, and lakewide average water column concentrations of TP and chlorophyll $a$.

\section{Water Temperature}

The water temperature data used for this analysis was taken from the four USGS core sites: WMR, MDN, RPT, and MDT. The lakewide average temperature time series was developed by applying to hourly temperature measurements the same weighted-averaging approach that was used for DO concentration (eqs. 5, 7, and 8). The daily lakewide average was then determined by averaging the hourly values. Missing values were added by linearly interpolating gaps of $6 \mathrm{~h}$ or less. Longer gaps were filled at each hour with a weighted average of the values collected at the same hour of the day prior to and after the gap.

Lakewide average NPP and water temperature time series generally tended to track each other at the beginning and end of the season, whereas in the middle of the season, there was more of an inverse relation, with the two time series often tracking as mirror opposites (fig. 13). In an attempt to better capture this nuanced correspondence between water temperature and NPP, a new time series was derived from the water temperature time series and tested as an explanatory variable.

The derived time series was created by taking the observed water temperature values $T_{U S G S}$ between the first $\left(t_{1}\right)$ and last $\left(t_{2}\right)$ day in a year when water temperature greater than $20{ }^{\circ} \mathrm{C}$ was measured, followed by scaling and "mirroring" those values across the $20^{\circ} \mathrm{C}$ line (fig. 13). The derived time series was calculated as:

$$
T_{U S G S}^{\prime}=\left\{\begin{array}{c}
T_{U S G S}, \quad t_{1}>t>t_{2} \\
-3 \times\left(T_{U S G S}-20\right)+20, \quad t_{1}<t<t_{2}
\end{array} .\right.
$$

The $20{ }^{\circ} \mathrm{C}$ threshold was selected over other temperatures because the derived time series had the highest correlation with NPP and previous work determined that that temperature corresponded with maximum algal growth rates (Walker, 2001). We also considered the time series describing the rate of change in daily water temperature as an explanatory variable, which was calculated as the difference in water temperature from one day to the next and referred to as $\Delta T_{U S G S}$.

\section{Stratification}

A simple indicator of stratification was calculated from continuous water temperature data collected at the top and bottom of the deepest USGS core site at MDT (fig. 1). This calculation was simply the difference between top and bottom temperature at each hour, which was then accumulated for each day:

$$
\text { STRAT }=\sum_{h=1}^{24}\left(T_{\text {MDTupper }}-T_{\text {MDTlower }}\right)_{h} .
$$

Similar to water temperature, we also considered as an explanatory variable a time series describing the rate of change in daily stratification by finding the difference in STRAT values from one day to the next. 

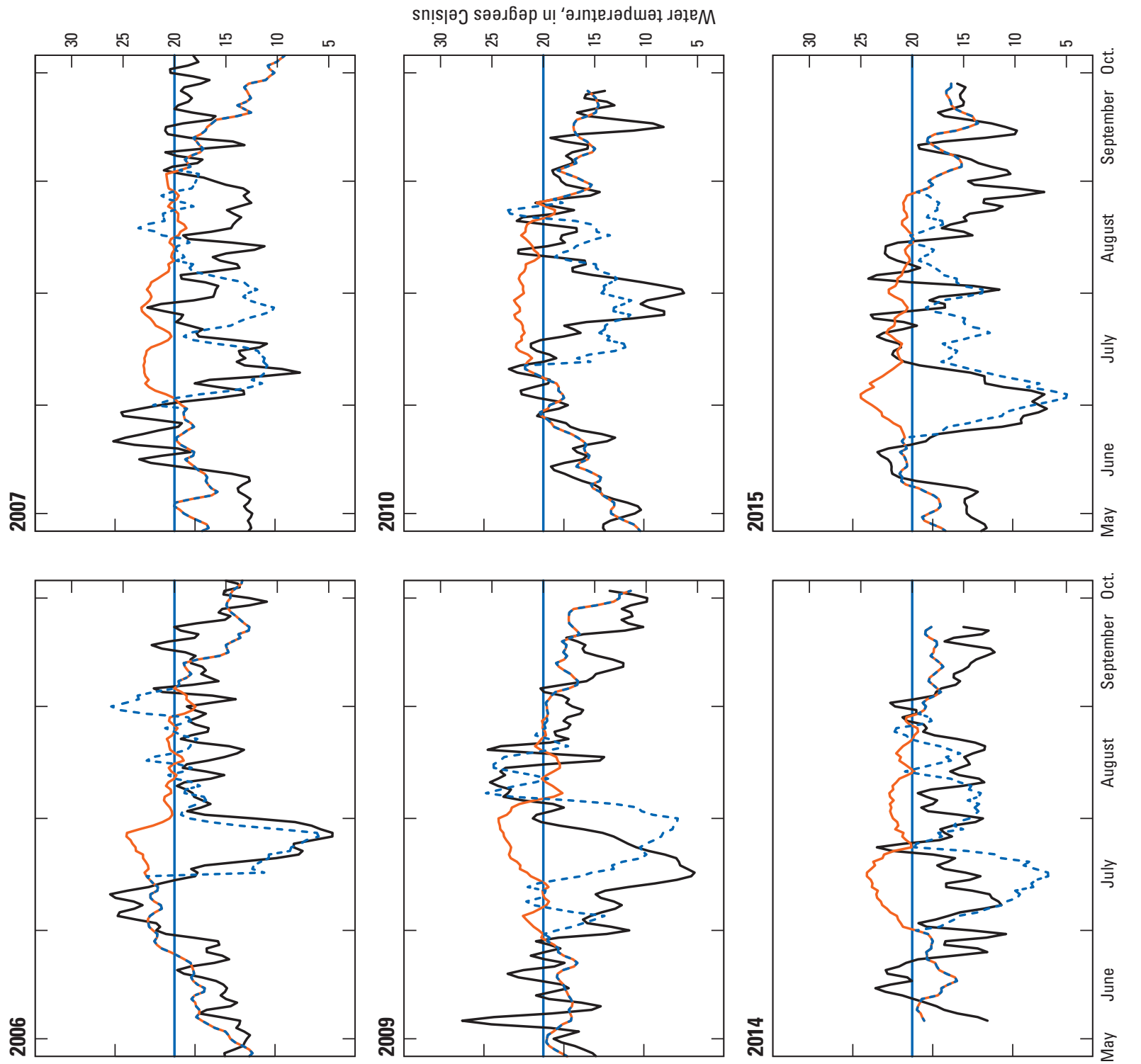

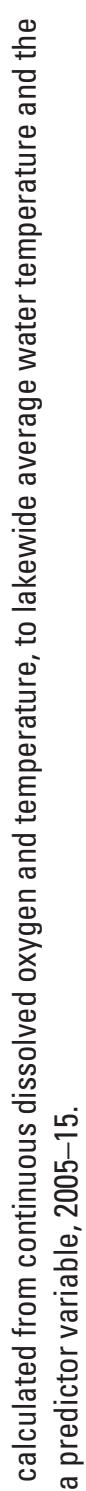
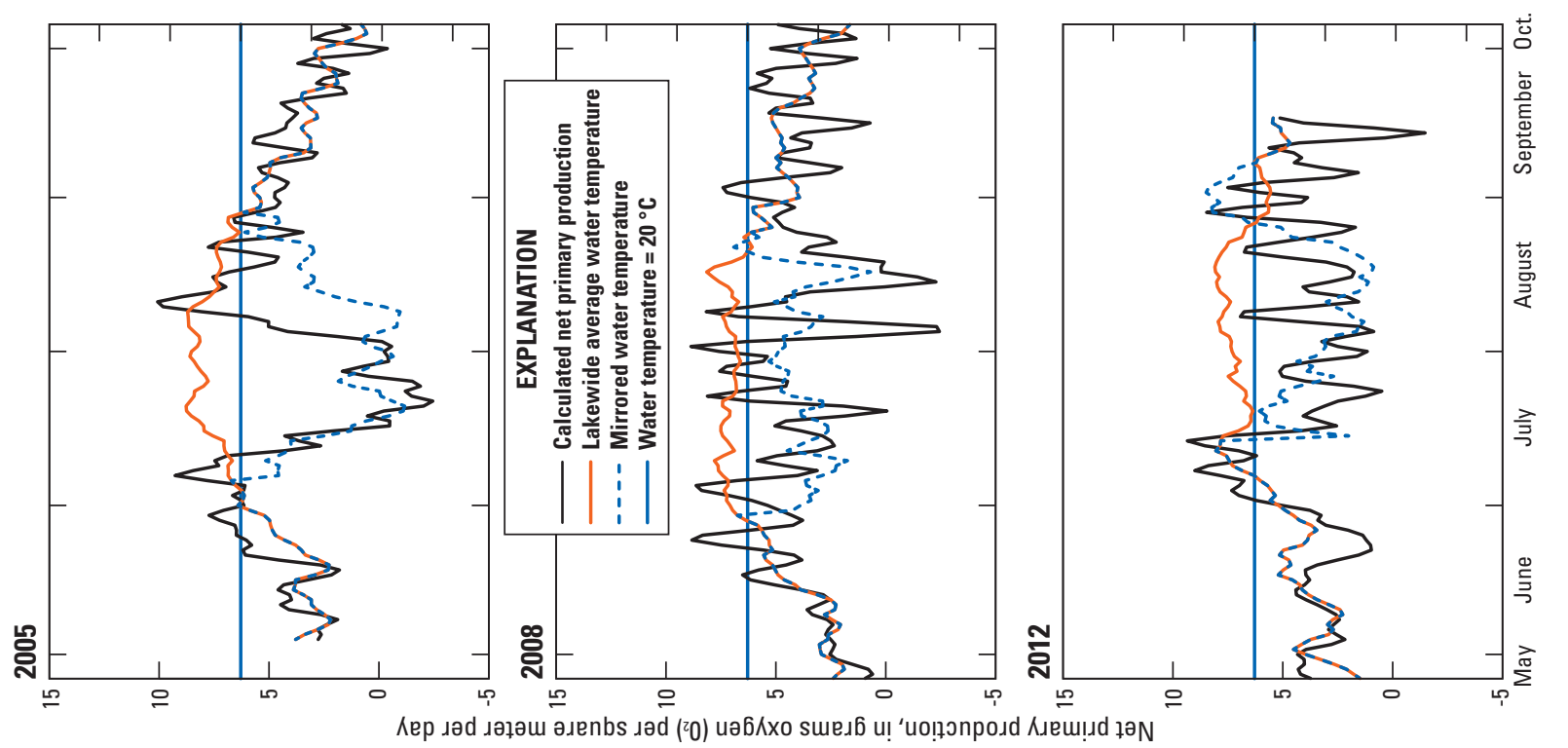

등 똥

웡

을

要

兵

응

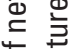

ธั ڤั

竞

吾

उ

뭉

흘 흘 


\section{Solar Radiation}

The solar radiation data used in developing the regression model was collected at the Reclamation AgriMet site AGKO, located at Agency Lake (fig. 1). Hourly values were averaged to create a time series of daily averaged solar insolation, referred to as $S I$.

\section{Wind Speed}

The wind speed data used in the regression model was collected by the USGS at site MDN (fig. 1), located in the northern part of the lake at 10-min intervals and at a height of $2 \mathrm{~m}$ above the water surface. The wind speed data were subsampled to hourly values, followed by conversion to a 10-m height wind speed by logarithmic approximation (Martin and McCutcheon, 1999). The 90th percentile (WS90) and daily average values $(W S)$ on each day were considered as potential explanatory variables.

\section{Total Phosphorus and Chlorophyll a Concentration}

The TP and chlorophyll $a$ concentration data used for model development were depth-integrated samples collected by the KT and USGS. The KT samples were collected at nine monitoring locations on an approximately biweekly time step. The USGS samples were collected from four monitoring locations on a weekly time step. Lakewide average concentrations were determined from both sets independently and then merged to create a time series representing all observed concentrations of TP and chlorophyll $a$ collected in the lake over the study period. On days when both organizations collected a sample, the average of the two lakewide average values was used.

\section{Filtering with Wavelet Analysis}

To quantify the variability in the NPP time series at different time scales, we used wavelet analysis. Wavelet analysis is a tool that decomposes a time series into time-frequency space and allows analysis of localized variations that might otherwise be unapparent (Torrence and Compo, 1998). The transformations were done with $\mathrm{R}$ version 3.1.1 (Bunn, 2008; R Core Team, 2016; package dplR) and used the Morlet wavelet base function (Torrence and Compo, 1998). After wavelet decomposition, the normalized global wavelet spectrum (NGWS) was calculated for each year. The NGWS averages the power at each frequency over the entire time series and normalizes by the total power in the time series (Torrence and Compo, 1998). NGWS results indicated that the 4-20-d period band and 20-102-d period band contained most of the variability in the NPP time series. Based on the NGWS results, the NPP time series was filtered to remove the highest-frequency wavelet component ( $<4$ day period) (which primarily was noise in the data from measurement uncertainty and advection) and then deconstructed into two separate components (1) a higher-frequency component constructed using only wavelet components with a 4-20-d period, and (2) a lower-frequency component constructed using only wavelet components with a 20-102-d period. Adding together the high- and low-frequency components results in a reconstructed NPP time series. For example, we compare the wavelet-filtered high- and low-frequency components of lakewide average water temperature to the original time series (fig. 14).

The same wavelet decomposition, separated into two frequency bands, was done with the continuous predictor variable time series to ensure that the response and predictor variables were matched in their time scales of variability. Based on the NGWS results for NPP, we filtered the predictor time series to a high-frequency component, representing the 4-20-d period, and a low-frequency component representing the 20-102-d period. These time series, in addition to weekly/ biweekly measurements of TP and chlorophyll $a$, were used to develop the regression models relating NPP to the predictor variables.

\section{Net Primary Production Regression Model}

Distinct models were developed for the high- and low-frequency components by regressing high-frequency, calculated NPP against high-frequency predictor variables, and regressing low-frequency calculated NPP against low-frequency predictor variables, which subsequently become separate parts of the WLE model (see section, "Whole Lake Eutrophication Model for Simulating Future Conditions"). For the high-frequency model, the list of potential predictor variables included all the time series discussed in section, "Predictor Variables," filtered to exclude variability at all but the high-frequency 4-20-d period band. These time series are relatively noisy and do not show any of the seasonal patterns one might be used to seeing in the data (fig. 14).

For the low-frequency model, the list of potential predictor variables included all the time series discussed in section "Predictor Variables," filtered to exclude variability at all but the low-frequency period band. These time series are less noisy than the high-frequency series and primarily show smooth seasonal patterns. Additionally, knowledge of the system was used to include measured nutrient and chlorophyll $a$ concentrations in the list of potential predictor variables. Observations over many years have shown that phosphorus limitation is most likely to occur during the initial period of bloom growth, prior to the first peak in the cyanobacteria bloom; later in the season, although the direct causes of bloom decreases remain unknown, bioavailable phosphorus concentrations (measured as soluble reactive phosphorus) historically have been high enough to not pose limitations on growth (for example, Hoilman and others, 2008; Lindenberg and others, 2009). 
During the early-season increase in the bloom, the most important factors influencing that expansion are TP, sunlight, and water temperature; however, during the midseason decreases in bloom and later-season bloom(s), phosphorus limitation is less important and the NPP seems more influenced by the size of the existing cyanobacteria population, and, potentially, by changes in wind speed, stratification, and water temperature. With this sequence of conditions in mind, the dependence of NPP on P was included as a potential predictor variable in the low-frequency regression model only on the initial increase in the bloom.

The regression was structured such that the potential predictor variables during the initial bloom increase were TP, sunlight, and water temperature. Once the initial bloom reached its peak, the allowable predictor variables were chlorophyll $a$, sunlight, water temperature, wind speed, and stratification. The transition from P-dependent to P-independent was set as the date of the first occurrence of chlorophyll $a$ concentration

A. High frequency (4-20 day) filtered water temperature in 2005

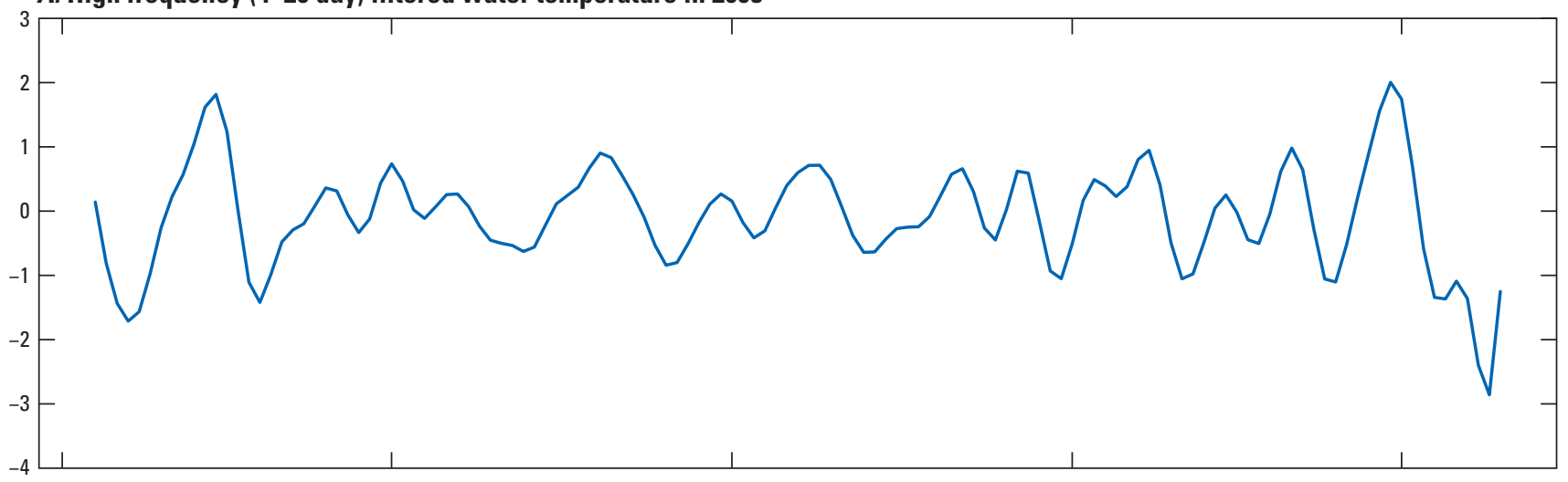

B. Low frequency (20-102 day) filtered water temperature in 2005

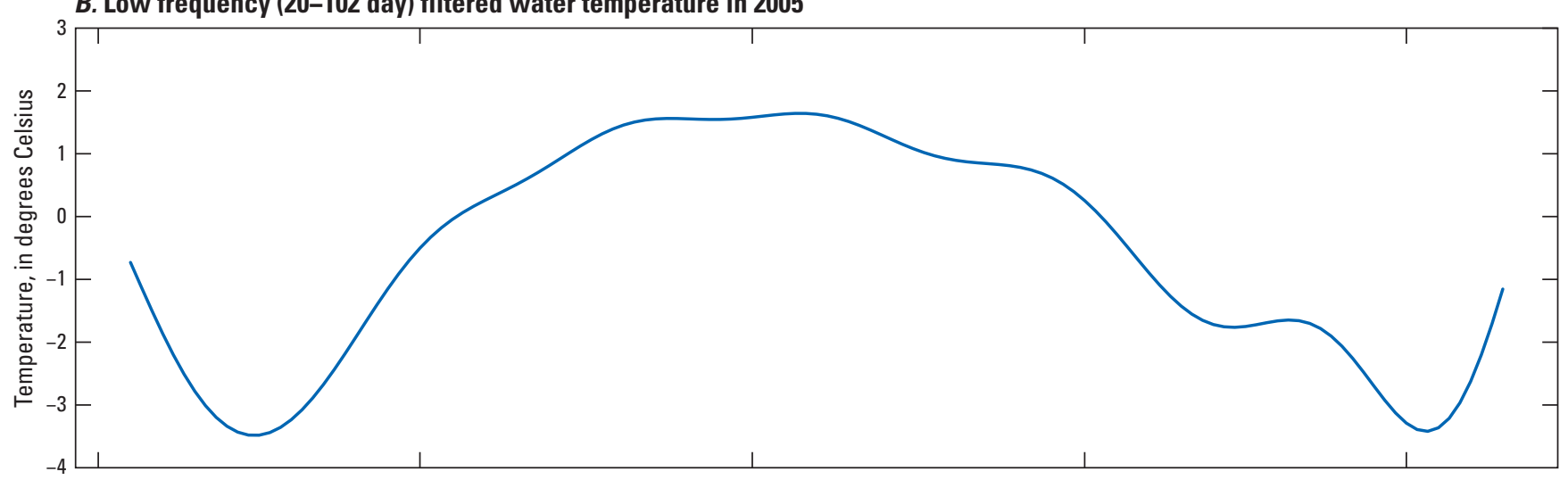

C. Lakewide daily average water temperature in 2005

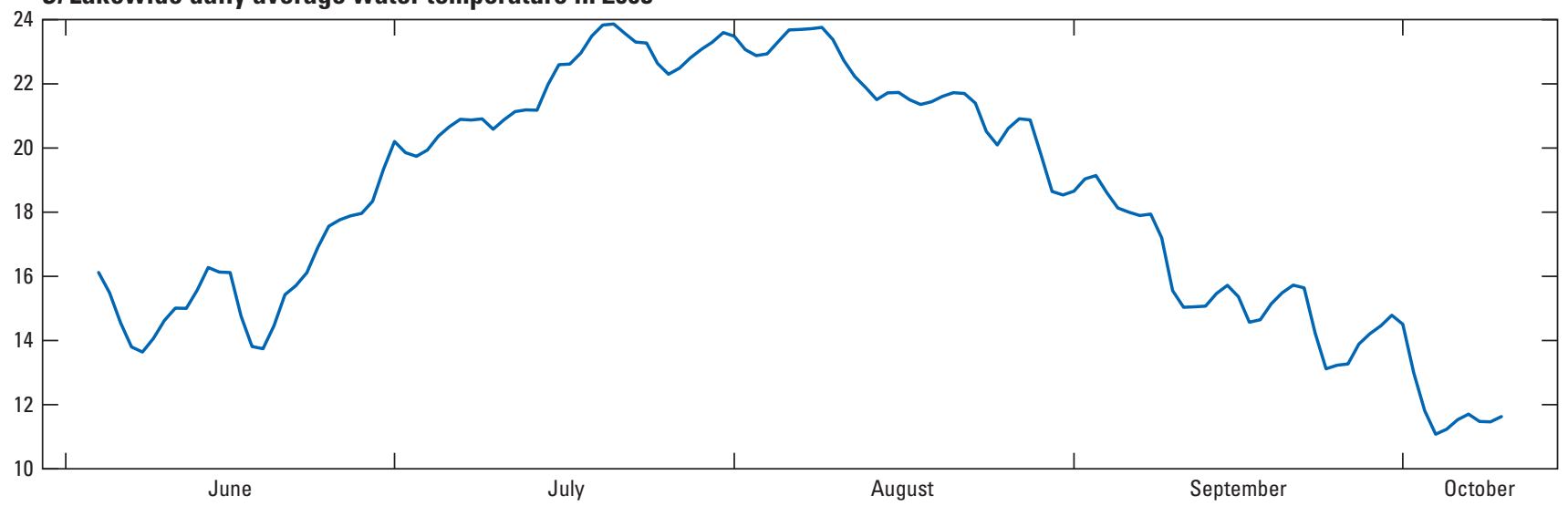

Figure 14. Wavelet filtered $(A)$ high- and $(B)$ low-frequency components and $(C)$ original time series, June-0ctober 2005. 
exceeding $100 \mathrm{ppb}$. The $100-\mathrm{ppb}$ threshold initially was selected because that concentration was exceeded by the first bloom peak chlorophyll $a$ measurements in every year of record, but sensitivity to this threshold was tested at values of 80,120 , and $150 \mathrm{ppb}$, and the results were relatively insensitive to this threshold, with the exception of the results in 2006 (fig. 15).

For both models, the complete list of predictor variables was initially considered and a stepwise procedure that eliminated one predictor variable at each step (based on Akaike's Information Criterion [Burnham and Anderson, 2002]) was used to determine the final set of predictor variables (table 9). The models were calibrated over the full bloom season in years 2005, 2007, 2009, 2012, and 2015 , followed by validation in years $2006,2008,2010$, and 2014. The regression model was moderately successful in simulating NPP calculated from the DO measured by continuous monitors, and the performance was similar during years set aside for calibration and validation (RMSE 1.2-1.8 [( $\left.\left(\mathrm{g} \mathrm{O}_{2} / \mathrm{m}^{2}\right) / \mathrm{d}\right]$, NS statistic $0.17-0.47$, and $\mathrm{R}^{2}$ 0.17-0.49 [table 10]). Fluctuations at all time scales are, however, dampened and steep bloom decreases indicated by negative NPP are not simulated by the multivariate regression model (fig. 15).

Table 9. Regression coefficients for the high- and low-frequency net primary productivity flux components based on calibration years 2005, 2007, 2009, 2012, and 2015.

[All variables were selected by the Akaike's Information Criterion (AIC) stepwise procedure. High-frequency NPP: AIC $-\mathrm{N}=693, \mathrm{R}^{2}=0.19$, p value $<2.2 \times 10^{-16}$. Low-frequency NPP: AIC $-\mathrm{N}=99, \mathrm{R}^{2}=0.37$, $\mathrm{p}$-value= $7.565 \times 10^{-9}$. Abbreviations: N, number of samples; NPP, net primary productivity; $\mathrm{R}^{2}$, coefficient of determination; $<$, less than]

\begin{tabular}{|c|c|c|c|c|}
\hline Explanatory variable & Estimate & $\begin{array}{l}\text { Standard } \\
\text { error }\end{array}$ & t value & $\operatorname{Pr}(>|t|)$ \\
\hline \multicolumn{5}{|c|}{ High-frequency NPP } \\
\hline (Intercept) & -0.03 & 0.04 & -0.77 & 0.440 \\
\hline 10-meter wind speed, daily average & 0.54 & 0.06 & 8.82 & $<2.00 \times 10^{-16}$ \\
\hline Solar Insolation, daily average & 0.14 & 0.02 & 6.82 & $1.98 \times 10^{-11}$ \\
\hline Stratification & -0.42 & 0.14 & -3.12 & 0.002 \\
\hline $\begin{array}{l}\text { Rate of change in daily average } \\
\text { water temperature }\end{array}$ & 30.08 & 4.48 & 6.71 & $3.96 \times 10^{-11}$ \\
\hline \multicolumn{5}{|c|}{ Low-frequency NPP } \\
\hline (Intercept) & -0.92 & 0.66 & -1.39 & 0.17 \\
\hline Mirrored water temperature & 0.28 & 0.09 & 3.24 & 0.002 \\
\hline 10-meter wind speed, daily average & 1.32 & 0.55 & 2.42 & 0.02 \\
\hline $\begin{array}{l}\text { Total phosphorus, lakewide average } \\
\text { (before chlorophyll } a \text { reaches } \\
100 \text { parts per billion) }\end{array}$ & 0.0095 & 0.0050 & 1.881 & 0.06 \\
\hline $\begin{array}{l}\text { Chlorophyll } a \text {, lakewide average } \\
\text { (after chlorophyll } a \text { reaches } \\
100 \text { parts per billion) }\end{array}$ & 0.16 & 0.15 & 1.05 & 0.30 \\
\hline
\end{tabular}

Table 10. Performance statistics for net primary productivity regression models for calibration (2005, $2007,2009,2012,2015)$ and validation $(2006,2008,2010,2014)$ years.

[Abbreviations: [ $\left(\mathrm{g} \mathrm{O}_{2} / \mathrm{m}^{2}\right) / \mathrm{d}$ ] , grams oxygen $\left(\mathrm{O}_{2}\right)$ per square meter per day; $\mathrm{N}$, number of samples; RMSE, root mean square error; $\mathrm{R}^{2}$, coefficient of determination; - , no units]

\begin{tabular}{lcccccc}
\hline \multirow{2}{*}{ Statistic } & Units & \multicolumn{2}{c}{ Calibration period } & & \multicolumn{2}{c}{ Validation period } \\
\cline { 3 - 4 } \cline { 6 - 7 } & & $\begin{array}{c}\text { High-frequency } \\
\text { model }\end{array}$ & $\begin{array}{c}\text { Low-frequency } \\
\text { model }\end{array}$ & & $\begin{array}{c}\text { High-frequency } \\
\text { model }\end{array}$ & $\begin{array}{c}\text { Low-frequency } \\
\text { model }\end{array}$ \\
\hline RMSE & {$\left[\left(\mathrm{g} \mathrm{O}_{2} / \mathrm{m}^{2}\right) / \mathrm{d}\right]$} & 1.16 & 1.84 & & 1.20 & 1.37 \\
Bias & {$\left[\left(\mathrm{g} \mathrm{O}_{2} / \mathrm{m}^{2}\right) / \mathrm{d}\right]$} & $1.08 \times 10^{-17}$ & $9.00 \times 10^{-18}$ & & -0.02 & -0.09 \\
Nash-Sutcliffe & - & 0.19 & 0.37 & & 0.17 & 0.47 \\
$\mathrm{R}^{2}$ & - & 0.19 & 0.37 & & 0.17 & 0.49 \\
$\mathrm{~N}$ & - & 693 & 99 & 554 & 100 \\
\hline
\end{tabular}




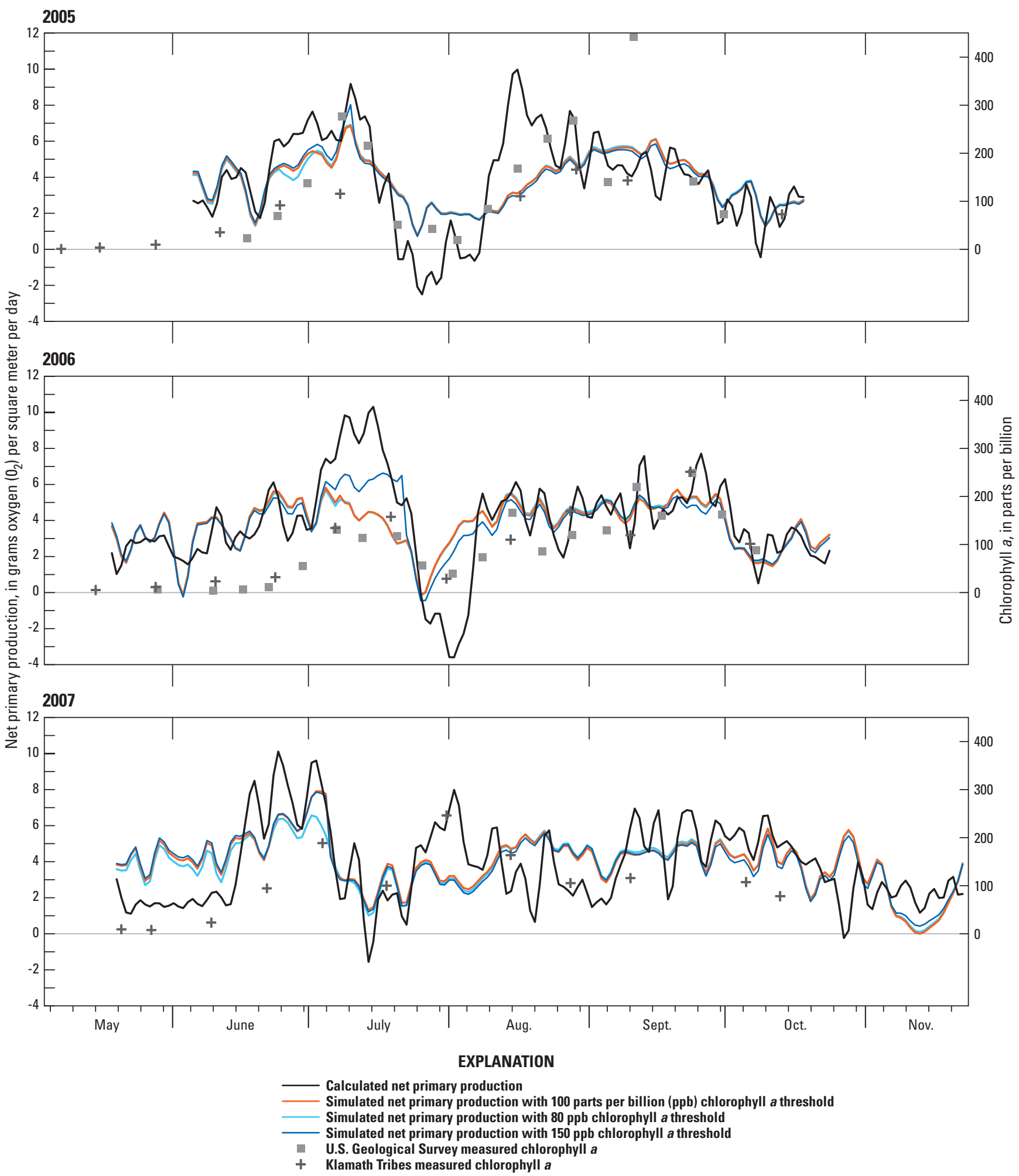

Figure 15. Time series of net primary production, as calculated from continuous dissolved oxygen and temperature; lakewide average chlorophyll $a$ values collected by the Klamath Tribes and U.S. Geological Survey; and net primary production as simulated with a multivariate regression model with meteorological data, water temperature, phosphorus, and chlorophyll $a$ as explanatory variables, in Upper Klamath Lake, south-central Oregon, 2005-10, 2012, 2014-15. 


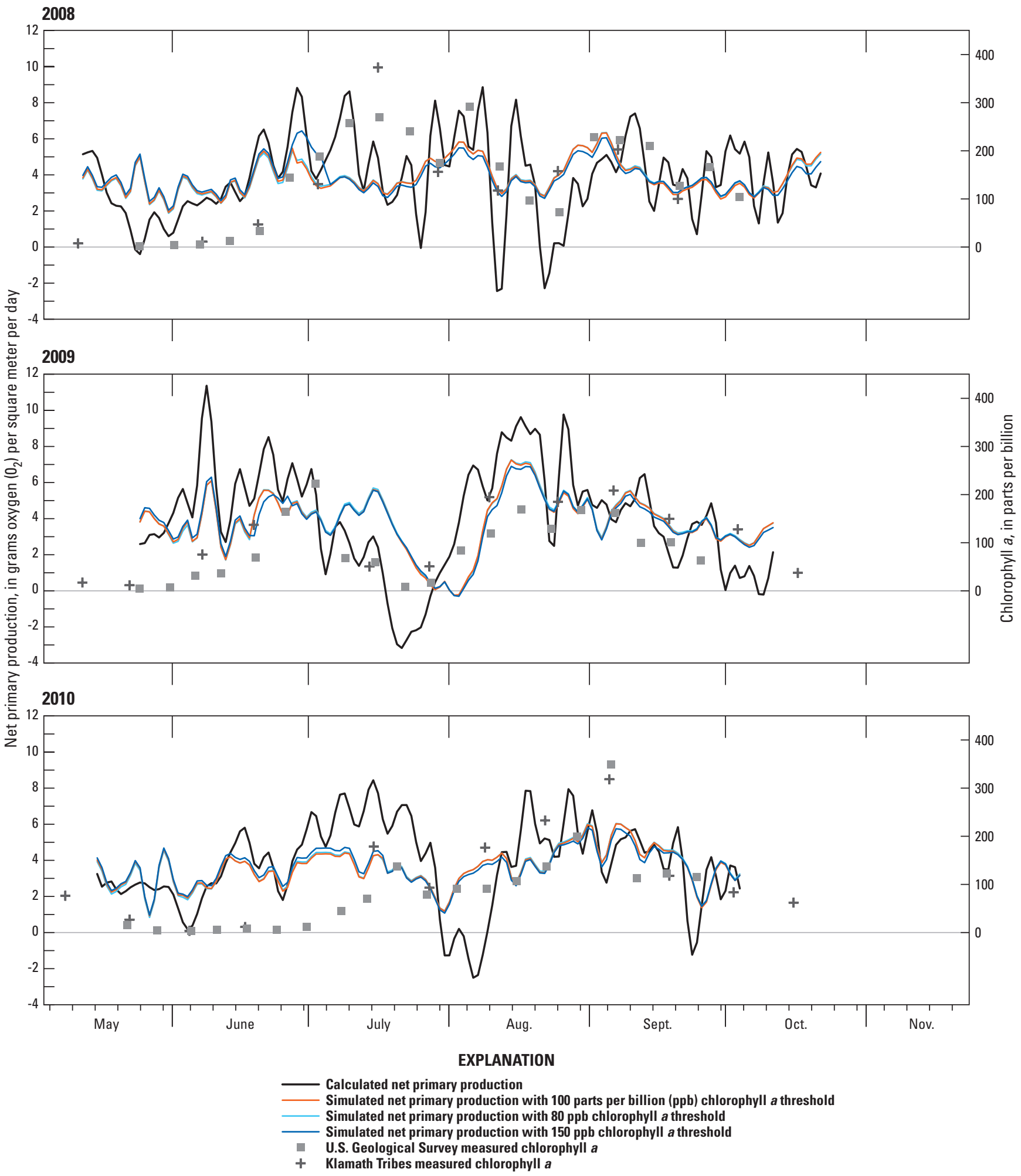

Figure 15.-Continued 
2012

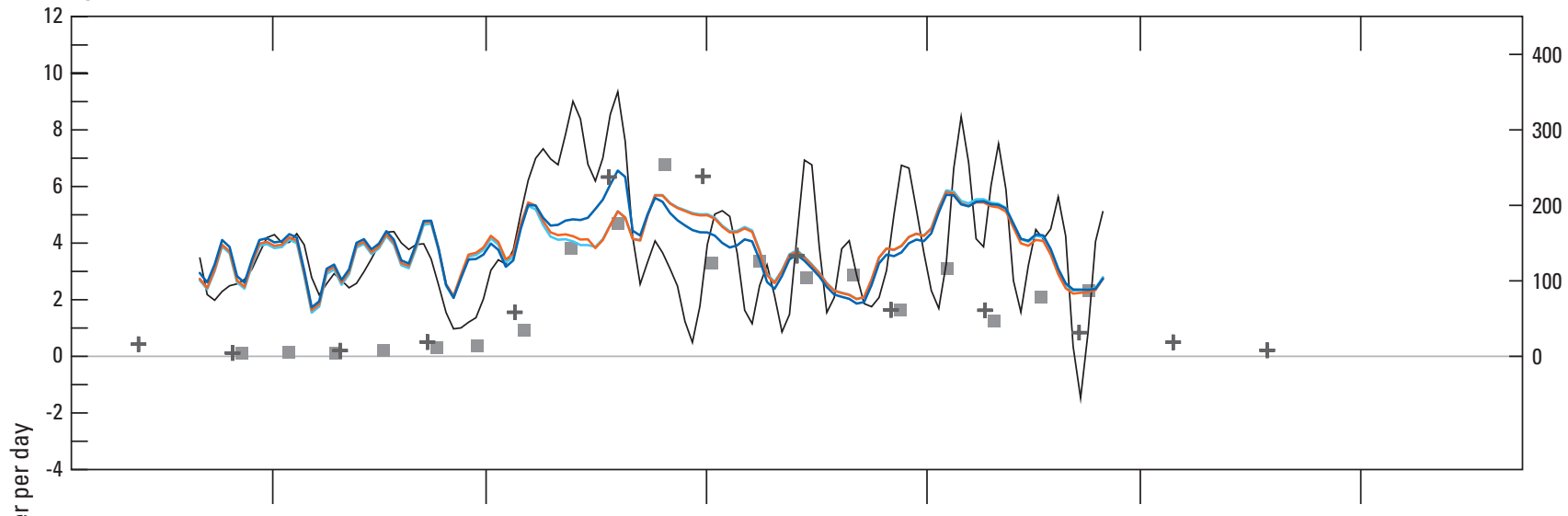

2014
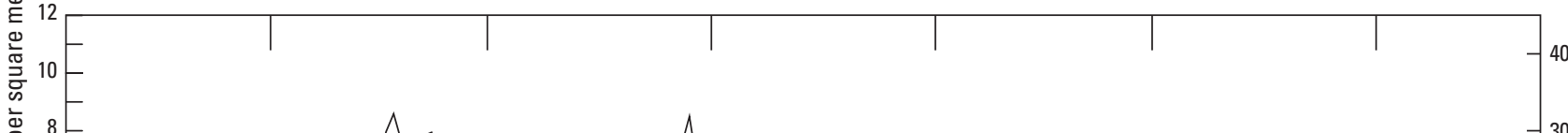

ळ $8-$

可 6

ब.

\. 4 -

营 $2-$

$\cong 0$
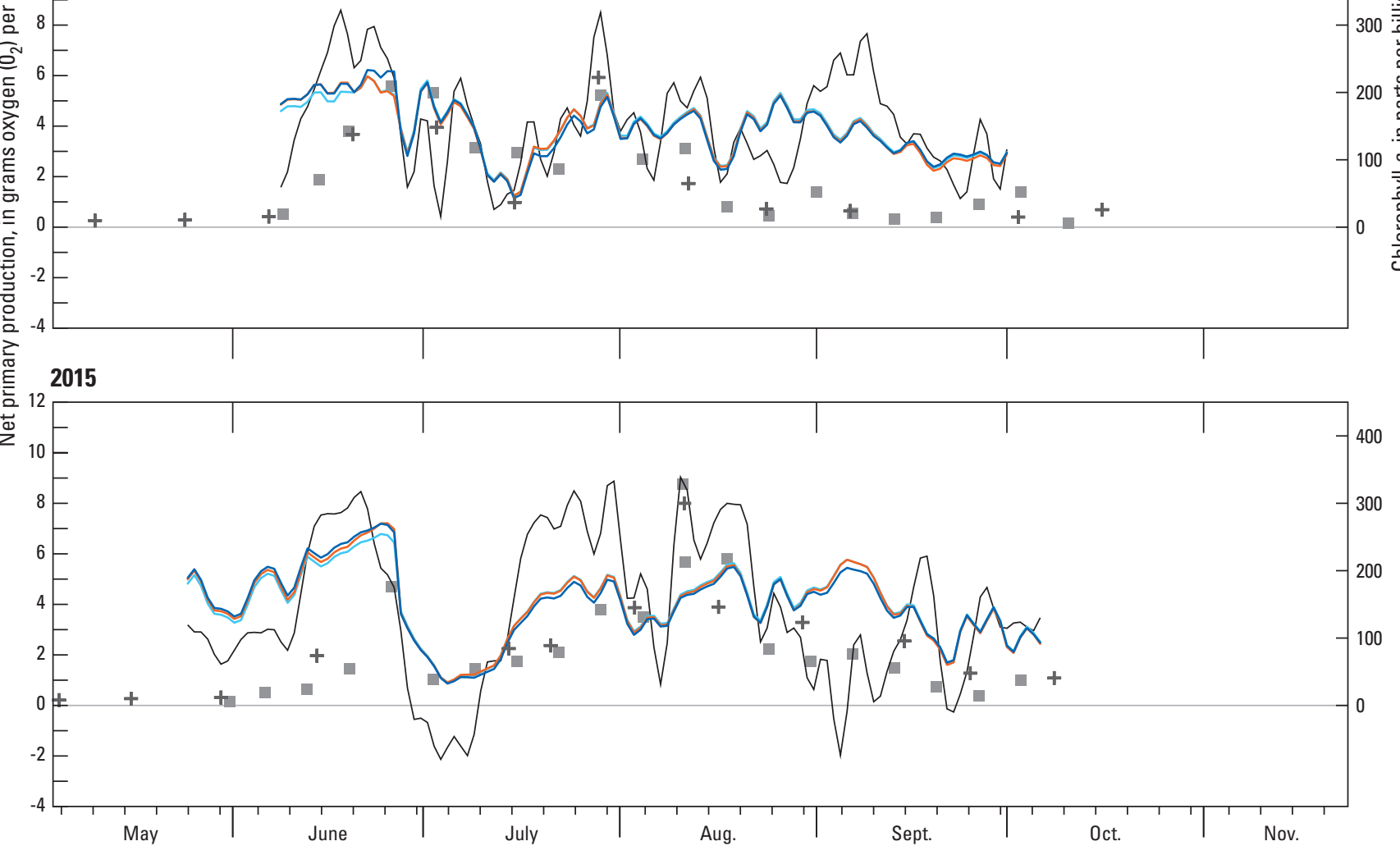

EXPLANATION

Calculated net primary production

Simulated net primary production with 100 parts per billion (ppb) chlorophyll a threshold

Simulated net primary production with $80 \mathrm{ppb}$ chlorophyll a threshold

Simulated net primary production with $150 \mathrm{ppb}$ chlorophyll a threshold

U.S. Geological Survey measured chlorophyll a

$+\quad$ Klamath Tribes measured chlorophyll a

Figure 15.-Continued 


\section{Whole Lake Eutrophication Model for Simulating Future Conditions}

The incorporation of the NPP regression in the WLE model is the final step in the process of creating a model that can predict the effects of restoration activities in future years on chlorophyll $a$ (fig. 16). Predicted NPP (the sum of a predicted high- and low-frequency time series, and the mean) replaces terms for growth and respiration in equation (1), which determines biomass (chlorophyll $a$ ):

$$
\begin{aligned}
\frac{d B}{d t} & =B_{N P P}-\left(\frac{u_{a \mathrm{lg}}}{z}+\frac{Q_{o u t}}{V}\right) \times B \\
& =\frac{\left(p N P P_{h i}+p N P P_{\text {low }}+\overline{N P P}\right) \delta_{C: O} \delta_{C h l a . C}}{z} \\
& -\left(\frac{u_{a \mathrm{lg}}}{z}+\frac{Q_{o u t}}{V}\right) \times B
\end{aligned}
$$

where

$$
\begin{aligned}
& p N P P_{h i}=f\left(W S_{h i}, S I_{h i}, S T R A T_{h i}, \Delta T_{U S G S_{h i}}\right), \text { and } \\
& p N P P_{l o w}=\left\{\begin{array}{ll}
f\left(T_{U S G S_{l o}}^{\prime}, W S_{l o}, P\right) & d<d_{100} \\
f\left(T_{U S G S_{l o}}^{\prime}, W S_{l o}, B\right) & d>d_{100}
\end{array} .\right.
\end{aligned}
$$

The subscripts $h i$ and lo indicate the high- and low-frequency components of the time series as determined by the wavelet filtering procedure, $\overline{N P P}$ is the mean of NPP over the entire calibration time period, and $d_{100}$ is the first day of the year when the lakewide average chlorophyll $a$ concentration measures $100 \mathrm{ppb}$ or greater.

\section{Model Performance}

When the WLE model incorporating simulated NPP (eq. 22) as a replacement for calculated NPP (eq. 1) (hereinafter referred to as the "scenario" WLE, or SWLE) was used with calibrated values of model parameters to simulate the calibration period, the performance statistics for the simulation of TP were nearly unchanged. The performance statistics for the SWLE simulation of chlorophyll $a$ indicated less success than when the WLE was run with calculated NPP: $\mathrm{R}^{2}$ decreased to 0.50 , bias decreased to $-18.4 \mathrm{ppb}$, and the NS statistic was 0.45 (table 8). The multivariate regression neither was able to simulate the highest peaks in chlorophyll $a$ nor the minima in chlorophyll $a$ associated with the steepest bloom decreases, but this had little effect on TP, as the bloom decreases largely represent an exchange between algal and non-algal phosphorus that leaves the TP relatively unchanged (fig. 12). This is consistent with observations in UKL that orthophosphate often increases in association with a bloom decrease, but the signal in TP can be muted or nonexistent (Hoilman and others, 2008; Lindenberg and others, 2009).

Nonetheless, the SWLE performed as well or better by some measures than previous versions of the TMDL model. Chlorophyll $a$ NS statistics reported in Wherry and others (2015) for the "best" model calibrated over the longest dataset ranged from 0.11 to 0.32 , based on a smaller sample size and calculated only over the months of May, June, and July. $\mathrm{R}^{2}$ values ranged from 0.18 to 0.45 . Likewise, the NS statistics for TP in the TMDL model ranged from 0.29 to 0.59 , again based on a smaller sample size and calculated over 3 months. $\mathrm{R}^{2}$ values for TP in the TMDL model were comparable to the SWLE results at $0.54-0.64$.

\section{Long-Term Simulations}

The SWLE was used to simulate 60 years by appending the 6 years of boundary conditions end-to-end for 10 cycles. Conditions were unchanged for the first 24 years to indicate that dynamic equilibrium between the water column and sediments was established, and at the beginning of the fifth cycle, external phosphorus load reductions were enforced in the model boundary conditions. The results in water column TP concentration for step changes of 10-, 20-, and 40-percent reductions are shown in figure 17, and the results in mass of total sediment phosphorus are shown in figure 18. Both sets of graphs show the system adjusting to the change in external load over time, and eventually achieving a new dynamic steady state in which water column phosphorus concentrations and sediment phosphorus mass are lower, representing less phosphorus in the combined system. This adjustment seems to take about 30 years, although the changes are more rapid in the first decade than in the second two decades, and the time scale is most apparent when the changes are larger, as in the 40-percent reduction scenario.

A close-up examination of the last 6 years of the simulations shows how nutrient load reductions progressively curtail the peaks of the blooms (fig. 19). Because TP and chlorophyll $a$ are biased low, the final concentrations are not as meaningful as the change between the years prior to and 30 years after nutrient load reduction. This change in the final, adjusted TP concentration, when averaged over the entire 6 years, was roughly proportional to the nutrient load reduction, but the change in chlorophyll $a$ concentration was smaller at 10- and 20-percent load reduction in TP (table 11). A 40-percent load reduction in TP resulted in a comparable decrease in chlorophyll $a$ concentration. Another metric that was used in the previous reports in this series is the number of years out of the calibration period in which chlorophyll $a$ concentration exceeded $100 \mathrm{ppb}$. By this metric, the changes are not seen until load reduction reaches 40 percent; at this level of load reduction, the bloom peaks were reduced to less than $100 \mathrm{ppb}$ in 4 of 6 years (table 11). A test of the sensitivity of these results to the choice of upper limit for control of biomass by TP showed that the results were not sensitive to this choice (table 11). 


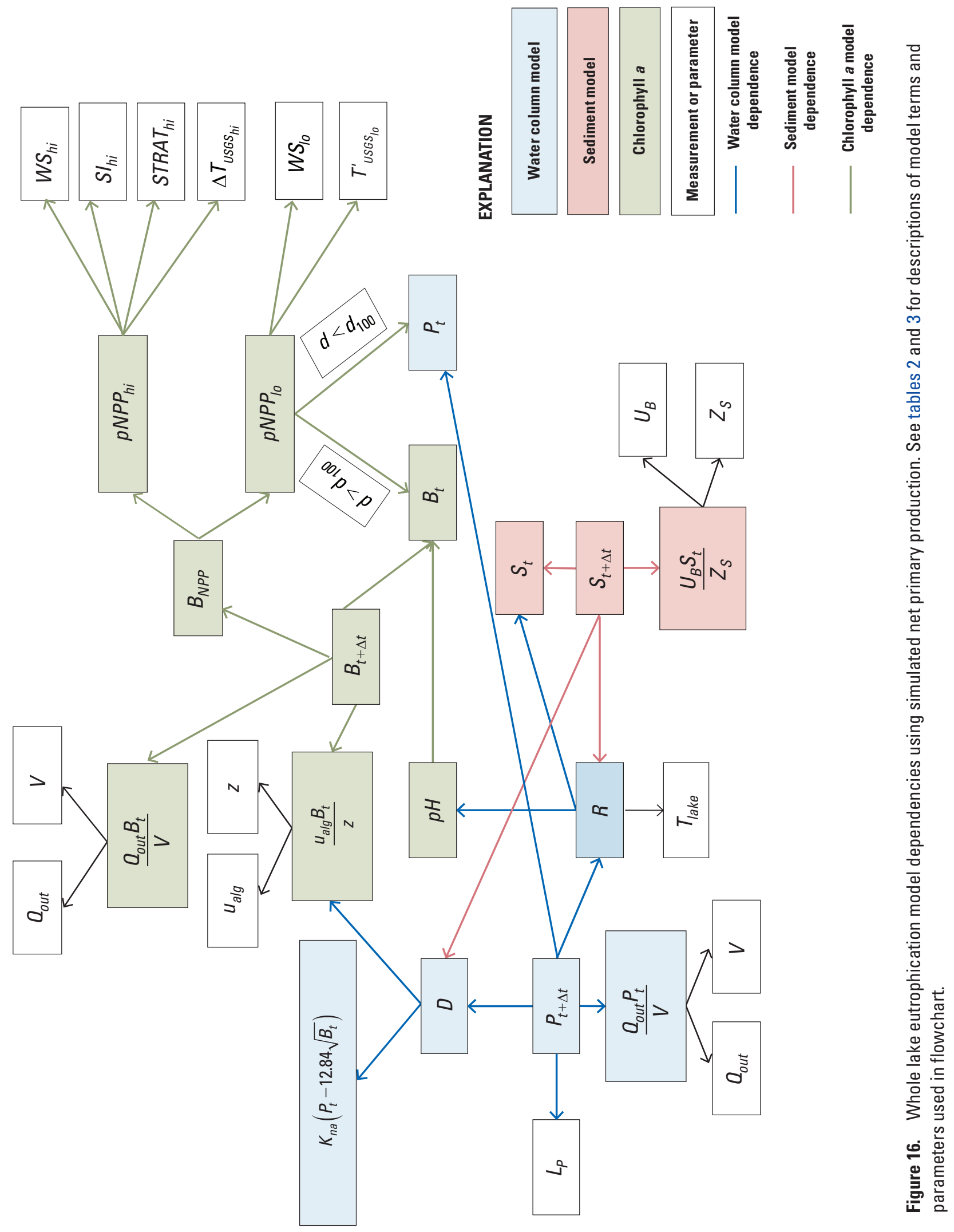


10-percent reduction

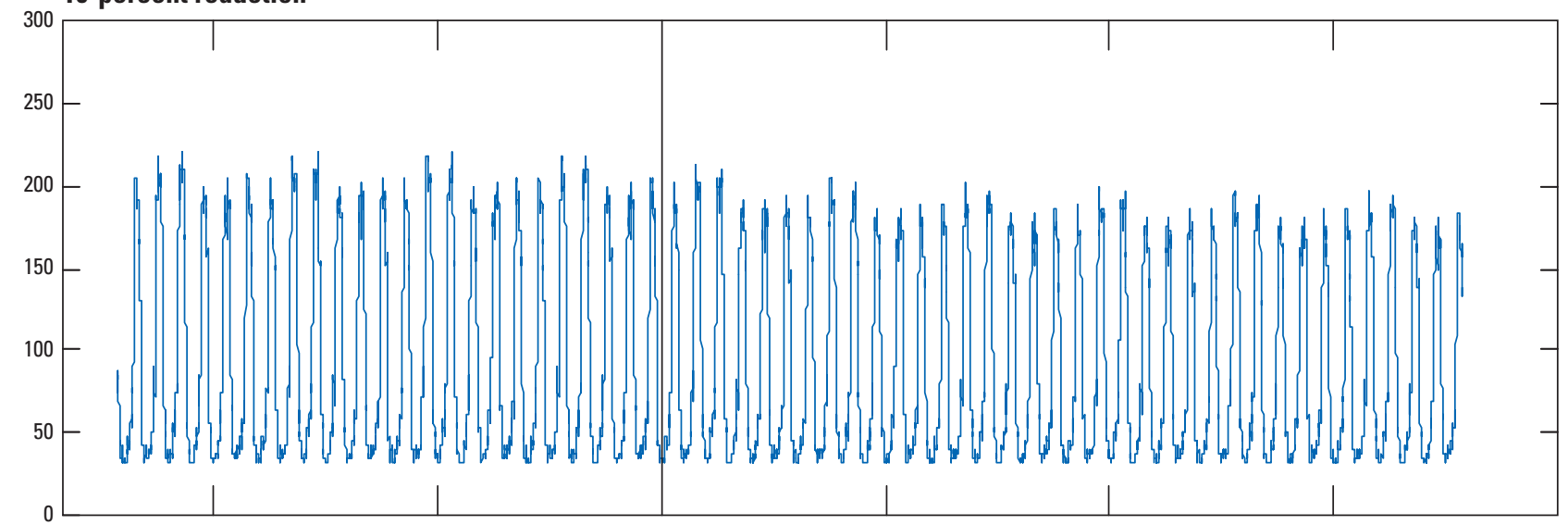

20-percent reduction
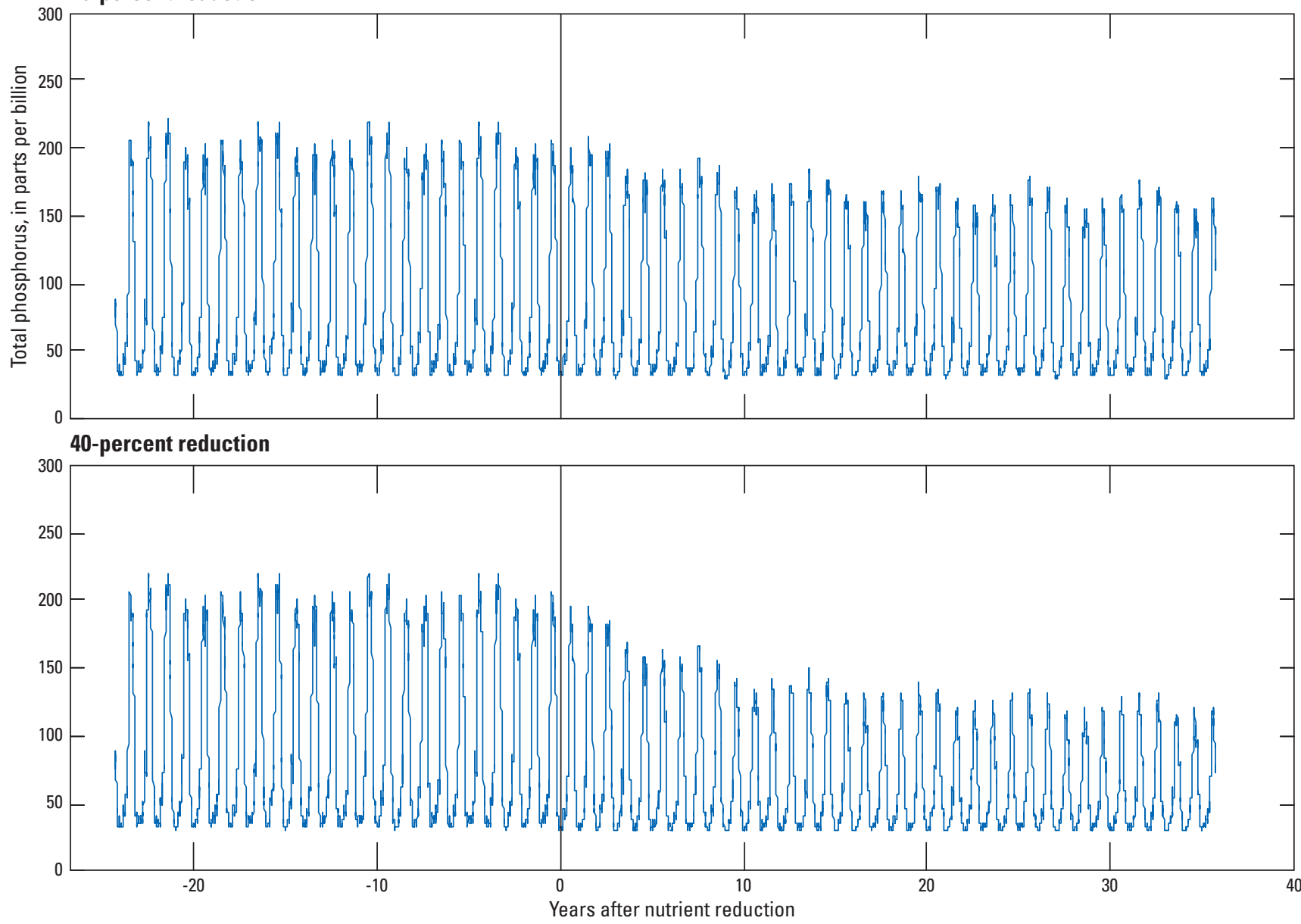

Figure 17. Time series of lakewide average total phosphorus for three nutrient load reduction scenarios. The time series begin 24 years before instantaneous load reduction at year " 0 " and continue 36 years after load reduction. 


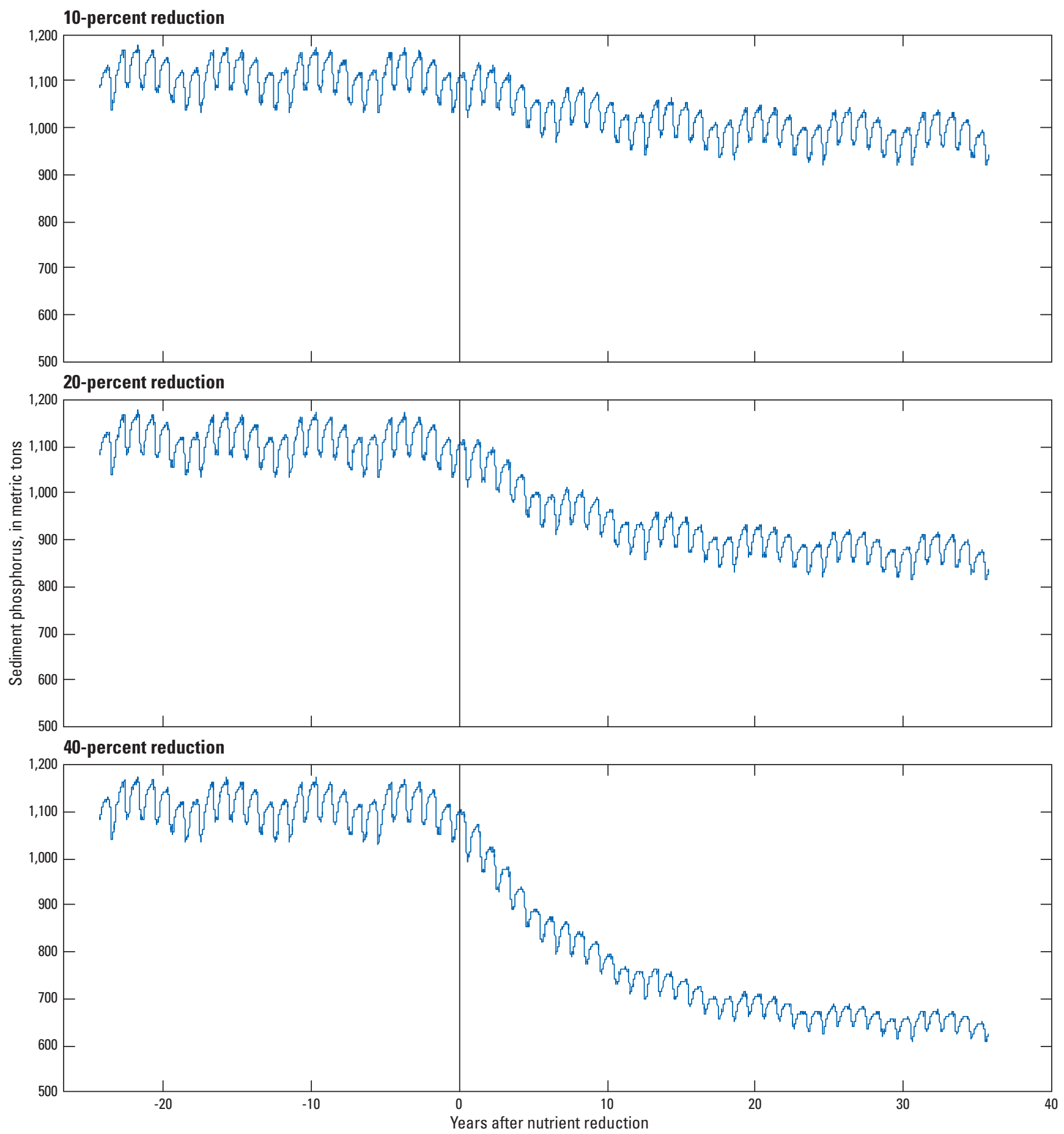

Figure 18. Time series of mass of total phosphorus in the sediments for three nutrient load reduction scenarios. The time series begin 24 years before instantaneous load reduction at year " 0 " and continue 36 years after load reduction. 

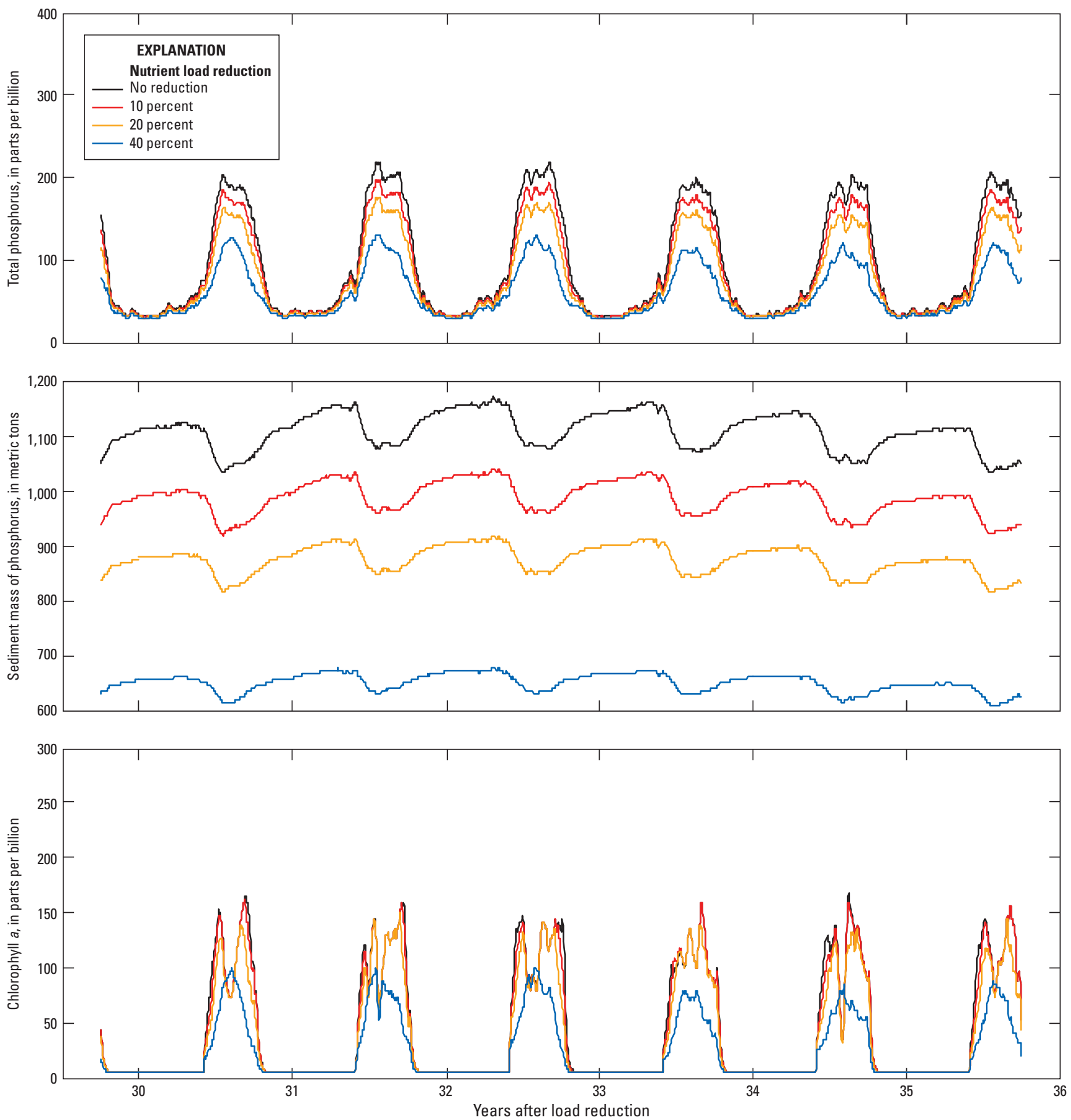

Figure 19. Simulated lakewide averaged total phosphorus in water column, phosphorus mass in sediment, and lakewideaveraged chlorophyll $a$ in water column for no reduction in external loads and three scenarios for load reduction, 30-35 years after instantaneous load reduction. 
Table 11. Results of simulations of nutrient load reduction scenarios with the Upper Klamath Lake whole lake eutrophication model.

[Abbreviations: TP, total phosphorus; ppb, parts per billion; N/A, not applicable; >, greater than]

\begin{tabular}{|c|c|c|c|}
\hline \multirow[t]{2}{*}{$\begin{array}{l}\text { Load reduction } \\
\text { scenario } \\
\text { (percent) }\end{array}$} & \multicolumn{2}{|c|}{$\begin{array}{l}\text { Percentage of change in 6-year } \\
\text { average concentration, from } \\
\text { 6-year average prior to input } \\
\text { load reduction to } 30 \text { years } \\
\text { after input load reduction }\end{array}$} & \multirow{2}{*}{$\begin{array}{l}\text { Number of years } \\
\text { (out of } 6 \text { ) with seasonal } \\
\text { chlorophyll a peak } \\
>100 \text { ppb, } 30 \text { years after } \\
\text { input load reduction }\end{array}$} \\
\hline & $\begin{array}{c}\text { TP } \\
\text { (percent) }\end{array}$ & $\begin{array}{c}\text { Chlorophyll a } \\
\text { (percent) }\end{array}$ & \\
\hline \multicolumn{4}{|c|}{ Upper limit for control by TP at $100 \mathrm{ppb}$} \\
\hline 0 & $\mathrm{~N} / \mathrm{A}$ & $\mathrm{N} / \mathrm{A}$ & 6 \\
\hline 10 & -9 & -4 & 6 \\
\hline 20 & -18 & -13 & 6 \\
\hline 40 & -36 & -44 & 2 \\
\hline \multicolumn{4}{|c|}{ Upper limit for control by TP at 80 ppb } \\
\hline 0 & $\mathrm{~N} / \mathrm{A}$ & $\mathrm{N} / \mathrm{A}$ & 6 \\
\hline 10 & -9 & -4 & 6 \\
\hline 20 & -18 & -13 & 6 \\
\hline 40 & -36 & -45 & 0 \\
\hline \multicolumn{4}{|c|}{ Upper limit for control by TP at $120 \mathrm{ppb}$} \\
\hline 0 & $\mathrm{~N} / \mathrm{A}$ & N/A & 6 \\
\hline 10 & -9 & -4 & 6 \\
\hline 20 & -18 & -13 & 6 \\
\hline 40 & -36 & -44 & 2 \\
\hline \multicolumn{4}{|c|}{ Upper limit for control by TP at $150 \mathrm{ppb}$} \\
\hline 0 & $\mathrm{~N} / \mathrm{A}$ & $\mathrm{N} / \mathrm{A}$ & 6 \\
\hline 10 & -9 & -4 & 6 \\
\hline 20 & -18 & -9 & 6 \\
\hline 40 & -36 & -45 & 2 \\
\hline
\end{tabular}

\section{Implications of Model Results for Restoration}

The lake metabolism approach used in this study to construct a whole lake averaged model has some advantages over the scaling up approach as used in the TMDL model. First, inaccuracy is introduced when the growth term that applies at very small scales is integrated over a lake that is highly variable in space and time (Wherry and others, 2015). By substituting lake metabolism for a growth term, we were able to calibrate the algal settling velocity, $u_{a l g}$, completely independently of phosphorus, and the value obtained $(0.25 \mathrm{~m} / \mathrm{d})$ was much higher than the previous range from 0.031 to $0.087 \mathrm{~m} / \mathrm{d}$. The settling velocity cannot be interpreted as a true particle settling velocity; it is a parameterization of a removal rate of biomass that is averaged over the lake and over a day, and is a weighted average of colonies that may be buoyant, non-buoyant, or neutrally buoyant (see appendix A in Wherry and others, 2015). Even so, the lake metabolism approach resulted in faster growth of cyanobacterial colonies that was balanced in the calibration process by more rapid deposition than was implied in previous versions of the TMDL model.

Because different formulations were adopted in the WLE for $\mathrm{pH}$ - and temperature-dependent recycling, these values of the recycling rate constants are not directly comparable to those reported in previous reports documenting the TMDL model (tables 8, 9, and 10 in Wherry and others, 2015), but the WLE model requires faster recycling overall to balance faster deposition in the phosphorus mass balance, which is consistent with the idea that algal growth and deposition is faster than previously estimated. Thus, using the lake metabolism approach rather than the scaling up approach requires a higher calibrated settling velocity, which in turn requires a higher recycling rate, meaning that, overall, the 
system is characterized by more rapid exchange of phosphorus between the water column and sediments than was previously understood. The time scales of exchange ultimately determine how quickly equilibrium between the sediments and water column is re-established. To show this, we ran simulations of 40-percent reduction in external loads using values of the phosphorus exchange rates (recycling rates and non-algal removal) that were 10 and 0.1 times the calibrated values in this study (fig. 20). Prior to load reduction, the simulations were run long enough to establish equilibrium between the water column and sediments, which resulted in different values of sediment phosphorus mass when load reduction was implemented. For that reason, the $y$-axis in figure 20 has an arbitrary lower limit in order to show all simulations on the same set of axes. When rate constants were an order of magnitude faster than calibrated values, re-establishment of equilibrium required about 2 decades, and when rate constants were an order of magnitude slower than calibrated values, re-establishment of equilibrium required about
5 decades. The result of using our calibrated parameterswhich re-established equilbrium after about 30 years - also is shown in figure 20. For this reason, knowing the values of the rate parameters with at least fair accuracy is important - the rate parameters establish the time scales for the response to restoration activities. The lake metabolism approach taken in this study has associated error; nonetheless, these results (which were arrived at through a different approach to the problem) should provide additional confidence in the results from the previous studies that concluded that the time scale for response to restoration activities in the form of tributary load reductions was on the order of a few decades.

All the simulations in this study treated load reduction as instantaneous. In reality, load reductions can only be accomplished over many years, undoubtedly with high variability based on external factors such as hydrologic conditions, and the time scale for response will be similarly protracted.

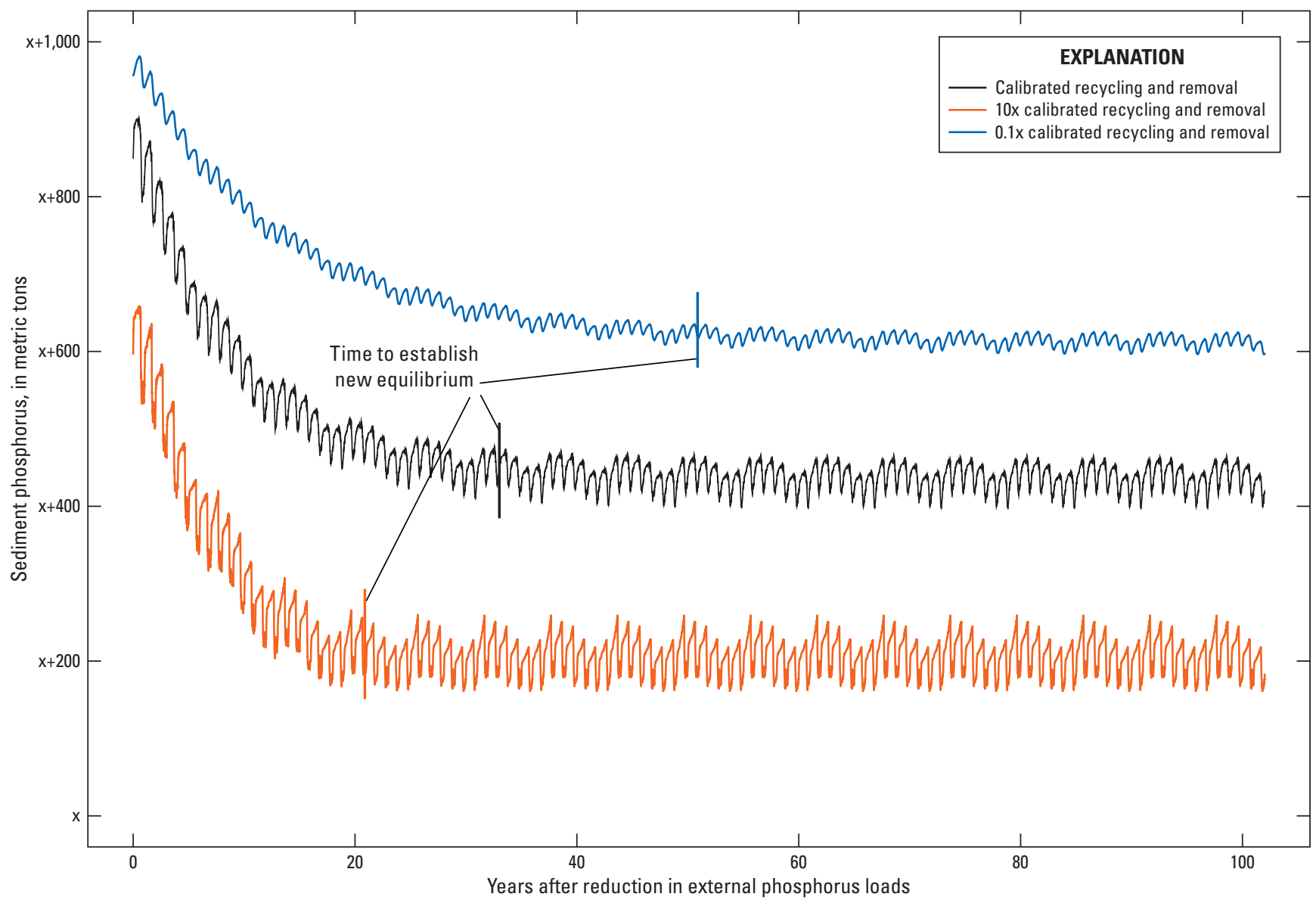

Figure 20. Time series of mass of total phosphorus in the sediments for 40-percent nutrient load reduction scenarios, for rate constants over three orders of magnitude and relative to an arbitrary starting concentration, indicating the time required in each case to establish a new equilibrium (defined as 95 percent of the final concentration). 
Another advantage of the WLE model approach was that we were able to use rate parameters that were consistent with a system in which the measured water column and best estimates of sediment phosphorus mass were in balance; in other words, the simulation of current conditions as described by the calibration years was already in an equilibrium state. Therefore, it was easier to isolate the effects of nutrient reduction. Reductions of 10 and 20 percent resulted in roughly proportional reductions in water column phosphorus concentrations ( 9 and 18 percent, respectively), but reductions in biomass that were substantially less (4 and 13 percent, respectively) because bloom growth was not consistently limited by phosphorus after the initial expansion, a feature of the model that is consistent with observations (Lindenberg and others, 2009). At 40-percent reduction in loads, however, the model showed a reduction of 36 percent in water column phosphorus and a reduction of 44 percent in biomass, indicating that somewhere between 20- and 40-percent reduction in loads, the final water column phosphorus concentration was reduced enough to be limiting to the bloom beyond the first rapid expansion phase. Although it would be inappropriate to interpret the results of such a simple model as being exact, these results provide additional confidence in the previous results of the TMDL model, which showed roughly proportional decreases in water column phosphorus and biomass to a 40-percent reduction in loads (Wherry and others, 2015). At smaller load reductions of 10 and 20 percent, however, the reduction in biomass was one-third to one-half of the load reduction.

This model included a recycling mechanism that combined temperature and $\mathrm{pH}$-dependence in one model, and described calculated recycling well. Over the 6-year calibration period, the mass of phosphorus recycled as a result of the temperature- and $\mathrm{pH}$-dependent mechanism was 2.3 times greater than the mass of phosphorus recycled from the $\mathrm{pH}$-dependent mechanism. Previous versions of the TMDL model have incorporated only the $\mathrm{pH}$-dependent mechanism. This study has shown that a temperature-dependent component is as important, and that a combination of both mechanisms can significantly improve the description of recycling, as determined independently through mass balance calculations, in a model of the lake.

Our simulations show that the reductions in biomass in response to load reductions are similar across years, whereas the earliest versions of the TMDL model showed a bimodal response in which blooms were severely curtained in some years and little affected in others after nutrient load reductions. This difference in results is a consequence of a series of revisions that have been made to the algorithms in combination with the incorporation of temperature-dependent recycling and the change in how $\mathrm{pH}$-dependent recycling is described. The cumulative result of all of these revisions is that load reductions decrease the peak of blooms relatively evenly across years, rather than resulting in some years when blooms are the same size and some years when almost no bloom occurs (Wood and others, 2013).
The results of this study, although arrived at using a different approach and using continuous DO data, are consistent with previous TMDL modeling in that they show that decreasing water column concentration in response to external load decreases does not continue indefinitely. The system eventually achieves a new balance between the sediments and water column, and water column concentrations show year-to-year variability but stabilize in the long-term mean. The same is true of the sediment phosphorus, with the consequence that sediment phosphorus storage does not have to be completely depleted before meaningful changes in the water column phosphorus concentration can be achieved.

Future improvements in model accuracy or confidence could be achieved by reducing the uncertainty in UKL NPP calculations and model parameters, and developing focused studies to analyze the relations between seasonal algal bloom dynamics and explanatory meteorological (temperature and wind) and water-quality (phosphorus) variables. The understanding of phosphorus control on the bloom would be aided by a better understanding of the fractionation of phosphorus, both in the external loads and in the water column. For example, the relation between algal $\mathrm{P}$ and chlorophyll $a$ is confounded by the unknown non-algal (inorganic and organic) particulate $\mathrm{P}$ fraction.

Perhaps the largest source of uncertainty in the measurements used for the NPP calculation is the small number of continuous monitoring sites - four sites over the entire $305 \mathrm{~km}^{2}$ lake, which includes Agency Lake and the restored land around the Williamson River Delta. Additionally, our sites were weighted toward depths in the lake that constitute a smaller fraction of the total surface area; more sites in shallower areas would improve accuracy. An analysis of the uncertainty in the terms of the equation used to calculate NPP showed that the greatest source of uncertainty was the reaeration term that is dependent on DO, a variable with high uncertainty (see section "Quantification of Uncertainty in Net Primary Production Calculations"), which is based on work done at Lake Onondaga, a smaller lake than Upper Klamath (Gelda and Effler, 2002a), and which can be lake-specific (Cole and others, 2010). A study to measure gas transfer fluxes across the air-water interface at UKL likely would result in more accurate reaeration equations. The model also could be improved through data collection and (or) analysis to better understand respiration rates in the lake - specifically, how respiration rates vary from nighttime to daytime, and the heterotrophic contribution. Respiration rates were not used explicitly in the model, but determining accurate respiration rates in the lake could lead to improved simulation of NPP through more accurate interpretation of DO fluctuations.

There also is uncertainty in the TMDL model parameters that would benefit from data collection. As was discussed in Wherry and others (2015), minimizing uncertainty in the nonalgal and algal settling rates, using a net algal settling approach, and performing data collection to parameterize the various sources of internal P loading would minimize uncertainty in the TMDL model. 
Finally, a study that could focus on analyzing the specific relations between the rapid mid-season decrease in AFA blooms and explanatory water-quality and meteorological variables would be beneficial to the TMDL model and its ability to predict changes in the bloom due to changes in management action and climate. Our use of a mirrored temperature time series as an explanatory variable provides an interesting insight into the relation between the bloom decreases and weather, but a mechanistic, process-based understanding of why the bloom decreases occur has yet to be developed.

\section{Summary}

A whole lake eutrophication (WLE) model approach for phosphorus and cyanobacterial biomass in Upper Klamath Lake is presented here. The model is a successor to a previous model developed to inform a Lake Total Maximum Daily Load (TMDL) for phosphorus in the lake, but is based on net primary production (NPP), which can be calculated from a dissolved oxygen budget, rather than scaling up a small-scale description of cyanobacterial growth and respiration rates. The phase 3 WLE model is a refinement of the proof-of-concept developed in phase 2, which was the first attempt to use NPP to simulate cyanobacteria in the TMDL model; however, we do not directly compare model outputs because of the types of changes to calculations and calibration processes made in this report.

In contrast to the previous TMDL model run with NPP, recycling processes were described by a combination of $\mathrm{pH}$ - and temperature-dependent mechanisms, as compared to using only a $\mathrm{pH}$-dependent recycling mechanism, and the $\mathrm{pH}$-dependence was changed to a polynomial form from a sigmoidal one. All rate parameters were recalibrated with these changes. The calibration of the recycle rates was revised to use only the steady-state period of the simulation, as compared to calibrating over the initial transient period, in order to ensure that the values of the parameters were not confounded by the effects of a transient solution. The calculation and model fitting of whole-lake NPP were also updated. In phase 2 , the NPP calculation used only shallow monitoring sites to minimize the effects of vertical mixing, which resulted in inflated estimates of whole-lake production. Finally, the form of the relation that estimates algal phosphorus was changed to a polynomial model based on comparisons of measurements of particulate phosphorus to chlorophyll $a$. This change resulted in a larger fraction of total phosphorus in the form of algal phosphorus, particularly at low chlorophyll $a$ concentrations. The cumulative effect of these changes was inflated model parameters describing algal settling and recycling for the proof-of-concept WLE from phase 2 (Wherry and others, 2015).
The calibration of the calculated NPP WLE model was successful, with performance metrics indicating a good fit to the 6 years of calibration data. The Nash-Sutcliffe statistic and coefficient of determination $\left(\mathrm{R}^{2}\right)$ value, for example, were 0.55 and 0.65 , respectively, for total phosphorus, and 0.53 and 0.58 , respectively, for chlorophyll $a$ concentration. The WLE model run with calculated NPP was able to simulate mid-season bloom decreases, a feature that previous models could not reproduce.

In order to be able to use the model to simulate future scenarios based on load reduction, dissolved oxygen (which is not simulated by the model) had to be removed as an explanatory variable. A multivariate regression model was created to simulate net primary production as a function of the model state variables (phosphorus and chlorophyll $a$ ) and meteorological and temperature variables that were measured and could be used as input to the model. The net primary production time series was split into a low- and high-frequency component using wavelet analysis, and regression models were fit to the components separately. The regression models were only moderately successful, with Nash-Sutcliffe statistics of $0.17-0.19$ and $0.37-0.47$ during calibration and validation periods for the high- and low-frequency components, respectively.

The regression models for net primary production were incorporated in the whole lake eutrophication model, referred to as the "scenario" WLE (SWLE), and the fit statistics for phosphorus during the calibration period were mostly unchanged, indicating that the overall mass balance of total phosphorus is relatively insensitive to the mid-season bloom decreases that are not well-captured in the regression models. The fit statistics for chlorophyll $a$, however, were degraded; the Nash-Sutcliffe statistics decreased to 0.45 and $\mathrm{R}^{2}$ decreased to 0.50 These statistics were still an improvement over prior models, and indicate that the SWLE is appropriate for long-term predictions even though it misses some of the seasonal variations in chlorophyll $a$ that are better represented when the WLE is run with calculated NPP.

The complete whole lake SWLE model, with multivariate regression to predict net primary production, was used to make long-term simulations of the response to 10-, 20-, and 40-percent reductions in tributary nutrient loads. The longterm mean water column concentration of total phosphorus was reduced by 9,18 , and 36 percent, respectively, in response to these load reductions. The long-term water column chlorophyll $a$ concentration was reduced by 4 , 13 , and 44 percent, respectively. The adjustment to a new equilibrium between the water column and sediments occurred over about 30 years.

The final products of this report are two WLE models, one dependent on calculated historical NPP and one dependent on simulated NPP. The calculated NPP WLE is more accurate in simulating historical chlorophyll $a$ concentrations and seasonal dynamics, but is limited to the time period for which 
NPP can be calculated from measurements. The simulated NPP "scenario" WLE is less accurate when simulating chlorophyll $a$ seasonal dynamics, but can provide insights on long-term trends and average conditions resulting from management actions. Future models would benefit from data collection to minimize the uncertainty in Upper Klamath Lake NPP calculations and model parameters, and focused studies to analyze the relation between Aphanizomenon flos-aquae bloom dynamics as represented by NPP and explanatory variables.

\section{References Cited}

Banish, N.P., Adams, B.J., Shively, R.S., Mazur, M.M., Beauchamp, D.A., and Wood, T.T., 2009, Distribution and habitat associations of radio-tagged adult Lost River suckers and shortnose suckers in Upper Klamath Lake, Oregon: Transactions of the American Fisheries Society, v. 138, p. $153-168$.

Bowie, G.L., Mills, W.B., Porcella, D.B., Campbell, C.L., Pagenkopf, J.R., Rupp, G.L., Johnson, K.M., Chan, P.W.H., Gherini, S.A., and Chamberlin, C.E., 1985, Rates, constants, and kinetics formulations in surface water quality modeling: U.S. Environmental Protection Agency, EPA/600/3-85/040, $455 \mathrm{p}$.

Bradbury, J.P., Colman, S.M., and Reynolds, R.L., 2004, The history of recent limnological changes and human impact on Upper Klamath Lake, Oregon: Journal of Paleolimnology, v. 31 , p. $151-161$.

Bunn, A.G., 2008, A Dendrochronology Program Library in R (dplR) - R package version 1.0: Dendrochronologia, v. 26, p. 115-124.

Bureau International des Poids et Mesures, 2008, GUMGuide to the expression of uncertainty in measurement: Bureau International des Poids et Mesures, accessed October 20, 2016, at http://www.bipm.org/en/publications/ guides/gum.html.

Bureau of Reclamation, 2016, Cooperative agricultural weather network (AgriMet) -Pacific Northwest region: Bureau of Reclamation database, accessed August 30, 2016, at https://www.usbr.gov/pn/agrimet/wxdata.html.

Burnham, K.P., and Anderson, D.R., 2002, Model selection and multimodel inference-A practical informationtheoretic approach (2d ed.): New York, Springer-Verlag.

Cole, J.J., Bade, D.L., Bastviken, David, Pace, M.L., and Van de Bogert, Matthew, 2010, Multiple approaches to estimating air-water gas exchange in small lakes: Limnology and Oceanography-Methods, v. 8, no. 6, p. 285-293, doi:10.4319/lom.2010.8.285.
Eilers, J.M., Kann, J., Cornett, J., Moser, K., and St. Amand, A., 2004, Paleolimnological evidence of change in a shallow, hypereutrophic lake-Upper Klamath Lake, Oregon, USA: Hydrobiologia, v. 520, no. 1, p. 7, http:// dx.doi.org/10.1023/B:HYDR.0000027718.95901.ae.

Eilers, J.M., Kann, J., Cornett, J., Moser, K., St. Amand, A., and Gubala, C.P., 2001, Recent paleolimnology of Upper Klamath Lake: Bureau of Reclamation, $44 \mathrm{p}$.

Gelda, R.K., and Effler, S.W., 2002a, Estimating oxygen exchange across the air-water interface of a hypereutrophic lake: Hydrobiologia, v. 487, p. 243-254, http://dx.doi. org/10.1023/A:1022994217578.

Gelda, R.K., and Effler, S.W., 2002b, Metabolic rate estimates for a eutrophic lake from diel dissolved oxygen signals: Hydrobiologia, v. 485, nos. 1-3, p. 51-66, http://dx.doi. org/10.1023/A\%3A1021327610570.

Hoilman, G.R., Lindenberg, M.K., and Wood, T.M., 2008, Water quality conditions in Upper Klamath and Agency Lakes, Oregon, 2005: U.S. Geological Survey Scientific Investigations Report 2008-5026, 44 p., http://pubs.usgs. gov/sir/2008/5026/.

Jacoby, J.M., Lynch, D.D., Welch, E.B., and Perkins, M.A., 1982, Internal phosphorus loading in a shallow eutrophic lake: Water Research, v. 16, p. 911-919.

Jassby, A., and J. Kann, 2010, Upper Klamath Lake monitoring program-Preliminary analysis of status and trends for 1990-2009: Prepared for Klamath Tribes Natural Resources Department, Chiloquin, Oregon.

Kann, J., 2016, Upper Klamath Lake 2015 data summary Report: Prepared for Klamath Tribes Natural Resources Department, Chiloquin, Oregon, by Aquatic Ecosystem Sciences LLC.

Kann, J., and Walker, W.W., 1999, Nutrient and hydrological loading to Upper Klamath Lake, Oregon, 1991-1998: Klamath Tribes, 48 p. plus appendices.

Lindenberg, M.K., Hoilman, Gene, and Wood, T.M., 2009, Water quality conditions in Upper Klamath and Agency Lakes, Oregon, 2006: U.S. Geological Survey Scientific Investigations Report 2008-5201, 54 p., http://pubs.usgs. gov/sir/2008/5201/pdf/sir20085201.pdf.

Martin, J.L., and McCutcheon, S.C., 1999, Hydrodynamics and transport for water quality modeling: Boca Raton, Florida, Lewis Publishers.

Neuman, M.J., 2017, Upper Klamath and Agency Lakes May/ June 1996 bathymetric mapping project: U.S. Geological Survey data release, https://doi.org/10.5066/F7WM1BXH. 
Oregon Department of Environmental Quality, 2002, Upper Klamath Lake drainage total maximum daily load (TMDL) and water quality management plan (WQMP): Oregon Department of Environmental Quality, 188 p., http://www. deq.state.or.us/WQ/TMDLs/klamath.htm.

Perkins, D., Kann, J., and Scoppettone, G.G., 2000, The role of poor water quality and fish kills in the decline of endangered Lost River and shortnose suckers in Upper Klamath Lake: U.S. Geological Survey Biological Resources Division report submitted to U.S. Bureau of Reclamation, Klamath Falls Project Office, Oregon, Contract 4-AA-29-12160.

Phinney, H.K., and Peek, C.A., 1961, Klamath Lake, an instance of natural enrichment-Transactions of the seminar on algae and metropolitan wastes, April 27-29, 1960: U.S. Public Health Service, p. 22-27.

R Core Team, 2016, R-A language and environment for statistical computing: Vienna, Austria, R Foundation for Statistical Computing, http://www.R-project.org/.

Simon, N., and Ingle, S., 2011, Physical and chemical characteristics including total and geochemical forms of phosphorus in sediment from the top 30 centimeters of cores collected in October 2006 at 26 sites in Upper Klamath Lake, Oregon: U.S. Geological Survey Open-File Report 2011-1168, 46 p., http://pubs.usgs.gov/of/2011/1168/.

Simon, N., Lynch, D., and Gallagher, T., 2009, Phosphorus fractionation in sediment cores collected in 2005 before and after onset of an Aphanizomenon flos-aquae bloom in Upper Klamath Lake, OR, USA: Water, Air, and Soil Pollution, v. 204, no. 1, p. 139-153, http://dx.doi.org/10.1007/s11270009-0033-9.

Staehr, P.A., Bade, D., Van de Bogert, M.C., Koch, G.R., Williamson, C., Hanson, P., Cole, J.J., and Kratz, T., 2010, Lake metabolism and the diel oxygen technique-State of the science: Limnology and Oceanography-Methods, v. 8 , no. 11 , p. $628-644$, http://dx.doi.org /10.4319/ lom.2010.8.0628.

Sullivan, A.B., Rounds, S.A., Deas, M.L., Asbill, J.R., Wellman, R.E., Stewart, M.A., Johnston, M.W., and Sogutlugil, I.E., 2011, Modeling hydrodynamics, water temperature, and water quality in the Klamath River upstream of Keno Dam, Oregon, 2006-09: U.S. Geological Survey Scientific Investigations Report 2011-5105, 70 p., http://pubs.usgs.gov/sir/2011/5105/.
Torrence, C., and Compo, G.P., 1998, A practical guide to wavelet analysis: Bulletin of the American Meteorological Society, v. 79, no. 1, p. 61-78.

U.S. Geological Survey, 2011, Change to solubility equations for oxygen in water: Office of Water Quality Technical Memorandum 2011.03, accessed July 15, 2011, at http:// water.usgs.gov/admin/memo/QW/qw11.03.pdf.

Walker, W.W., 2001, Development of a phosphorus TMDL for Upper Klamath Lake, Oregon: Prepared for Oregon Department of Environmental Quality, Bend, 80 p., accessed August 26, 2013, at http://www.deq.state.or.us/wq/ tmdls/docs/klamathbasin/ukldrainage/devphostmdl.pdf.

Walker, W.W., Walker, J.D., and Kann, J., 2012, Evaluation of water and nutrient balances for the Upper Klamath Lake Basin in water years 1992-2010: Technical Report to the Klamath Tribes Natural Resources Department, 50 p. plus appendixes.

Wherry, S.A., Wood, T.M., and Anderson, C.W., 2015, Revision and proposed modification of a total maximum daily load model for Upper Klamath Lake, Oregon: U.S. Geological Survey Scientific Investigations Report 20155041, 55 p., http://dx.doi.org/10.3133/sir20155041.

Wood, T.M., 2001, Sediment oxygen demand in Upper Klamath and Agency Lakes, Oregon, 1999: U.S. Geological Survey Water-Resources Investigations Report 01-4080, 13 p., http://pubs.usgs.gov/wri/2001/4080/wri01-4080.pdf.

Wood, T.M., Hoilman, G.R., and Lindenberg, M.K., 2006, Water-quality conditions in Upper Klamath Lake, Oregon, 2002-04: U.S. Geological Survey Scientific Investigations Report 2006-5209, 52 p., http://pubs.usgs. gov/sir/2006/5209/pdf/sir20065209.pdf.

Wood, T.M., Wherry, S.A., Carter, J.L., Kuwabara, J.S., Simon, N.S., and Rounds, S.A., 2013, Technical evaluation of a total maximum daily load model for Upper Klamath and Agency Lakes, Oregon: U.S. Geological Survey Open-File Report 2013-1262, 69 p. plus appendix, http:// pubs.usgs.gov/of/2013/1262/. 

Publishing support provided by the U.S. Geological Survey Science Publishing Network, Tacoma Publishing Service Center

For more information concerning the research in this report, contact the Director, Oregon Water Science Center

U.S. Geological Survey

2130 SW 5th Avenue

Portland, Oregon 97201

https://www.usgs.gov/centers/or-water 


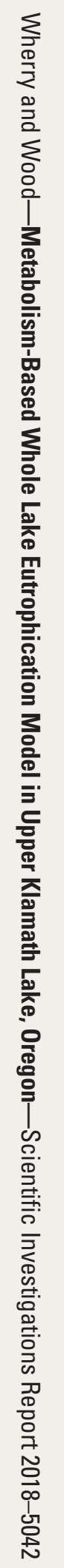

